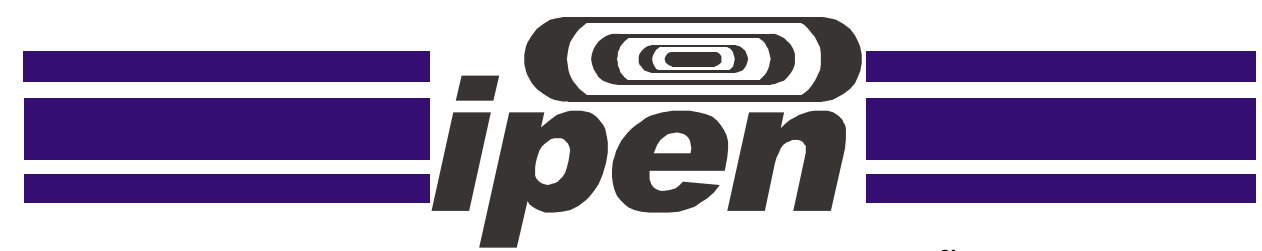

AUTARQUIA ASSOCIADA À UNIVERSIDADE DE SÃO PAULO

OBTENÇÃO E CARACTERIZAÇÃO DE VIDROS A BASE DE LAMA VERMELHA VISANDO A IMOBILIZAÇÃO DE REJEITOS NUCLEARES

Heveline Vieira

Tese apresentada como parte dos requisitos para obtenção do Grau de Doutor em Ciências na Área de Tecnologia Nuclear - Materiais

Orientador:

Prof. Dr. José Roberto Martinelli 
INSTITUTO DE PESQUISAS ENERGÉTICAS E NUCLEARES

Autarquia associada à Universidade de São Paulo

\title{
OBTENÇÃO E CARACTERIZAÇÃO DE VIDROS A BASE DE LAMA VERMELHA VISANDO A IMOBILIZAÇÃO DE REJEITOS NUCLEARES
}

\author{
Heveline Vieira \\ Tese apresentada como parte dos \\ requisitos para obtenção do Grau de \\ Doutor em Ciências na Área de Tecnologia \\ Nuclear - Materiais \\ Orientador: \\ Prof. Dr. José Roberto Martinelli
}

Versão Corrigida

Versão Original disponível no IPEN

São Paulo

2015 
Aos meus pais, Vera e Francisco, responsáveis por quem eu sou e por tudo de mais valioso que tenho na vida, minha família. 


\section{AGRADECIMENTOS}

Ao Dr. José Roberto Martinelli pela orientação constante, dedicação, compreensão, paciência (muita paciência!), incentivo e amizade. Foram 10 anos trabalhando ao lado do Dr. Martinelli, no grupo LAVICOM. Foi uma honra para mim e um grande aprendizado.

Ao Dr. Richard K. Brow por me receber de modo tão acolhedor em seu grupo de pesquisa, me orientar durante todo o meu período de doutorado sanduíche e pela paciência em entender as minhas dificuldades relacionadas à língua e a saudade de casa e de pessoas queridas.

A Comissão Nacional de Energia Nuclear (CNEN), pela bolsa de doutorado concedida no país e ao Conselho Nacional de Desenvolvimento Científico e Tecnológico (CNPq) pela bolsa concedida no exterior durante o meu estágio na Missouri University of Science and Technology, Missouri, EUA.

Ao IPEN pela oportunidade de realizar este trabalho utilizando as suas instalações.

A Alcoa Alumíno S.A. por fornecer o resíduo estudado nesse trabalho e ao Dr. Ulisses Soares Prado por realizar o contato com essa instituição.

Aos Doutores Reginaldo Mucillo, Eliana Mucillo, Ana Helena Bressiani e Hidetoshi Takiishi por diversas vezes me disponibilizarem os seus laboratórios.

Ao Dr. Fábio Branco pelos valiosos auxílios fornecidos em momentos cruciais no desenvolvimento desse trabalho.

A todos os funcionários do CCTM, entre eles, Glauson, Cebola, Cebolinha, Rene e Edson por sempre me auxiliarem na preparação e caracterização das minhas amostras.

Aos funcionários dos setores de bolsa e pós-graduação pela paciência em me orientar pessoalmente, mesmo quando todas as informações que eu necessitava estavam no manual de sobrevivência da pós-graduação. 
Ao grupo LAVICOM, Ana, Carlita, Eraldo, Frank (que sempre será integrante desse grupo), Ju e Zé Mário. Foi muito proveitoso e divertido dividir alguns desses 10 anos de LAVICOM com vocês.

Ao grupo MRC que me recebeu de braços abertos e me acolheu de uma forma super especial. Em especial: CharM, Li Na, Rick, Katie, Xiaoming, Jamie, Ali e Sissy. Thank you, guys.

Aos amigos queridos do Ipen, amigos que quero ter para sempre na minha vida: Carola, Chris, Deiby, Fernando, Grazi, Horácio, Ivanildo, Jair, Kalan, Karol, Renata, Tami, Ton.

Ao Sr. Posada por tudo o que já me proporcionou em tão pouco tempo. Amor, amizade, alegria, aventura, diversão, companheirismo, confiança em mim, confiança nele e, sobretudo confiança em nós. Obrigada, meu amor.

A minha irmã Hellen, tão especial, por ser a melhor irmã, a melhor amiga, meu orgulho, meu exemplo de coragem, determinação e solidariedade. Obrigada por me apoiar em tudo, sempre.

Aos meus queridos pais por estarem presentes em tudo, desde sempre, me mostrando que não importa o que eu faça ou aonde eu vá, eles sempre estarão comigo. Eles, junto com a minha irmã, são co-autores desse trabalho.

A todos que não mencionei aqui, mas que auxiliaram direta ou indiretamente na conclusão desse trabalho.

A Deus por sua infinita bondade.

Heveline Vieira 


\title{
Obtenção e caracterização de vidros a base de lama vermelha visando a imobilização de rejeitos nucleares
}

\author{
Heveline Vieira
}

\section{Resumo}

Neste trabalho, vidros contendo um resíduo industrial denominado lama vermelha, foram desenvolvidos e caracterizados. Foi utilizada a quantidade mínima de $60 \%$ em massa de lama vermelha na produção dos vidros para promover a utilização desse resíduo. De acordo com os resultados de difração de raios $X$ obtidos, observa-se que é possível produzir materiais a partir da lama vermelha com fases amorfas consideráveis, embora fases cristalinas referentes ao Fe originário do resíduo estejam presentes. O material denominado 60L40S, o qual possui $60 \%$ em massa de lama vermelha na sua composição nominal, apresentou as melhores propriedades dentre as composições estudadas, porém apresentou também alta temperatura de fusão. Ajustes na composição desse material foram realizados buscando diminuir essa temperatura. Os resultados mostram que os ajustes foram satisfatórios no desempenho de diminuir a temperatura de fusão, porém perdas na propriedade química desse material foram observadas. Elementos comumente encontrados na composição química de rejeitos nucleares foram adicionados aos vidros produzidos neste trabalho visando estudar os efeitos dessa adição nas propriedades químicas e térmicas desses materiais. Foi observado que é possível adicionar até 15\% em massa de elementos simuladores aos materiais produzidos e essa adição promove a diminuição da temperatura de fusão. Acima de 15\% em massa os elementos adicionados se precipitam na estrutura do material. Foi observado que, embora haja perdas na durabilidade química do material 60L40S após a adição dos elementos simuladores, esse material, quando em contato com água, mantém os elementos simuladores confinados em sua estrutura. Esse resultado é promissor, pois sugere que o material 60L40S é capaz de imobilizar em sua estrutura elementos provenientes de rejeitos nucleares. 


\title{
Production and characterization of red mud based glasses for the immobilization of nuclear wastes
}

\author{
Heveline Vieira
}

\begin{abstract}
Glasses based on red mud, a residual material from bauxite processing, were developed and characterized in this work. In order to promote its use, a minimum $60 \mathrm{wt} \%$ of red mud was used in the production of the glasses. According to XRD results, materials containing considerable amorphous phases were produced when using red mud as raw material. These amorphous phases were observed even though crystalline phases associated to Fe coming from the red mud itself were present. The material denominated 60L40S, which has a nominal composition of $60 \mathrm{wt} \%$ red mud showed the best properties comparing with the others compositions studied. However, these materials presented a high melting temperature. Changes in the composition of this material were made with the objective of lowering this temperature. Results indicated that the changes made to the material were successful in the reduction of the melting temperature. However, a reduction in the chemical properties of the resulting material was observed. Elements usually found in the chemical composition of nuclear wastes were added to the glasses produced. It was done with the objective of determining the effect of these elements on the chemical and physical properties of the red mud based glasses obtained. It was found that it was possible to add up to $15 \mathrm{wt} \%$ of these elements to the materials produced. The addition of these simulants materials promoted a reduction in the melting temperature of the resulting material. Above $15 \mathrm{wt} \%$, the added elements precipitate in the structure of the resulting material. Even though the reduction in the chemical durability of the 60L40S material when simulant elements were added, it was observed that this material contained the simulant elements confined in its structure when in contact with water. This is a promising result, since it indicates that the 60L40S has the potential to immobilize elements from nuclear wastes.
\end{abstract}




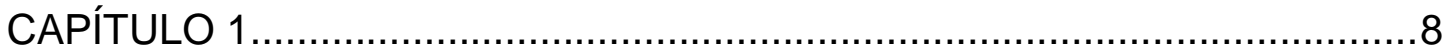

1. INTRODUÇÃO

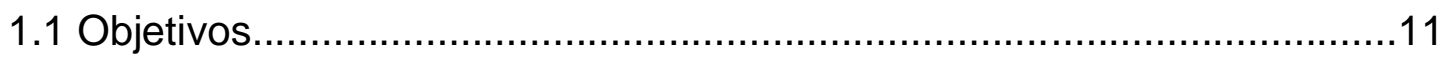

CAPÍTULO 2

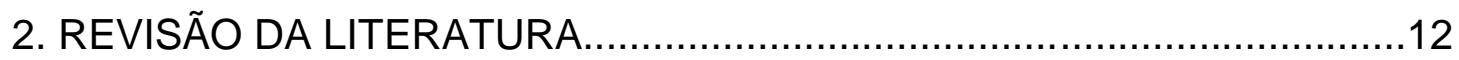

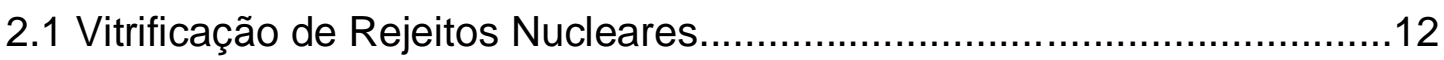

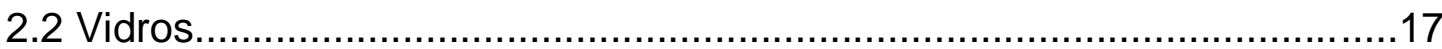

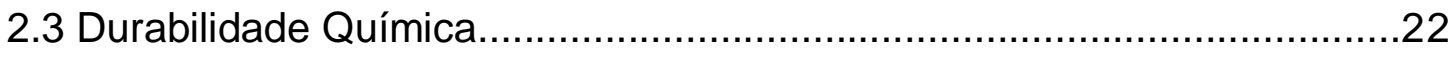

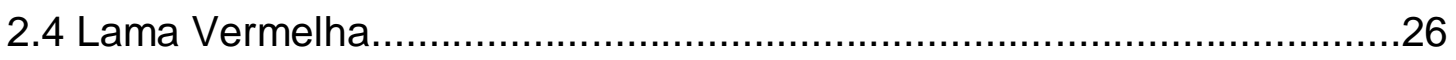

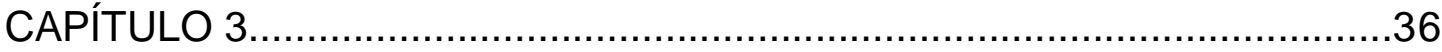

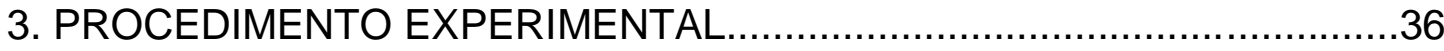

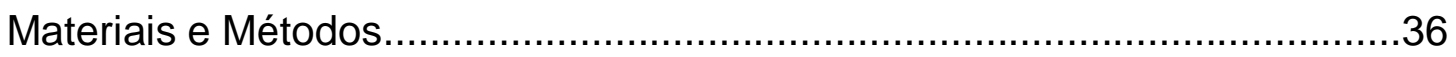

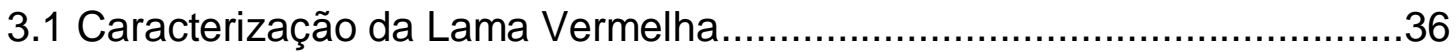

3.2 Produção e Caracterização dos Materiais Estudados................................38

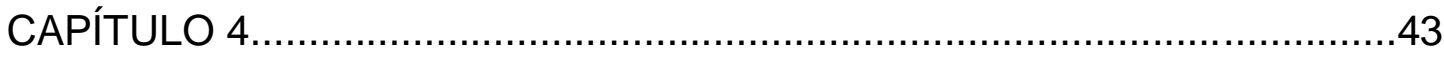

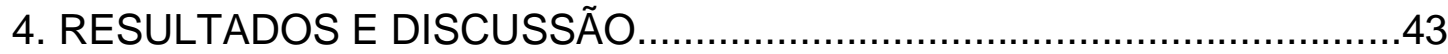

4.1 Lama Vermelha

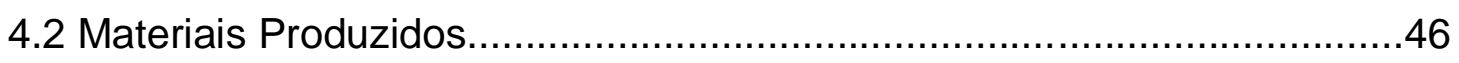

4.3 Adição de $\mathrm{BaO}$, SrO e $\mathrm{ZrO}_{2}$ nos Materiais 60L40S e 60L25S15B (Grupo

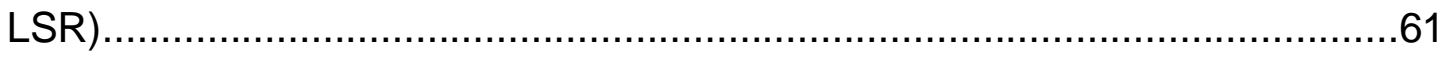


4.4 Adição Individual de $\mathrm{BaO}$, $\mathrm{SrO}$ e $\mathrm{ZrO}_{2}$ no Material 60L40S (Grupo

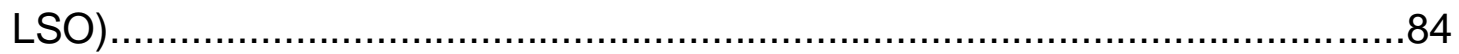

CAPÍTULO 5

5. CONCLUSÃO

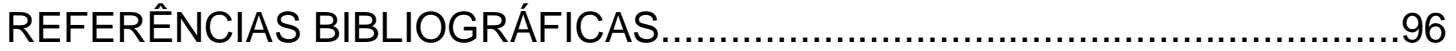




\section{INTRODUÇÃO}

Rejeito radioativo é qualquer material resultante de atividades humanas que contenha radionuclídeos em quantidades superiores aos limites de isenção especificados na Norma CNEN-NE-6.02 e, para o qual a reutilização é imprópria ou imprevista ${ }^{1}$. Conseqüentemente, o tratamento e disposição dos rejeitos nucleares, obstáculo para o completo aproveitamento da energia nuclear, deve ser abordado com maior intensidade. Os rejeitos radioativos são produzidos em pequenas quantidades quando comparados à quantidade de resíduos produzidos por outros tipos de combustíveis, e são classificados em diferentes formas quanto ao seu nível de atividade que pode ser baixa, média e alta atividade ${ }^{2}$.

Os rejeitos de baixa e média atividade contêm, predominantemente, radionuclídeos emissores $\beta$ e y com meia vida da ordem de 30 anos. A quantidade de emissores a é igual ou inferior a $3,7 \times 10^{3} \mathrm{~Bq} / \mathrm{g}$ e as taxas de calor não ultrapassam a $2 \mathrm{~kW} / \mathrm{m}^{31}$.

Exemplos de rejeitos de baixa atividade são, entre outros, papéis, flanelas, panos de limpeza, peças de vestuário e filtros utilizados em hospitais, centros de pesquisas, instalações industriais e usinas nucleares. Os rejeitos de média atividade 
são resinas iônicas, lamas químicas e revestimentos metálicos do combustível, assim como os equipamentos contaminados e rejeitos das operações de descomissionamento, ou seja, desativação de instalações nucleares ${ }^{2}$.

Rejeitos de alta atividade consistem de combustível irradiado proveniente dos núcleos de reatores nucleares e de rejeitos, em sua maioria líquidos, produzidos durante o reprocessamento desses combustíveis ${ }^{2}$.

O combustível irradiado contém elementos transurânicos como, por exemplo, ${ }^{237} \mathrm{U}$ e ${ }^{239} \mathrm{Pu},{ }^{240} \mathrm{Pu},{ }^{241} \mathrm{Pu}$ e ${ }^{242} \mathrm{Pu}$ e produtos de fissão como o ${ }^{126} \mathrm{Sn}$, o ${ }^{129} \mathrm{I}$ e o ${ }^{137} \mathrm{Cs}$, entre outros. Com o reprocessamento do combustível queimado, o plutônio e o urânio ainda remanescente são extraídos do combustível irradiado por meio de um tratamento químico e podem ser reaproveitados. Dessa forma, além de promover a reciclagem do combustível, o volume de rejeitos de alta atividade a ser armazenado é reduzido consideravelmente. No entanto, o reprocessamento é restrito em alguns países, pois o plutônio extraído pode ser utilizado na fabricação de armas nucleares ${ }^{2}$.

Para cada classe de rejeitos radioativos é utilizada uma tecnologia de controle e estocagem apropriada. Os rejeitos de baixa e média atividade são acondicionados em tambores metálicos que, por sua vez, são colocados em blocos monolíticos de concreto. Para eliminar o risco de dispersão, os rejeitos líquidos são transformados em blocos sólidos pela mistura com cimento, betume ou polímeros antes de serem embalados. O armazenamento final desses rejeitos é realizado colocando esses blocos de concreto em depósitos definitivos construídos em locais onde a integridade da sua estrutura seja garantida ${ }^{2}$.

No Brasil existem quatro depósitos iniciais para a estocagem dos rejeitos radioativos de baixa e média atividade gerados pelas usinas nucelares Angra 1, Angra 2 e, futuramente, Angra 3.

A previsão é que a unidade Angra 3 entre em operação em julho de 2018 e a ocupação plena de todos os quatro depósitos iniciais está prevista para ocorrer também em 2018.

Além dos depósitos mencionados, existe também o Depósito Inicial de Rejeitos de Angra 2 - KPE, localizado na área controlada da usina. A ocupação plena desse depósito estava prevista para ocorrer em $2012^{2}$. 
Sendo assim, um depósito definitivo está sendo planejado para abrigar os rejeitos produzidos ao longo de toda a vida útil dessas usinas, pois o único depósito definitivo existente no Brasil fica em Goiás e abriga os rejeitos produzidos pelo acidente ocorrido em 1987 com a fonte de ${ }^{137} \mathrm{Cs}^{2}$.

O armazenamento dos rejeitos de alta atividade é feito, inicialmente, no local do reator onde eles foram produzidos, pois como o elemento combustível utilizado gera grande quantidade de calor, faz-se necessário o seu resfriamento. Tendo em vista que o tempo necessário para a redução da atividade destes rejeitos a níveis considerados seguros é de cerca de 10.000 anos, após o resfriamento, a deposição definitiva desses rejeitos é feita em repositórios subterrâneos de grande profundidade localizados em áreas com condições geológicas naturais milenarmente estáveis após um condicionamento preliminar para a imobilização dos constituintes. A profundidade é para eliminar os riscos de intervenção humana, animal, vegetal, entre outros. O condicionamento dos rejeitos é uma etapa importante, pois mantém os radionuclídeos confinados de forma segura por longos períodos de tempo. Após o condicionamento, o rejeito é selado em cilindros de aço, constituindo o que se define como "pacote". Este cilindro permite a locomoção segura e pode também ser considerado como uma barreira de confinamento ${ }^{2}$.

Há vários tipos de materiais sólidos que podem ser utilizados para a imobilização dos rejeitos radioativos de alta atividade, que dependem da estratégia de gerenciamento adotada. Materiais policristalinos, tais como cerâmicas constituídas de titanato $\left(\mathrm{BaAl}_{2} \mathrm{Ti}_{6} \mathrm{O}_{16}, \mathrm{CaTiO}_{3}\right.$ e $\left.\mathrm{SrTiO}_{3}\right)$ e cerâmicas constituídas de fosfato, foram indicados para aplicações como matrizes imobilizadoras de rejeitos radioativos em virtude da sua estabilidade química e térmica e da sua capacidade de formar solução sólida com os elementos actinídeos ${ }^{3,4,5,6}$.

Porém, a vitrificação é hoje um dos principais caminhos em escala industrial para o manejo de rejeitos radioativos de alta atividade, e para o transporte e estocagem a curtos e longos períodos. 


\subsection{OBJETIVOS}

O objetivo dessa tese de doutorado foi avaliar a utilização de um resíduo da indústria do alumínio, denominado lama vermelha, como matéria-prima para a obtenção de vidros, com o intuito de possibilitar o reuso de um material que vem sendo estocado ao longo dos últimos anos.

Em específico, analisar o efeito da adição de $\mathrm{BaO}, \mathrm{SrO}$ e $\mathrm{ZrO}_{2}$, óxidos comumente presentes na composição química de rejeitos nucleares, nas propriedades químicas e térmicas do vidro produzido com o uso da lama vermelha e, assim, estimar o seu desempenho como material aplicado à imobilização de rejeitos nucleares. 


\section{REVISÃO DA LITERATURA}

\subsection{Vitrificação de Rejeitos Nucleares}

As pesquisas relacionadas à vitrificação de rejeitos nucleares se tornaram intensas na década de 50 e, se definiu como uma aplicação em potencial quando, no Canadá, um rejeito nuclear foi incorporado pela primeira vez em um vidro ${ }^{8}$.

A temperatura de fusão do vidro utilizado nessa ocasião, $1350^{\circ} \mathrm{C}$, foi considerada muito alta e estudos que buscavam desenvolver uma nova composição vítrea com temperatura de fusão mais baixa para reduzir a perda de radionuclídeos por volatização, foram realizados na década de 60 em países como os Estados Unidos, Canadá, Alemanha, França, Itália, Japão e Inglaterra ${ }^{8}$.

Os vidros são utilizados como matriz imobilizadora de rejeitos radioativos por terem uma alta resistência à radiação, boa estabilidade química e mecânica, e por serem capazes de incorporar em sua estrutura, devido sua desordem estrutural, rejeitos nucleares com composição química complexas que podem conter até 30 componentes, e mantê-los por longos períodos. 
Uma composição típica de um rejeito radioativo obtido na unidade de reprocessamento do combustível nuclear, La Hague, situada na França, é constituída por aproximadamente 300 litros de rejeito por tonelada de $\mathrm{U}$ reprocessado. Desses 300 litros, cerca de 140 litros correspondem ao rejeito de alta atividade que contem resíduos insolúveis. Nos 140 litros de rejeito de alta atividade estão presentes cerca de $40 \mathrm{~kg}$ de HNO, $29 \mathrm{~kg}$ de produtos de fissão (principalmente $\mathrm{Ba}, \mathrm{Sr}, \mathrm{Ce}, \mathrm{Cs}, \mathrm{Eu}, \mathrm{Gd}$, La, Nd, Mo, Pd, Pr, Rb, Rh, Sm, Tc, Y e Zr), $6 \mathrm{~kg}$ de $\mathrm{Fe}, 2,3 \mathrm{~kg}$ de Ni, Cr e P, $1 \mathrm{~kg}$ de $\mathrm{U}, 0,05 \mathrm{~kg}$ de Pu, 0,3 kg de Am, 0,4 kg de $\mathrm{Np}$ e $0,03 \mathrm{~kg}$ de $\mathrm{Cm}^{7}$.

Embora as composições dos vidros utilizados para este propósito sejam bastante complexas, pois dependem da composição dos rejeitos, os vidros borosilicatos são, no momento, os únicos utilizados comercialmente como imobilizadores. A temperatura de fusão desses vidros é consideravelmente mais baixa $\left(1100-1150^{\circ} \mathrm{C}\right)$ quando comparada a temperatura de fusão do primeiro vidro de confinamento desenvolvido no Canada ${ }^{8}$.

Uma das propriedades mais importantes a ser avaliada nos materiais propostos para imobilizar rejeitos nucleares é a corrosão. Por este motivo, os mecanismos de corrosão dos vidros borosilicatos vêm sendo extensivamente estudados desde 1987, utilizando quase todas as condições possíveis por períodos de vários anos e, por isso, já são bem conhecidos. Acima de $250^{\circ} \mathrm{C}$ os vidros borosilicatos contendo rejeitos radioativos são rapidamente corroídos e se devitrificam. Portanto, há a necessidade de resfriamento dos vidros borosilicatos contendo rejeitos radioativos por longos períodos antes de serem colocados no repositório final ${ }^{8}$.

Em temperaturas inferiores a $100^{\circ} \mathrm{C} \mathrm{e}$, em ambientes onde o fluxo da solução de lixiviação é baixo, ou seja, em condições típicas dos repositórios, os vidros borosilicatos são estáveis e a taxa de corrosão é determinada pelas propriedades intrínsecas do vidro ou pela composição da solução. É previsto também que os efeitos da radiação nesses vidros são mínimos ${ }^{8}$.

No entanto, esses vidros apresentam uma série de restrições e incompatibilidades como, por exemplo, baixa solubilidade de fosfatos e sulfatos e separação de fase ${ }^{9}$. 
Alguns rejeitos nucleares de alta atividade contêm $\mathrm{Fe}_{2} \mathrm{O}_{3}, \mathrm{P}_{2} \mathrm{O}_{5}, \mathrm{Cr}_{2} \mathrm{O}_{3}$ e, óxidos de metais pesados como $0 \mathrm{Bi}_{2} \mathrm{O}_{3}$, e $\mathrm{UO}_{2}$. A vitrificação desses rejeitos em vidros borosilicatos pode causar separação de fase, sobretudo pela presença de $\mathrm{P}_{2} \mathrm{O}_{5}$, e isto pode levar a uma alteração nas suas propriedades como, por exemplo, a sua durabilidade química. Vidros borosilicatos podem ser utilizados na vitrificação de um rejeito radioativo de alta atividade sem que haja separação de fase se o rejeito conter no máximo de 2 a $3 \%$ em peso de $\mathrm{P}_{2} \mathrm{O}_{5}{ }^{9}$.

A solubilidade química do $\mathrm{Cr}_{2} \mathrm{O}_{3}$ em vidros borosilicatos de alumínio é aproximadamente $0,5 \%$ em massa. Portanto, para vitrificar um rejeito radioativo de alta atividade contendo 4,5\% em massa de $\mathrm{Cr}_{2} \mathrm{O}_{3}$ utilizando um vidro borosilicato de alumínio é necessário que o vidro tenha nove vezes o volume do rejeito e, isto aumenta o custo do tratamento desse rejeito ${ }^{10}$.

Assim, não existe uma solução única para todos os rejeitos, devendo cada caso ser examinado individualmente.

Outras composições vítreas vêm sendo estudadas para serem aplicadas na imobilização de rejeitos radioativos. De acordo com trabalhos anteriores, vidros ferrofosfatos, com aproximadamente $40 \%$ de $\mathrm{Fe}_{2} \mathrm{O}_{3}$ e $60 \%$ de $\mathrm{P}_{2} \mathrm{O}_{5}$ (\% em mol), possuem durabilidade química, em água à $90^{\circ} \mathrm{C}$, igual ou superior a dos vidros borosilicatos e são capazes de acomodar rejeitos que contém uma grande quantidade de $\mathrm{P}_{2} \mathrm{O}_{5}$. Dependendo da quantidade de $\mathrm{P}_{2} \mathrm{O}_{5}$ no rejeito, o vidro ferrofosfato utilizado para imobilizá-lo pode ter apenas entre 20 a 33\% do volume necessário em relação a dos vidros borosilicatos ${ }^{9,11}$. Outra vantagem desse vidro é o limite de solubilidade do $\mathrm{Cr}_{2} \mathrm{O}_{3}$ que é cerca de três vezes maior em relação a do vidro borosilicato ${ }^{12}$.

A estabilidade desses vidros contra a devitrificação aumenta com a adição de $\mathrm{UO}_{2}$ e a durabilidade química de vidros ferrofosfatos contendo $\mathrm{Na}_{2} \mathrm{O}$ aumenta com o acréscimo de $\mathrm{UO}_{2}{ }^{13}$.

No entanto, quando o material de partida do vidro ferrofosfato é fundido entre 1100 e $1200^{\circ} \mathrm{C}$, por 1 ou 2h, em ar, e resfriado à temperatura ambiente, o vidro resultante possui uma fração de Fe(II) entre 0,15 e 0,25. Essa fração aumenta com o aumento da temperatura de fusão e a facilidade do líquido em formar vidro diminui quando essa fração excede 0,45 . O aumento dessa fração também leva a uma 
maior taxa de corrosão do vidro em meio aquoso ${ }^{11,13}$. Desta forma, a fusão desse material deve ser controlada para se obter uma fração de $\mathrm{Fe}(\mathrm{II})$ menor que 0,45 e, assim, garantir as boas propriedades desse material.

Muitos aditivos tendem a melhorar a durabilidade química dos vidros fosfatos, mas o chumbo reduz ao mesmo tempo a taxa de dissolução desse vidro em água e a sua temperatura de fusão e, além disso, vidros fosfato de chumbo podem acomodar até $20 \%$ de óxidos metálicos que simulam a composição de rejeitos radioativos. Com o acréscimo desses óxidos a $T_{g}$ desses vidros aumenta e 0 coeficiente de expansão térmica, e a taxa de dissolução diminuem ${ }^{14}$.

Um outro tipo de vidro que vem sendo estudado para ser aplicado como matriz imobilizadora de rejeitos radioativos é o vidro niobofosfato. Uma composição específica de um vidro niobofosfato, $37 \mathrm{P}_{2} \mathrm{O}_{5} \cdot 23 \mathrm{~K}_{2} \mathrm{O} .40 \mathrm{Nb}_{2} \mathrm{O}_{5}$ (\% em mol), denominado $\mathrm{Nb40}$, apresentou durabilidade química adequada para ser utilizada nesta finalidade. Esse vidro também possui alta estabilidade térmica contra a devitrificação e, quando adicionado $20 \%$ em peso de $\mathrm{U}_{3} \mathrm{O}_{8}$ à sua composição, a densidade obtida por meio da sinterização atingiu 97\% em relação à densidade teórica. A densificação desse vidro foi superior a dos vidros ferrofosfatos também estudados neste trabalho. Além disso, não há evidências que alterações no estado de valência do íon nióbio possam afetar a durabilidade química do vidro ${ }^{15}$.

A vitrificação é utilizada como método de imobilização por países que adotaram o reprocessamento dos rejeitos radioativos como a França e o Japão.

$\mathrm{Na}$ França o procedimento atual de vitrificação ocorre em duas etapas: a evaporação-calcinação das soluções dos produtos de fissão seguida da vitrificação do material calcinado.

A etapa de evaporação-calcinação é realizada em um forno rotativo. $O$ material calcinado, composto pelos elementos da solução sob forma de nitratos ou óxidos, escoa em um recipiente metálico aquecido por indução. O vidro ou as fritas são então acrescentados ao material calcinado para formar o vidro de confinamento. Esse material é colocado em um contêiner posteriormente selado por soldagem. Este contêiner é mantido em um local seco até o resfriamento, pois o calor gerado pelos rejeitos mantém o bloco de vidro aquecido. Com a temperatura mais baixa, 
esse contêiner é levado a um repositório geológico ${ }^{16}$. As etapas realizadas na França para a vitrificação dos rejeitos estão mostradas na Fig. 1.

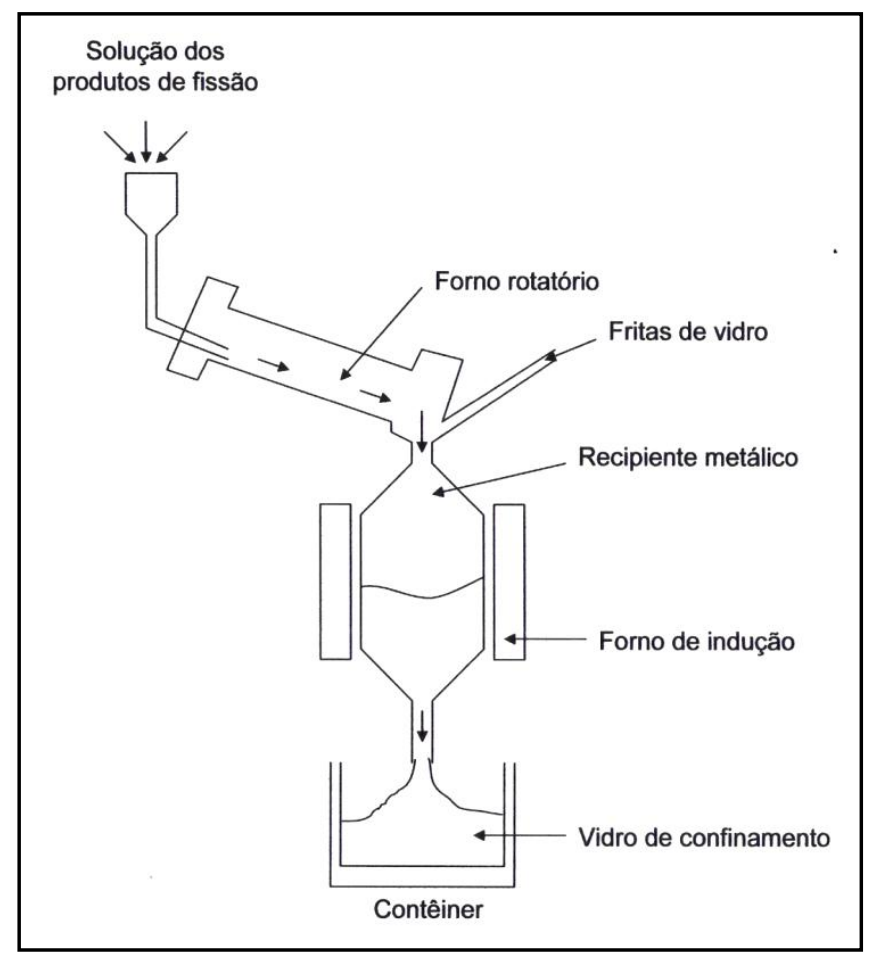

FIGURA 1: Etapas da vitrificação dos rejeitos radioativos realizadas na França $^{16}$.

O vidro utilizado para a imobilização, no caso da Planta de La Hague, é um borosilicato constituído principalmente de $\mathrm{SiO}_{2}$ (aproximadamente 80\% em mol), denominado R7T7. Este vidro permite a incorporação de produtos de fissão na faixa de 12 a 18\%. Se a composição dos rejeitos é alterada, novas matrizes vítreas, baseadas na composição do R7T7, são desenvolvidas visando assegurar uma taxa de corrosão baixa e propriedades mecânicas e térmicas que atendam os critérios de confinamento em um meio ambiente agressivo ${ }^{16,17}$. 


\subsection{VIDROS}

Os vidros naturais denominados rochas obsidianas e "tektites" são formados quando alguns tipos de rochas são fundidas a elevadas temperaturas e solidificadas rapidamente; a origem desses vidros são as erupções vulcânicas e o choque de meteoritos com a crosta terrestre ${ }^{18}$.

Há muitas incertezas sobre o período em que os primeiros vidros foram sintetizados artificialmente, mas sua obtenção é atribuída aos fenícios que, à aproximadamente 7000 anos a. C., observaram uma substância líquida e brilhante que escorria e solidificava rapidamente ao se fazer fogo sobre blocos de salitre e areia. Essa descoberta foi reproduzida pelos fenícios e difundida através do Egito e Mesopotâmia ${ }^{18}$.

Os primeiros vidros incolores foram produzidos em Alexandria e, no período do império romano, a qualidade e o refinamento da arte de produzir e moldar os vidros permitiu a criação de perfeitas imitações de pedras preciosas ${ }^{18}$.

Michael Faraday, em 1830, foi o primeiro a estudar cientificamente os materiais vítreos e os definiu como sendo "materiais mais aparentados a uma solução de diferentes substâncias do que um composto em si”. Desde então, tem surgido diferentes definições para os vidros e novas explicações sobre a sua estrutura ${ }^{18}$.

No artigo "O Arranjo Atômicos dos Vidros", publicado em 1932 por Zachariasen ${ }^{19}$, foi proposto que o arranjo atômico dos vidros é caracterizado por uma rede tridimensional estendida com ausência de simetria e periodicidade. Ainda, segundo Zachariasen, essa ausência de simetria e periodicidade é o fator que diferencia o vidro de um cristal. Ele propôs também que as forças interatômicas são comparáveis com a dos cristais correspondentes.

Zachariasen idealizou modelos bidimensionais da estrutura simétrica e periódica de um cristal com composição $\mathrm{A}_{2} \mathrm{O}_{3}$ e do arranjo assimétrico e sem 
periodicidade de um vidro com a mesma composição do cristal, que são mostrados na Fig. 2 (a) e (b), respectivamente.

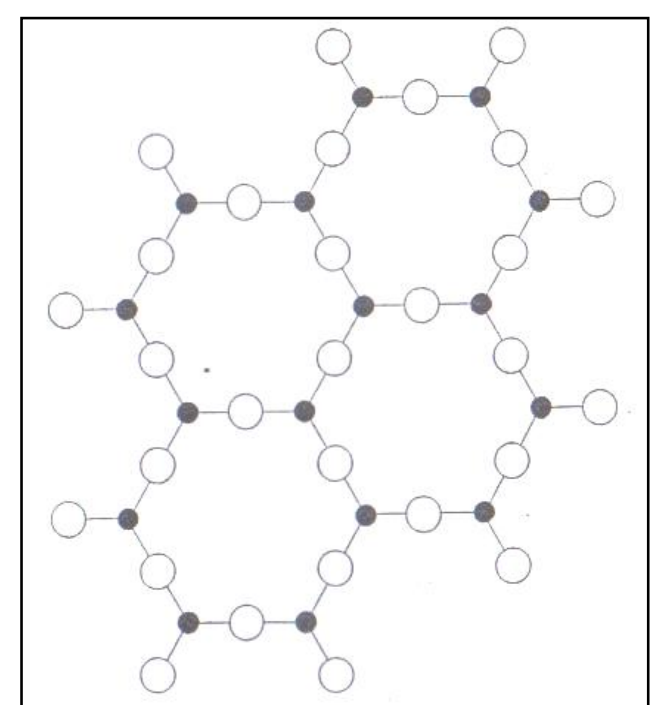

(a)

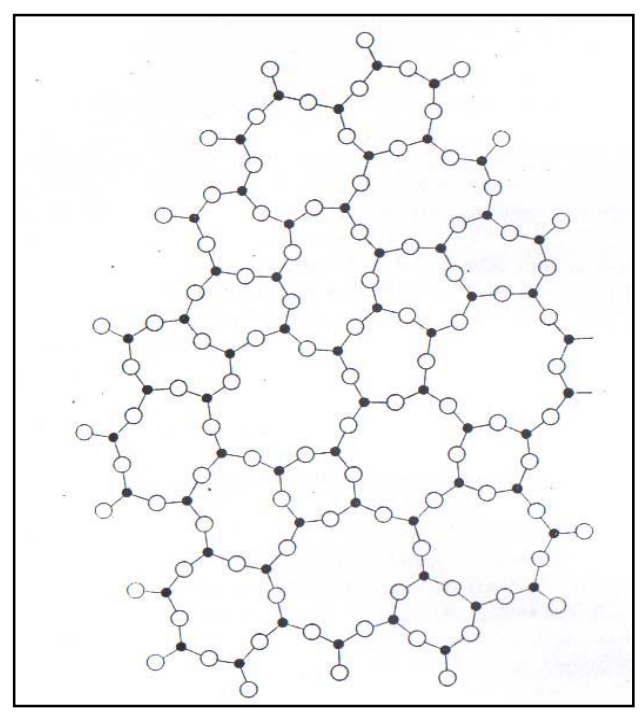

(b)

FIGURA 2: Representação bidimensional idealizada por Zachariasen da estrutura de um cristal de composição $\mathrm{A}_{2} \mathrm{O}_{3}(\mathrm{a})$ e a de um vidro com a mesma composição $(b)^{19}$.

Tradicionalmente, os vidros são formados por compostos inorgânicos e não metálicos, utilizando processos de fusão/resfriamento. Porém novos processos de fabricação de vidros, como o processo sol-gel, deposição química de vapor, e irradiação de nêutron em um material cristalino, foram desenvolvidos e, permitiram a obtenção de vidros metálicos e orgânicos ${ }^{20}$.

Assim, de acordo com Shelby, em 1997, o vidro pode ser definido como um sólido amorfo com ausência completa de uma estrutura atômica periódica de longo alcance e, que exibe uma faixa de temperatura onde ocorre a transição vítrea. Dessa forma, qualquer material inorgânico, orgânico ou metal, obtido por qualquer técnica e que exibe um fenômeno de transição vítrea é um vidro ${ }^{20}$. 
Os vidros óxidos são constituídos por compostos classificados em três categorias distintas: formadores, modificadores e intermediários, em razão da função que desempenham na constituição dos vidros.

Compostos formadores são óxidos que participam na formação da estrutura fundamental do vidro, ou seja, são os compostos tipicamente formadores de vidros e, dentre eles podemos citar $\mathrm{SiO}_{2}, \mathrm{~B}_{2} \mathrm{O}_{3}$ e $\mathrm{P}_{2} \mathrm{O}_{5}$. Os modificadores são elementos que auxiliam a formação de vidros por meio, por exemplo, da diminuição da temperatura utilizada para fusão e da alteração da viscosidade dos vidros. Os cátions $\mathrm{K}^{+}, \mathrm{Na}^{+}, \mathrm{Pb}^{2+}, \mathrm{Fe}^{2+}$, e $\mathrm{Ca}^{2+}$ são, entre outros, exemplos de modificadores. Os compostos intermediários, em razão das suas propriedades, podem atuar como formadores ou modificadores. Alguns exemplos de elementos intermediários são $\mathrm{Fe}^{3+}, \mathrm{Al}^{3+}, \mathrm{Be}^{2+}, \mathrm{Zn}^{4+}, \mathrm{Sn}^{4+}$ e $\mathrm{Ga}^{3+} 21$.

Durante o processo convencional de formação de um vidro, os componentes precursores são misturados, homogeneizados e fundidos. Após a fusão, o líquido deve ser resfriado rapidamente para que não ocorra a cristalização.

A variação do volume específico de um material líquido durante o seu resfriamento é mostrada na Fig. $3^{21}$. Durante o resfriamento ocorre a diminuição contínua do volume específico do material no trajeto $A B$. Abaixo de sua temperatura de fusão $\left(T_{f}\right)$, o material atravessa uma região de equilíbrio metaestável e, nesta região, pequenas perturbações podem ocasionar a sua cristalização. Se a cristalização ocorrer, observa-se no gráfico uma descontinuidade caracterizada pela contração $\mathrm{BC}$ e, a partir desse momento, prosseguindo o resfriamento, o volume específico do material cristalizado continua a diminuir em CD, porém, em menor proporção em virtude do seu menor coeficiente de dilatação.

Por outro lado, leva-se um tempo até que os átomos assumam posições de equilíbrio de um cristal e, portanto, para evitar que os átomos assumam essas posições o material deve ser rapidamente resfriado até uma temperatura na qual os rearranjos estruturais sejam cineticamente impedidos. Dessa forma, se a cristalização for evitada, o líquido é mantido em equilíbrio metaestável e a diminuição do volume específico ocorre sem que haja nenhuma descontinuidade na curva volume específico versus temperatura ${ }^{21}$. 


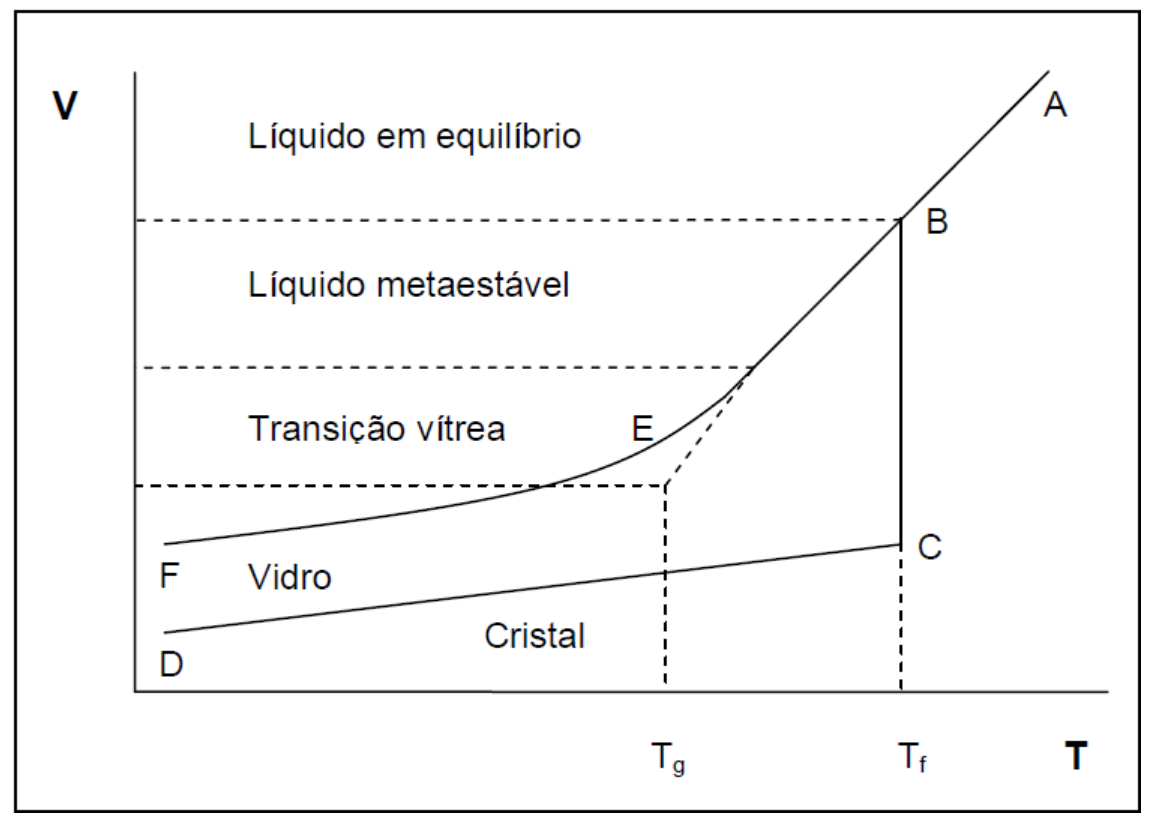

FIGURA 3: Variação do volume específico de um material durante o seu resfriamento ${ }^{21}$.

Prosseguindo o resfriamento do material não cristalizado, a contração do volume específico continua até o ponto $\mathrm{E}$ da curva. Este ponto coincide com um notável aumento da viscosidade do material e representa um intervalo de temperatura denominado temperatura de transição vítrea $\left(T_{g}\right)$. Quando o vidro é reaquecido, ocorre neste intervalo o fenômeno de relaxação estrutural. Abaixo deste intervalo a redução do volume específico continua em EF, em um ritmo praticamente igual a do cristal, e o material permanece no estado vítreo ${ }^{21}$.

A $T_{g}$ ocorre a uma viscosidade de valor médio correspondente a $10^{11,3}$ Pa.s e depende de alguns parâmetros, tais como a propriedade medida para a sua determinação, a taxa de aquecimento e o tamanho da amostra. Por esta razão, vidros supostamente idênticos podem apresentar valores diferentes de $T_{g}$. A temperatura de transição vítrea pode ser determinada por meio de medidas da capacidade calorífica, análise térmica diferencial e calorífica exploratória, expansão térmica, taxa de prolongamento de uma fibra suspensa verticalmente em um forno, entre outras ${ }^{20}$.

A temperatura na qual os átomos perdem a sua total mobilidade translacional dentro do líquido é denominada temperatura de transição fictícia e nela, o material 
passa do estado de um líquido super-resfriado para o estado sólido. Por isso essa temperatura representa a última estrutura do líquido agora, no estado sólido ${ }^{21}$.

Após a fusão do material precursor, o líquido é vertido em moldes que forneçam formatos específicos ao vidro. Esta etapa de produção do vidro denominada moldagem pode ser feita por quatro métodos principais: sopro, prensagem, fundição e estiramento ou flutuação ${ }^{21}$.

Após a moldagem os vidros são submetidos a um processo denominado recozimento para que as tensões internas resultantes do resfriamento sejam aliviadas. E, por aliviar as tensões internas, este processo aumenta a resistência mecânica do vidro ${ }^{21}$.

Em alguns casos os vidros são também submetidos a um processo de têmpera. Neste procedimento, o vidro já pronto é reaquecido entre as temperaturas de recozimento superior e de amolecimento e, então é subitamente resfriado por rajadas de ar frio ou pela imersão em óleo ${ }^{21}$. 


\subsection{DURABILIDADE QUÍMICA}

Quando um vidro entra em contato com um meio líquido, pode ocorrer a corrosão desse material e o vidro pode até mesmo se dissolver por completo por conta dessa interação. Além disso, os produtos dessa corrosão provocam alterações na composição química e no $\mathrm{pH}$ da solução ${ }^{21}$.

Antes que vidros imobilizadores de rejeitos nucleares começassem a ser investigados, o desempenho dos vidros em meio aquoso não era amplamente estudado. Os testes aplicados a vidros de garrafa e janela, por exemplo, não eram adequados aos vidros de confinamento. A finalidade desses testes era apenas comparar quanto um vidro foi corroído em relação a outro e, o vidro considerado bom era aquele que resistia mais tempo. A corrosão relacionada a esse vidro era considerada uma corrosão aceitável. Porém, quando os primeiros vidros de confinamento começaram a ser investigados por meio dos testes de corrosão existentes na época, tornou-se claro que os testes não eram suficientes ${ }^{21}$.

A partir de então, em 1979, iniciou-se uma série de estudos visando formular um teste padrão que possibilitasse a determinação da termodinâmica e da cinética associada à dissolução do vidro.

Foram desenvolvidos cinco testes, cada um com um propósito definido, como parte do Centro de Caracterização dos Materiais (MCC). Esses testes foram minuciosamente investigados durante o seu desenvolvimento e ainda são amplamente utilizados nos dias atuais ${ }^{22}$.

O primeiro teste, denominado MCC-1, é utilizado para comparar vidros de confinamento. É um teste estático, a amostra é analisada na forma de particulados e a razão área superficial da amostra analisada pelo volume do líquido utilizado (S/V) equivale, geralmente, a $10 \mathrm{~m}^{-1}$. Inicialmente, esse teste foi desenvolvido para ser realizado em um recipiente fechado, porém sabe-se atualmente que ao se realizar esse teste em um recipiente de teflon a solução estabiliza-se rapidamente com a atmosfera ambiente. Por isso, esse teste pode ser realizado tanto em um recipiente fechado quanto em um recipiente aberto, desde que em recipientes de teflon ${ }^{23}$. 
O teste MCC-2 é um a versão do teste MCC-1 em alta temperatura, maior que $90^{\circ} \mathrm{C}$. É um teste estático realizado em um recipiente fechado de teflon ou de aço inoxidável ${ }^{23}$.

No teste conhecido como MCC-3 analisa-se amostras em forma de materiais particulados, porém o vidro é agitado dentro do líquido para acelerar a reação vidroágua. Geralmente é um teste fechado, mas pode ser aberto se recipientes de teflon forem utilizados ${ }^{23}$.

O teste MCC-4 é realizado em recipiente aberto e tem por objetivo determinar a dissolução do vidro em função do fluxo de líquido. Diferentemente dos testes anteriores, foi desenvolvido para ser aplicado em amostras na forma de blocos monolíticos, porém atualmente já é possível realizar esse teste em amostras na forma de particulados $23,24,25$.

O quinto teste, teste MCC-5, é utilizado para determinar a taxa de dissolução do vidro. É realizado em recipiente aberto com alto fluxo de líquido e, por esse motivo, observa-se uma variação na temperatura aplicada no teste. Atualmente, esse teste está ultrapassado devido a avanços no equipamento utilizado ${ }^{23}$.

Atualmente, além dos cinco testes mencionados, foram desenvolvidos novos métodos para testar os vidros de confinamento em outras condições de análise.

Dentre os novos métodos podemos mencionar o Auto Clave. Esse teste é realizado em recipiente fechado, com temperatura acima de $100^{\circ} \mathrm{C}$, em recipientes revestidos com ouro, aço inoxidável ou titânio. O Auto Clave é utilizado principalmente na área geoquímica, porém é aplicado também em vidros de confinamento devido à alta temperatura existente nos depósitos inicias de rejeitos radioativos. Com esse método é possível determinar a solubilidade e a cinética de alteração do vidro ${ }^{26}$.

Outro teste recentemente desenvolvido é o teste de Hidratação por Fase Vapor. Este teste é realizado em recipiente fechado, com amostras na forma de pastilhas, e é aplicado quando se quer acelerar a reação do vidro. O tipo de reação que ocorre nesse tipo de teste, quando realizado de forma adequada, é entre a água que condensa na superfície do vidro e a superfície do vidro ${ }^{27}$.

Outra opção de estudo da reação do vidro em meio líquido é por meio do teste denominado Fluxo Pulsado. Esse teste pode ser realizado em recipiente 
aberto ou fechado e consiste na substituição parcial do líquido "gasto" por um líquido "virgem", ou então na reposição da amostra para um ambiente com líquido "virgem". O Fluxo Pulsado é aplicado quando é necessário saber o comportamento do vidro em condições de fluxo muito baixo, ou quando há a necessidade de se obter informações sobre a solução, em dias específicos do teste, sem trocar a amostra $^{28}$.

O método mais recentemente desenvolvido é o teste de Fluxo Insaturado Pressurizado, e sua aplicação se faz necessária quando se quer acelerar a interação do vidro com o líquido ${ }^{29}$.

Normalmente, é utilizado o termo lixiviação para se referir ao estudo da corrosão do vidro em um meio líquido. Esse termo é empregado para definir o fenômeno de remoção dos constituintes solúveis presentes em um sólido quando imerso em um determinado meio líquido.

O primeiro estágio de lixiviação do vidro envolve a troca iônica entre íons alcalinos $\left(\mathrm{Na}^{+}, \mathrm{K}^{+}\right.$, entre outros) presentes na estrutura vítrea e íons de hidrogênio do líquido a que estão expostos. Como conseqüência, essa troca iônica conduz ao aumento do pH do líquido. Neste estágio, os demais constituintes do vidro não são alterados e a taxa de extração de álcalis ( $\mathrm{Na}, \mathrm{K}$ ) do vidro é lenta e decresce aproximadamente com a raiz quadrada do tempo. Dessa forma, com a lixiviação dos íons alcalinos, há um aumento na área superficial do vidro, deixando uma camada rica em elementos formadores ( $\mathrm{Si}, \mathrm{P}$, entre outros) com micro poros hidratados.

No segundo estágio da lixiviação ocorre a quebra das ligações principais (SiO-Si ou P-O-P), ocasionando a dissolução do vidro ${ }^{21}$.

$\mathrm{O} \mathrm{pH}$ do meio em que o vidro está em contato interfere na corrosão do mesmo. Em meio ácido, o ataque ao vidro ocorre especialmente pelo processo de difusão iônica. Por esta razão, vidros constituídos apenas por sílica, ou seja, isentos de íons alcalinos, praticamente não são corroídos em meio líquido com pH menor que 7. Nos vidros que contem óxidos modificadores ocorre a extração dos íons alcalinos com uma taxa proporcional a raiz quadrada do tempo, e essa taxa se mantém praticamente constante ao modificar o $\mathrm{pH}$ para valores próximos de $8^{21}$.

Se a quantidade de íons alcalinos no vidro é pequena, o ataque inicial em meio ácido melhora a resistência química do vidro em razão da extração dos íons 
alcalinos que proporciona a formação de uma camada rica em elementos formadores de vidro. Essa camada atua como uma barreira protetora dificultando o processo de difusão e, portanto, a extração de novos íons alcalinos ${ }^{21}$.

No entanto, em vidros com alto teor de íons alcalinos, há uma intensa troca iônica que pode levar a importantes alterações na estrutura do vidro ${ }^{21}$.

A natureza do ácido empregado como agente químico na solução de lixiviação não exerce nenhuma influência importante na corrosão do vidro, com exceção do ácido fluorídrico. Porém, de acordo com a solubilidade dos produtos extraídos dos vidros, diferenças nas taxas de corrosão podem ocorrer. De uma forma geral, o ataque ao vidro é mais rápido em meio aquoso com ácido nítrico em relação ao ácido clorídrico e ao ácido sufúrico ${ }^{21}$.

O ácido fluorídrico é uma exceção, pois tem um efeito fortemente agressivo nos vidros e os corrói por meio de um mecanismo diferente dos citados anteriormente. Este ácido é facilmente desassociado em meio aquoso formando os íons $\mathrm{F}^{-}$. Esses íons deslocam os radicais $\mathrm{OH}^{-}$ligados aos elementos formadores, e podem romper as pontes de oxigênio destruindo progressivamente as ligações principais $^{21}$.

Em meio alcalino, o ataque ao vidro é muito mais rápido em relação ao meio ácido ou neutro, pois o predomínio de $\mathrm{OH}$ - produz a destruição da rede vítrea por meio da ruptura das ligações principais ${ }^{21}$. 


\subsection{LAMA VERMELHA}

A lama vermelha é um resíduo gerado por meio do processamento de minérios ${ }^{30}$. Em particular será abordada a lama vermelha gerada por meio do processamento químico do mineral bauxita para a produção de alumina.

O processamento químico mencionado foi desenvolvido em 1888, por Karl Josef Bayer, um químico austríaco, e denominado processo Bayer. Este processamento químico foi desenvolvido originalmente para atender a demanda da indústria têxtil, que utilizava $\mathrm{O}_{2} \mathrm{Al}_{3}$ como fixador para tingir do algodão. Porém, com a sua associação ao processo eletrolítico para a obtenção do alumínio metálico, ganhou importância na metalurgia ${ }^{31}$.

Cada planta de refinaria possui suas peculiaridades quanto à produção de alumina pelo processo Bayer, mas de uma forma geral, desconsiderando essas peculiaridades, este processo pode ser esquematizado conforme a Fig. 4.

Como é mostrado na Fig. 4, o processo Bayer pode ser dividido em quatros estágios, são eles: digestão, clarificação, precipitação e calcinação ${ }^{31}$.

A digestão equivale à moagem da bauxita seguida pela sua mistura com uma solução cáustica de hidróxido de sódio sob temperatura e pressão controlada. As condições aplicadas nessa etapa permitem que fases contendo alumínio sejam dissolvidas.

A clarificação é a etapa onde ocorre a separação da fase sólida (resíduo insolúvel) e líquida. Normalmente, as técnicas empregadas nessa etapa consistem na decantação dos sólidos seguida de filtração.

Na terceira etapa, precipitação, a fase líquida é esfriada e cristais de alumina são adicionados ao líquido para estimular a precipitação. Podemos classificar essa etapa como uma operação reversa à digestão.

$\mathrm{Na}$ calcinação, etapa final do processo, a alumina cristalizada é lavada para eliminar resíduos da fase líquida, seca e calcinada a aproximadamente $1000^{\circ} \mathrm{C}$ para desidratar os cristais e formar cristais de alumina puros. A fase líquida remanescente é reenviada para a etapa de digestão para o reaproveitamento do $\mathrm{NaOH}$ residual. 


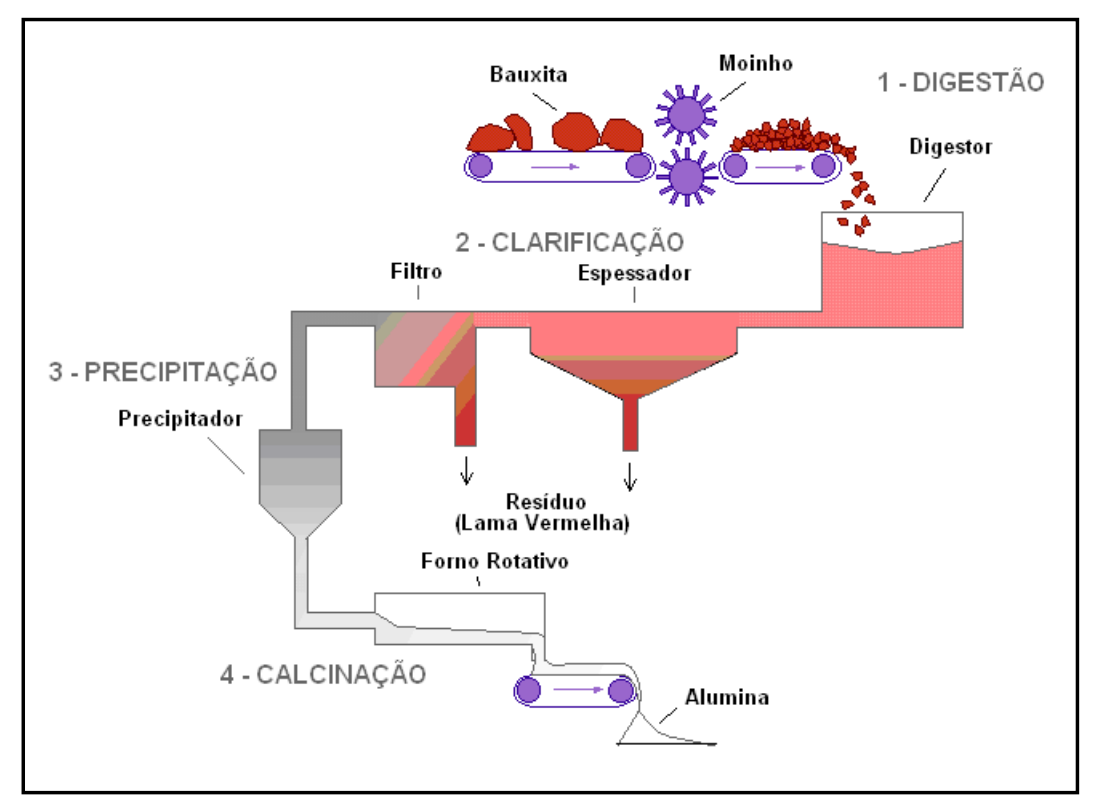

Figura 4: Desenho esquemático da produção da alumina pelo processo Bayer.

O resíduo insolúvel gerado na clarificação é o resíduo denominado lama vermelha.

A lama vermelha é uma polpa altamente alcalina com pH entre 10 e 13, possui uma alta capacidade de troca iônica, apresenta área superficial entre 13 e 22 $\mathrm{m}^{2} \mathrm{~g}^{-1}$, e cerca de $95 \%$ das partículas que a constituem possuem tamanho inferior a $44 \mathrm{~m}^{31}$.

A composição química da lama vermelha varia de acordo com a natureza da bauxita e da técnica empregada no processo Bayer em cada planta industrial, por isso, observa-se uma grande variação na composição química da lama vermelha, mesmo quando gerada no mesmo país, como é mostrado na Tab. 1.

Porém, de uma forma geral, a composição típica desse resíduo é constituída de ferro, titânio e sílica presentes no minério, além do alumínio residual e o sódio que foi adicionado no estágio inicial do processo $^{31}$.

Como observado na Tab. 1, vários componentes da lama gerada no Brasil podem ser utilizados na preparação de vidros. Particularmente, observa-se a presença de altos teores de óxido de ferro, o qual tem sido utilizado na preparação de vidros ferrofosfatos preliminarmente propostos para a imobilização de rejeitos 
nucleares, e sílica e alumina, utilizadas nas composições de vidros borossilicatos preparados para a mesma finalidade.

Tabela 1: Composição química da lama vermelha gerada em diferentes países.

\begin{tabular}{|c|c|c|c|c|c|c|c|c|c|}
\hline \multicolumn{10}{|c|}{$\%$ em Massa } \\
\hline País & $\mathrm{Fe} 2 \mathrm{O} 3$ & Al2O3 & $\mathrm{SiO} 2$ & $\mathrm{NaO} 2$ & TiO2 & $\mathrm{MgO}$ & $\mathrm{CaO}$ & $\mathrm{K} 2 \mathrm{O}$ & Ref. \\
\hline Brasil & $30-60$ & $10-20$ & $3-50$ & $2-10$ & $0-10$ & - & $2-8$ & - & 22 \\
\hline China & $6-10$ & 7,0 & $17-22$ & $2-4$ & $0-3$ & 1,5 & 38,0 & 0,5 & 32 \\
\hline Coréia & 16,6 & 23,7 & 22,9 & 11,9 & 6,7 & - & 6,7 & - & 33 \\
\hline Turquia & $35-40$ & $14-24$ & $12-17$ & $7-11$ & $4-6$ & $0-1$ & $2-5$ & - & 34 \\
\hline Austrália & 34,1 & 25,6 & 17,1 & 2,7 & 4,9 & 1,7 & 3,7 & - & 35 \\
\hline Itália & 35,2 & 20,0 & 11,6 & 7,5 & 9,2 & 0,4 & 6,7 & - & 36 \\
\hline Índia & $20-60$ & $14-26$ & $3-15$ & $1-6$ & $4-20$ & $0-1$ & $0-15$ & $0-13$ & 37 \\
\hline EUA & 53,0 & 16,0 & 3,0 & 2,0 & 10,0 & 1,0 & - & - & 38 \\
\hline Grécia & 42,5 & 15,6 & 9,2 & 2,4 & 5,9 & - & 19,7 & - & 39 \\
\hline Espanha & 31,8 & 21,1 & 6,1 & 4,7 & 22,6 & 0,2 & 4,7 & - & 40 \\
\hline Japão & 45.5 & 20,6 & 4,0 & 3,2 & 8,4 & - & 4,0 & - & 41 \\
\hline Guiné & 48,4 & 26,6 & 5,5 & - & 2,8 & 0,9 & 1,2 & - & 42 \\
\hline Jamaica & $25-55$ & $4-45$ & $0-2$ & $0-2$ & 3-11 & - & 0,5 & - & 43 \\
\hline
\end{tabular}

As fases minerais mais comuns presentes na lama vermelha são a hematita $\left(\mathrm{Fe}_{2} \mathrm{O}_{3}\right)$, a goetita $(\alpha-\mathrm{FeOOH})$, a magnetita $\left(\mathrm{Fe}_{3} \mathrm{O}_{4}\right)$, a boemita $(\mathrm{AlOOH})$, o quartzo $\left(\mathrm{SiO}_{2}\right)$, a sodalita $\left(\mathrm{Na}_{4} \mathrm{Al}_{3} \mathrm{Si}_{3} \mathrm{O}_{12} \mathrm{Cl}\right)$, a gipsita $\left(\mathrm{CaSO}_{4} \cdot 2 \mathrm{H}_{2} \mathrm{O}\right)$, a calcita $\left(\mathrm{CaCO}_{3}\right)$ e a gibisita $\left(\mathrm{Al}(\mathrm{OH})_{3}\right)^{44}$.

Além da composição química, a quantidade de lama vermelha gerada também varia de acordo com a natureza da jazida de bauxita utilizada. Desta forma, não há uma previsão exata para a proporção entre a quantidade de alumina produzida e a quantidade de lama vermelha gerada, porém, trabalhos publicados fazem referência 
a valores entre 0,6 a 2,5 toneladas de lama vermelha seca por tonelada de alumina produzida $^{45}$.

Logo, não há um consenso em relação à quantidade de lama vermelha gerada mundialmente e os números mencionados variam de 30 a 84 milhões de toneladas por ano ${ }^{46}$.

Considerando 30 ou 84 milhões de toneladas/ano, a questão é que a quantidade de lama gerada na produção da alumina é relativamente grande, e a previsão é que esta quantidade dobre a cada década devido ao aumento da capacidade das fábricas de alumínio; sabe-se que a alumina é o principal insumo para a produção do alumínio.

O Brasil ocupa o terceiro lugar na escala de reservas mundiais de bauxita e, atualmente, a região Norte é a maior produtora de alumina no país devido a sua abundância em bauxita de alta qualidade e a disponibilidade de energia hidrelétrica. A produção nacional de alumina conta com a atuação de grandes empresas como a Alumina do Norte do Brasil (ALUNORTE). Criada em 1978 e localizada em Barcarena no Pará, a ALUNORTE atingiu em 2008 a capacidade de produzir 6,26 milhões de toneladas de alumina por ano, o que corresponde a $7 \%$ da produção mundial $^{47}$. O Consórcio de Alumínio do Maranhão (ALUMAR) localizado em São Luís no Maranhão foi criado em 1984, é formado pelas empresas Alcoa, RioTintoAlcan e BHP Billiton e, atualmente, produz cerca de 1,5 milhão de tonelada de alumina por $a_{n o}{ }^{48}$. Pode-se mencionar, também, a Companhia Brasileira de Alumínio (CBA) que, inaugurada em 1955 na cidade de Alumínio, SP, marcou a implantação da primeira indústria de alumínio do Brasil e, atualmente, possui filiais distribuídas por 10 estados brasileiros ${ }^{49}$.

Analisando a capacidade das empresas nacionais na produção de alumina e a previsão de que para cada tonelada de alumina produzida, é gerada uma quantidade entre 0,6 e 2,5 toneladas de lama vermelha, como mencionado anteriormente, observamos que, se considerarmos a previsão mais favorável, apenas na empresa ALUNORTE foi gerada 3,7 milhões de toneladas de lama vermelha no ano de 2008 e, considerando a previsão menos favorável, pode ter sido gerado 15,6 milhões de toneladas desse resíduo. Em 2004 a ALUNORTE produziu 2,5 milhões de toneladas de alumina remetendo, assim, a geração de 1,5 milhão de 
tonelada de lama, segundo a previsão mais favorável. Comparando a geração desse resíduo pela empresa ALUNORTE entre os anos 2004 e 2008 observamos um aumento de $150 \%$.

A disposição da lama é feita em lagos para a decantação dos baixos teores de sólidos, Fig. 5. Esta técnica de disposição é conhecida como método úmido e, após a decantação, o líquido é reaproveitado no processo industrial ${ }^{50}$.

Embora a lama vermelha não seja classificada como um resíduo perigoso em outros países ${ }^{51}$, no Brasil é classificada como resíduo de classe $1^{52} \mathrm{e}$, em todos os casos, cuidados especiais são necessários para evitar a contaminação de águas superficiais e subterrâneas por hidróxido de sódio, ferro, alumínio ou outro agente químico e assegurar a proteção do solo e de mananciais evitando o contato direto da lama com animais, plantas e seres humanos. Portanto, os lagos de resíduos são construídos com tecnologia apropriada, impermeabilizados por meio de membranas plasmáticas ou aplicação de camadas de material impermeável antes da disposição e monitorados permanentemente ${ }^{50}$.
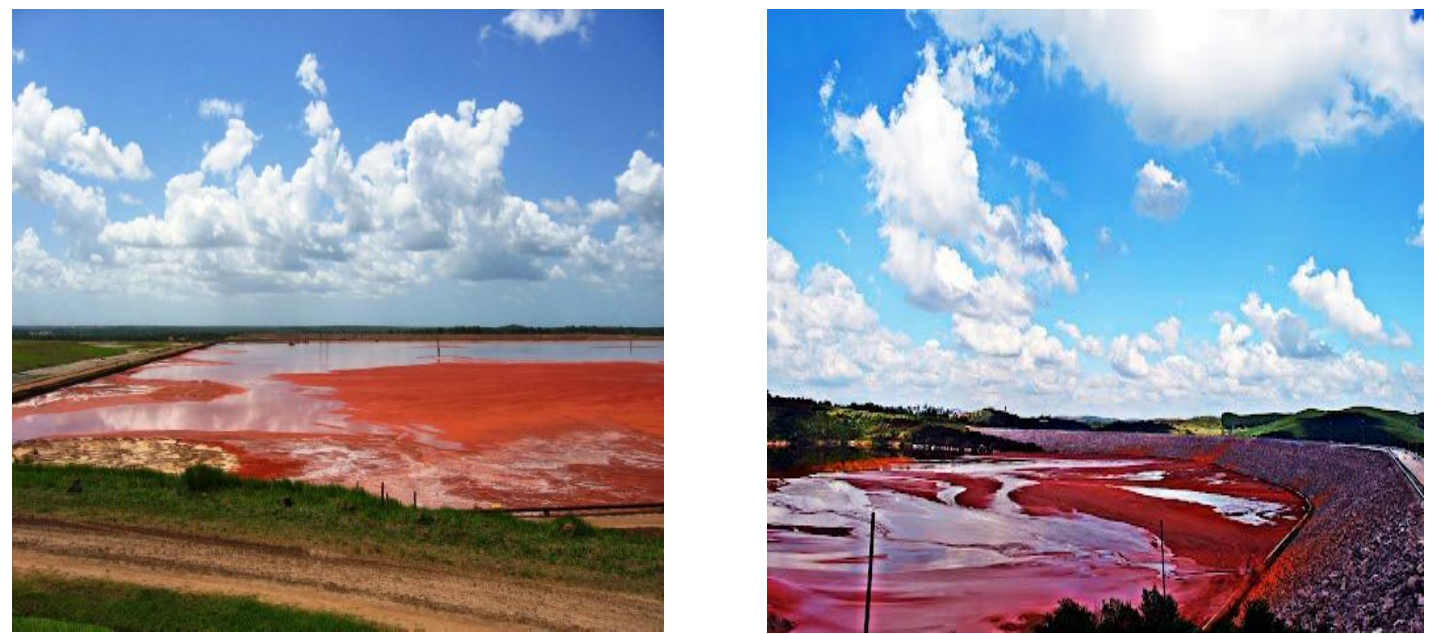

Figura 5: Lago de disposição da lama vermelha.

O método úmido é simples, porém o potencial de impacto sobre o meio ambiente é alto, pois a área de disposição final necessária é grande, cerca de 100 a 200 acres, sua vida útil é curta, entre 4 e 7 anos e a reabilitação da área é um processo lento. Além disso, os custos associados são altos devido aos cuidados necessários com a impermeabilização da área ${ }^{50}$. 
Há também os métodos de disposição conhecidos como métodos secos ou semi-secos, onde a lama é disposta com um teor de sólidos mais elevado resultando em uma textura pastosa. Esses métodos são mais modernos e vantajosos em relação ao método úmido, pois com a menor quantidade de líquido na lama o manuseio do resíduo se torna mais fácil e mais seguro, o volume de lama para a disposição é menor e, portanto a área ocupada para a disposição também é menor $^{31,50,53 .}$

Dentre os métodos de disposição a seco, o mais aplicado a disposição da lama vermelha é o método conhecido como dry-stacking. Neste caso, o lago de disposição é dividido em leitos de secagem e a lama é descarregada progressivamente nesses leitos até atingir certa altura. Quando a ocupação total desses leitos é alcançada repete-se o ciclo depositando uma nova camada de lama no leito inicial ${ }^{53}$.

Uma variação do dry-stacking é a secagem solar. Neste método os leitos de secagem possuem baixa profundidade para facilitar a evaporação ${ }^{54}$.

Outro método para a disposição da lama vermelha e o qual a lama é disposta no ponto central da área de disposição formando um monte cônico. A geometria adquirida com essa disposição elimina a necessidade de barragens, aumenta a estabilidade do depósito e facilita a reintegração da área ao meio ambiente ${ }^{53}$.

Um método de disposição utilizado por apenas 7 das 84 unidades de beneficiamento da alumina é o off-shore disposal. Neste caso, a lama é lançada em um rio ou no oceano. Esse método persiste em países com escassez de área para a disposição final ${ }^{55}$.

São poucas as informações a respeito do tipo de disposição adotada pelas refinarias brasileiras, mas sabe-se que a Alunorte adota o método de disposição a seco onde a lama é colocada nos lagos de disposição na forma de uma pasta que contem $60 \%$ em massa de fase sólida ${ }^{56}$.

A forma mais comum para o transporte da lama vermelha é o bombeamento. Em várias plantas industriais o bombeamento da lama ocorre por distâncias de 3 a 6 km até chegar ao local de disposição. Porém, o bombeamento só é utilizado quando a viscosidade da suspensão não é muito alta, principalmente quando a distância a 
ser percorrida é alta. Para suspensões com alta viscosidade são utilizados tratores e vagões como meio de transporte ${ }^{50,53}$.

Apesar do monitoramento e cuidado permanente para evitar qualquer problema na disposição da lama, alguns acidentes ambientais já foram relatados no Brasil e em outros países. Em 2003 houve um vazamento de lama vermelha no município de Barcarena no Pará que contaminou o rio Murucupi alterando a tonalidade da água desde a nascente até a foz do rio, Fig. 6. A mudança de tonalidade ocorreu devido ao aumento nos teores de alumínio e sódio na água ${ }^{57}$. Em 2003 o vazamento ocorreu em São Paulo e cerca de 900.000 litros de lama contaminaram as águas dos córregos Bugre e Varjão e do rio Pirajibu, afluente do rio Sorocaba, tornando-as avermelhadas ${ }^{58}$.

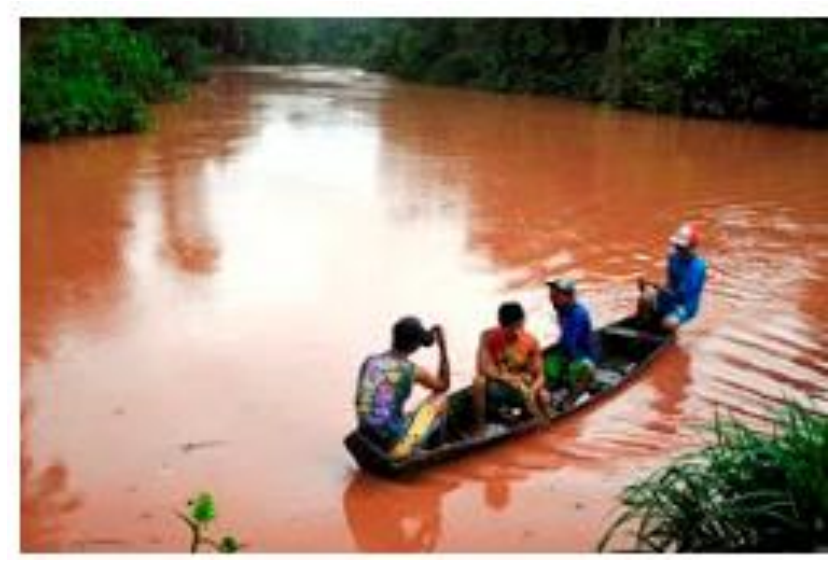

Figura 6: Rio Murucupi contaminado pela lama vermelha após acidente ocorrido em 2003 com um lago de disposição desse resíduo.

O acidente mais recente ocorreu na Hungria, em 2010, onde 1,1 milhão de metros cúbicos de lama vermelha invadiu três cidades e contaminou uma área de pelo menos 40 quilômetros quadrados, Fig. 7. Após três dias do vazamento a lama chegou ao rio Danúbio provocando a morte de peixes que habitavam suas águas, e países vizinhos pelos quais o rio atravessa como a Croácia, Sérvia, Romênia, Bulgária, Ucrânia e Moldova já traçam planos de emergência. Este vazamento causou a morte de quatro pessoas e mais de 150 ficaram feridas. A empresa responsável pelo reservatório onde a lama estava armazenada, Companhia Húngara de Produção e Comércio de Alumínio (MAL), informou que a quantidade de 
lama que vazou corresponde a $2 \%$ da quantidade total de lama contida nesse reservatório. Este acidente foi considerado a catástrofe ecológica mais grave da história da Hungria ${ }^{59,60,61,62 .}$

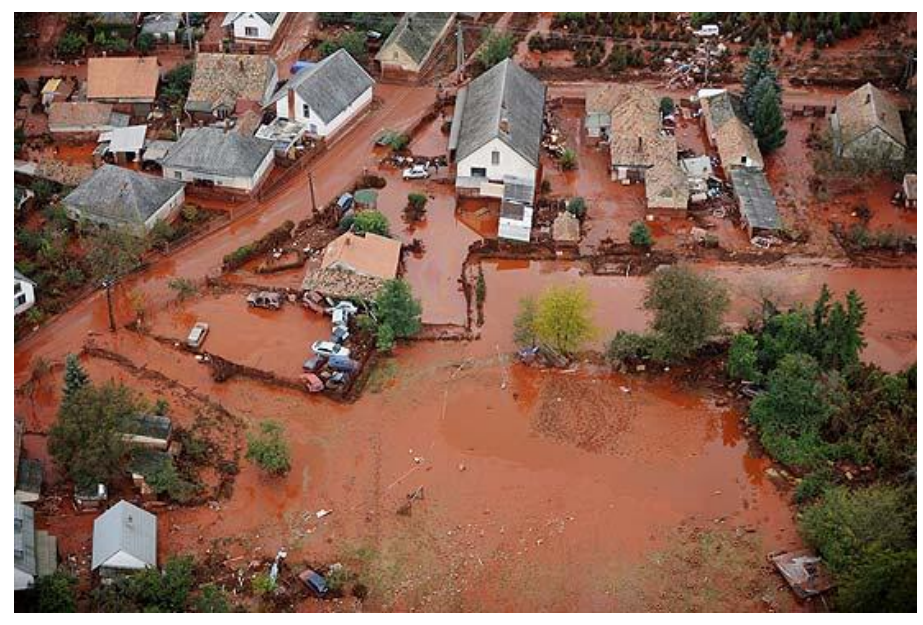

Figura 7: Um dos vilarejos afetados pelo vazamento da lama vermelha ocorrido na Hungria.

Conseqüentemente, a grande quantidade de resíduo gerado na produção da alumina, a previsão de aumento na demanda por alumina, os riscos ambientais associados a sua disposição e os custos relacionados ao seu manejo e disposição motivaram nos últimos anos a busca por alternativas para a aplicação desse resíduo, o que diminuiria o volume de lama na disposição final, os riscos dos possíveis danos ambientais e o custo da produção de alumina.

Portanto, considerando a grande quantidade de resíduo gerado na produção da alumina, a previsão de aumento na demanda por alumina, a lama vermelha representa um sério problema ambiental.

As áreas investigadas para aplicações da lama são variadas. Alguns exemplos são a área ambiental, indústria química, construção civil e indústria cerâmica. Em todos os casos, o intuito é produzir materiais comercializáveis com menor quantidade de matérias primas puras contribuindo, assim, para aproveitamento do resíduo de bauxita já existente, e diminuir o custo do produto final. 
Na área ambiental a lama vermelha foi investigada para fins de tratamento de águas e solos contaminados e os resultados obtidos foram satisfatórios ${ }^{44,63,64,65}$.

O pré tratamento do aço carbono utilizando a lama vermelha para inibir o processo de corrosão foi investigado e em algumas situações a aplicação desse resíduo é adequada para este fim $^{66}$.

O efeito da adição da lama vermelha nos parâmetros de corrosão do concreto também foi investigado e foi observado que essa adição beneficia o concreto por inibir o processo de corrosão do mesmo e aumentar sua resistividade elétrica ${ }^{67}$.

Na China, resíduos de bauxita gerados por processos de sinterização são pesquisados na produção de materiais de construção e a primeira fábrica de cimento em Shandong foi construída considerando a pré-existência de matéria prima para a produção de cimento. A aplicação da lama vermelha gerada pelo processo Bayer foi estudada na preparação de "tijolos queimados" e os materiais obtidos cumpriram os requisitos das normas de qualidade aplicadas aos tijolos comuns. "Tijolos não queimados" também foram preparados por meio da utilização de resíduos de bauxita e os resultados das análises realizadas nesses materiais mostraram que esses tijolos alcançam o primeiro grau do padrão chinês para tijolos $^{68}$.

Outra possível aplicação desse resíduo é a sua utilização como matéria prima para a produção de materiais poliméricos inorgânicos que podem ser utilizados como materiais estruturais, tais como, "tijolos maciços". Os resultados mostraram que, considerando propriedades como estabilidade térmica e resistência ao fogo, a lama é uma matéria prima promissora para esta aplicação ${ }^{69}$.

Ainda na área da construção civil, vem sendo desenvolvido no Brasil estudos sobre a utilização da lama na produção de blocos cerâmicos vazados industriais. Esses blocos foram desenvolvidos a partir do uso de 60\% em massa de lama e 40\% em massa de argila e, segundo os resultados de caracterização obtidos, os materiais produzidos atenderam aos parâmetros normativos quanto ao índice de adsorção de água e resistência à compressão ${ }^{70}$.

Os efeitos da lama vermelha nas propriedades de argilas naturais utilizadas como revestimentos em aterros de resíduos sólidos também foram estudados e os resultados mostram que os efeitos são benéficos para essa aplicação ${ }^{45}$. 
A utilização da lama vermelha como matéria-prima para a síntese de hidrotalcita, material que pode ser aplicado em processos de recuperação ambiental por ser capaz de adsorver metais pesados, representa, segundo os estudos realizados, uma maneira efetiva de uso desse resíduo ${ }^{71}$.

No entanto, apesar das pesquisas apontarem que a utilização de lama vermelha na indústria de cimento e tijolos é satisfatória, cuidados relacionados à elevada quantidade de íons alcalinos e a reologia desse resíduo, devido a presença de partículas muito finas, devem ser considerados ${ }^{72}$.

Também tem sido investigada a fabricação de vidros utilizando como matéria prima principal a lama vermelha. Trabalhos publicados anteriormente mostram que é possível fabricar vidros com a adição de até $85 \%$ em massa de lama vermelha na composição inicial $^{73}$. Além disso, os processos de cristalização desses vidros têm sido estudados, e sabe-se que é possível controlar a cristalização desses materiais para a obtenção de vitrocerâmicas com fases nano cristalinas, e este processo é beneficiado pela própria composição química da lama vermelha, pois o início da nucleação ocorre devido às impurezas presentes na lama que atuam como agentes nucleantes. As microestruturas das vitrocerâmicas nano cristalinas obtidas propiciam ao material boas propriedades mecânicas ${ }^{74}$.

A lama vermelha também tem sido utilizada como aditivo para a produção de vitrocerâmicas que possuem como matéria prima principal outro tipo de rejeito industrial, como exemplo, cinzas provenientes da combustão do carvão em usinas térmicas. Os materiais obtidos possuem propriedades adequadas para o uso industrial em materiais de construção, ladrilhos e revestimentos ${ }^{75}$. 


\section{PROCEDIMENTO EXPERIMENTAL}

\section{Materiais e Método}

\subsection{Caracterização da Lama Vermelha}

A lama vermelha utilizada neste trabalho foi fornecida pela Alcoa Alumínio S.A. e gerada na unidade de Poços de Caldas, Minas Gerais. Para a sua caracterização, a mesma foi homogeneizada em um moinho rotatório sem meios de moagem por 4 horas e seca a $110^{\circ} \mathrm{C}$ por 48 horas em estufa. Após a secagem, a lama foi moída manualmente em dispositivo de aço inoxidável que consiste de um cilindro, um êmbolo e uma base de maceração.

Na Fig. 8 é mostrada a lama vermelha utilizada nesse trabalho após a homogeneização e antes da secagem em estufa.

Após o processo de secagem e moagem, foi realizado o teste de perda ao fogo para determinar a fração dos componentes voláteis ${ }^{76}$. Para este teste, foi medida a massa da lama já condicionada em um cadinho de alumina de massa conhecida utilizando uma balança com precisão de 0,01 mg. Foi utilizado um forno elétrico aquecido a $900^{\circ} \mathrm{C}$ por 4 horas. Após a calcinação da lama, o conjunto 
cadinho-lama foi novamente medido e a massa perdida durante o aquecimento foi determinada.

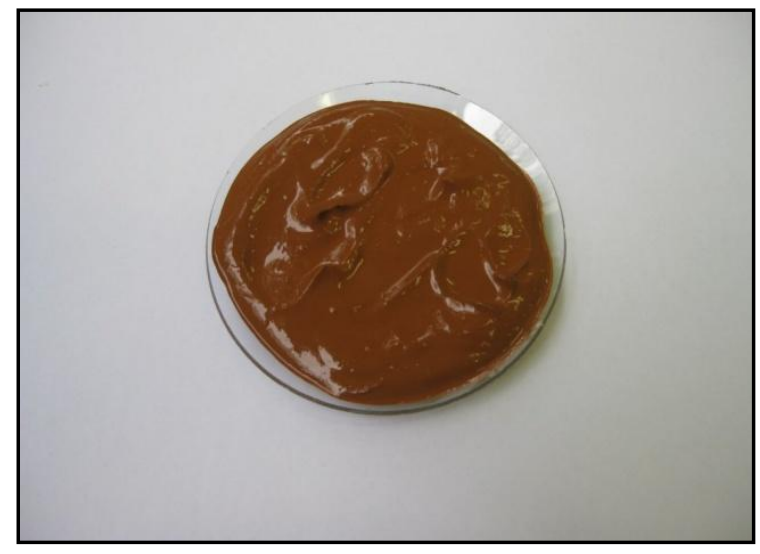

Figura 8: Lama vermelha após a homogeneização.

Os elementos que compõem a lama foram determinados por espectroscopia de fluorescência de raios $X$ por energia dispersiva (EDX) em um equipamento Shimadzu, modelo EDX-720. A análise foi realizada a vácuo com colimador de 5 $\mathrm{mm}$.

Para a verificação de fases cristalinas presentes na lama foram realizadas análises de difratometria de raios $X(D R X)$ em um intervalo de varredura de 10 a $80^{\circ}$, e passo de $2^{\circ} / \mathrm{min}$. Para essa análise foi utilizado o equipamento Rigaku, modelo Multiflex.

Todos os processos de caracterização mencionados acima foram também realizados em outras duas amostras de lama vermelha, com o intuito de comparar as características desses resíduos quando gerados em diferentes épocas e locais. Essas outras duas amostras foram geradas também em Minas Gerais e fornecidas novamente pela Alcoa Alumínio S.A. e pela Companhia Brasileira de Alumínio (CBA) três anos após o primeiro fornecimento. 


\subsection{Produção e Caracterização dos Materiais Estudados}

Foram produzidos cinco grupos de materiais.

Os materiais do primeiro grupo, denominado LS, foram produzidos a partir da mistura manual da lama vermelha e sílica na forma de quartzo. Esses materiais abrangem as composições produzidas durante a busca pela melhor proporção entre lama e sílica para a obtenção um material amorfo. A composição nominal dos materiais do primeiro grupo foi determinada a partir da seguinte denotação: (100$x) L \times S$ onde, $L$ representa a lama vermelha, $S$ representa a sílica e $x=10,20,30$ e $40 \%$ em massa.

O segundo grupo, denominado LSN, é formado pelo material do primeiro grupo (LS) que apresentou a melhor característica amorfa dentre os materiais produzidos neste grupo e contem, além da lama vermelha e sílica, sódio, adicionado na forma $\mathrm{Na}_{2} \mathrm{CO}_{3}$ com o intuito de diminuir a temperatura de fusão. Sabe-se que o $\mathrm{Na}$ contribui de forma significativa para a diminuição da temperatura de fusão de vidros silicatos, mas que simultaneamente pode diminuir a resistência desses vidros à corrosão, consequência que é indesejada neste trabalho. Portanto, buscou-se neste grupo de materiais uma composição na qual a implicação negativa dessa adição fosse contrabalanceada pela implicação positiva. A composição nominal dos materiais produzidos no segundo grupo obedeceu à seguinte denotação: (100$\mathrm{x})(60 \mathrm{~L} 40 \mathrm{~S}) \times \mathrm{XN}$ onde, $\mathrm{L}$ representa a lama vermelha, $\mathrm{S}$ representa a sílica, $\mathrm{N}$ representa sódio e $x=10,20,30$ e 40\% em massa.

O terceiro grupo, denominado LSB, é formado por materiais produzidos por meio da mistura de lama vermelha, sílica e boro, adicionado na forma $\mathrm{H}_{3} \mathrm{BO}_{3}$. O boro foi adicionado gradativamente à composição base reduzindo o teor de sílica, porém mantendo o teor de lama, com o intuito de baixar a temperatura de fusão pela diminuição da sílica e concomitantemente tentar atenuar a provável perda na durabilidade química do material, pois sabe-se que, assim como a sílica, a presença do boro pode promover aos materiais boa resistência à corrosão. A denotação 60L(40-x)S XB determina a composição nominal dos materiais produzidos nesse grupo onde, $L$ representa a lama vermelha, $S$ representa a sílica, B representa $O$ boro e $x=5,10,15$ e $20 \%$ em massa. 
O quarto grupo, denominado LSR, é constituído dos materiais do segundo e terceiro grupo que, de acordo com as propriedades apresentadas, são os mais indicados para a aplicação almejada, adicionados de óxidos comumente presentes na composição química de rejeitos nucleares. Os óxidos adicionados foram o óxido de bário, na forma $\mathrm{BaCO}_{3}$, óxido de estrôncio, na forma $\mathrm{SrCO}_{3}$, e óxido de zircônio, na forma $\mathrm{ZrO}_{2}$.

A composição nominal dos materiais do grupo quatro foi determinada de acordo com as denotações (100-x)(60L40S)xR e (100-x)(60L25S15B)xR onde, L representa a lama vermelha, $S$ representa a sílica, $B$ representa o boro e $R=5,10$, 15 e 20\% (\% em massa) representa a mistura dos três óxidos ( $\mathrm{BaO}$ ou SrO ou $\mathrm{ZrO}_{2}$ ) adicionados simultaneamente às composições base. Na adição simultânea, o teor de cada óxido respeitou a porcentagem estimada a partir de uma simulação da concentração de produtos de fissão que serão gerados em um alvo de UAlx após 7 dias de radiação no Reator Multipropósito Brasileiro (RMB). A simulação mostra que a representação em massa desses três elementos pode chegar a 25,4\%, sendo 7,8\% referente ao $\mathrm{BaO}, 5,7 \%$ referente ao $\mathrm{SrO}$ e 11,9\% ao $\mathrm{ZrO}_{2}$, de acordo com informações fornecidas pelo Centro de Combustível Nuclear do Instituto de Pesquisas Energéticas e Nucleares.

Nos quatro grupos os materiais de partida foram pesados, homogeneizados manualmente e aquecidos em forno elétrico em um cadinho de alumina até $900^{\circ} \mathrm{C}$ para a decomposição dos carbonatos adicionados, e então foram transferidos para um forno aquecido entre $1330^{\circ} \mathrm{C}$ e $1560^{\circ} \mathrm{C}$, temperaturas adequadas para verter esses materiais. As amostras produzidas permaneceram neste patamar por 1 hora para homogeneização do líquido.

O líquido foi vertido em água para a produção de fritas e em molde de alumínio a temperatura ambiente para a produção de amostras na forma de blocos. Os materiais vertidos em molde de alumínio foram tratados termicamente em temperaturas próximas a $T_{g}$ para aliviar tensões residuais.

Amostras dos materiais produzidos nesses quatro grupos foram caracterizadas por:

- Difratometria de raios X para avaliar as possíveis fases cristalinas presentes.

Essa análise foi feita sob as mesmas condições da análise realizada na lama 
vermelha, utilizando os equipamentos Rigaku, modelo Multiflex e Philips XPert;

- Análise térmica diferencial entre a temperatura ambiente e $1100^{\circ} \mathrm{C}$ utilizando taxas de aquecimento entre $10^{\circ} \mathrm{C}$ e $40^{\circ} \mathrm{C} / \mathrm{min}$, atmosfera de nitrogênio, cadinho de alumina e amostras com granulometria entre 425 e $38 \mu \mathrm{m}$ para a determinação das temperaturas de transição vítrea, cristalização e fusão das fases cristalinas. As análises foram feitas em um equipamento NetzschSimultaneous TGA/DTA;

- Termodilatometria entre a temperatura ambiente e $1100^{\circ} \mathrm{C}$, em ar e com taxa de aquecimento de $10^{\circ} \mathrm{C} /$ min para determinar a faixa de transição vítrea dos materiais estudados;

- Espectroscopia de fluorescência de raios X por energia dispersiva (EDX) utilizando um equipamento Shimadzu, modelo EDX-720 e um espectrômetro acoplado ao microscópio eletrônico de varredura HeliosNanoLab 600, para a determinação dos elementos constituintes dos materiais produzidos. Em ambos os equipamentos, as análises foram realizadas a vácuo, utilizando o método quali-quantitativo e, quando realizadas no equipamento Shimadzu, foi utilizado colimador entre 3 e 10mm;

- Testes estáticos de lixiviação (MCC-2) em água destilada a $90^{\circ} \mathrm{C}$ por períodos de até 21 dias utilizando recipientes de teflon para determinar a razão de dissolução e a fração de lixiviação desses materiais em meio líquido ${ }^{77}$. Para a determinação da razão de dissolução foram produzidas amostras na forma de pastilhas com dimensão de $1 \times 1 \times 0,1 \mathrm{~cm}^{3}$, lixadas com lixas de grano 100, 180 e 240 mesh. A razão de dissolução foi determinada através da seguinte fórmula:

$$
R D=\frac{\Delta m}{A . t}
$$

onde RD é a razão de dissolução expressa em $\mathrm{g} / \mathrm{cm}^{2}$.dia, $\Delta \mathrm{m}$ é a variação de massa da amostra durante o teste nos dias $0,1,3,7$ e 14, A é a área da amostra e t é o tempo de duração do teste.

Para determinar a fração de lixiviação foram preparadas também amostras na forma de materiais particulados com granulometria entre 150 e 
$75 \mu \mathrm{m}$. Os líquidos utilizados nesse teste de lixiviação foram analisados por espectrometria de emissão baseada em fontes de plasma (ICP) para a determinação da fração de lixiviação de cada elemento que constitui cada material.

A fração de lixiviação foi determinada pela seguinte fórmula:

$$
\text { FraçãodeLixiviação }=\frac{C_{i} \cdot V}{f_{i} \cdot m}
$$

onde $C_{i}$ é a concentração em $\mathrm{mg} / \mathrm{L}$ ou $\mu \mathrm{g} / \mathrm{mL}$ de cada elemento encontrado no líquido utilizado no teste de lixiviação por meio da análise de ICP, $V$ é o volume do líquido utilizado no teste de lixiviação, $m$ é a massa do material utilizado no teste de lixiviação e $f_{i}$ é a porcentagem de cada elemento na composição do material.

Após o término desse teste, os materiais particulados foram secos em estufa à $100^{\circ} \mathrm{C}$ e analisados por difratometria de raios $\mathrm{X}$ para verificar se após o contato com a água houve alguma alteração no espectro obtido quando comparado ao espectro dessas amostras antes do contato com a água;

- microscopia eletrônica de varredura na superfície externa e interna (após um corte transversal) de cada material. Para esta análise os materiais foram polidos com lixas de grano 600, 800, 1200 e 2400 mesh e pasta de diamante com granulometria de 6, 3 e $1 \mu \mathrm{m}$. Após cada etapa do polimento os materiais foram limpos em ultrassom com acetona e em seguida foram atacados em HF, 6\% em volume, por 15 segundos para permitir a visualização das estruturas contidas nessas superfícies. Após o ataque em ácido, as amostras foram novamente limpas em ultrassom com acetona e secas em estufa a $90^{\circ} \mathrm{C}$ por 1 hora. Também foram analisadas as superfícies de amostras polidas pelo mesmo processo de polimento mencionado anteriormente e que foram imersas em água destilada a $90^{\circ} \mathrm{C}$ por 14 dias, simulando um teste de lixiviação, para avaliar possíveis mudanças estruturais na superfície desses materiais após a imersão em água. É importante ressaltar que a razão de dissolução das amostras polidas não foi 
determinada visto que as superfícies dessas amostras não estão de acordo com a norma do teste de lixiviação.

Foram também produzidos e analisados, em paralelo, materiais com a adição particular de cada um dos óxidos estudados nesse trabalho $\left(\mathrm{BaO}, \mathrm{SrO}, \mathrm{ZrO}_{2}\right)$ para investigar o efeito de cada adição nas suas propriedades térmicas e estruturais. Este estudo foi realizado apenas para o material 60L40S e as amostras obtidas a partir dessa investigação formam o quinto grupo de materiais, grupo denominado LSO.

A composição nominal dos materiais do quinto grupo foi determinada de acordo com a seguinte denotação: (100-x)(60L40S) xO onde, L representa a lama vermelha, S representa a sílica e $x=5,10,15$ e $20 \%$ em massa representa um dos três óxidos ( $\mathrm{BaO}$ ou $\mathrm{SrO}$ ou $\mathrm{ZrO}_{2}$ ) adicionados individualmente à composições base. 


\section{RESULTADOS E DISCUSSÃO}

\subsection{Lama Vermelha}

Por meio da análise de EDX observa-se que, de acordo com os resultados obtidos e apresentados na Tab. 2, a lama vermelha utilizada neste trabalho, lama LV1, é constituída principalmente por $\mathrm{SiO}_{2}, \mathrm{Al}_{2} \mathrm{O}_{3}, \mathrm{Fe}_{2} \mathrm{O}_{3}$ e $\mathrm{Na}_{2} \mathrm{O}$. A presença de $\mathrm{SiO}_{2}$ e $\mathrm{Al}_{2} \mathrm{O}_{3}$ é vantajosa para a obtenção de vidros, pois permite o uso da lama vermelha em substituição a minerais normalmente obtidos por processos extrativistas. A presença do $\mathrm{Na}_{2} \mathrm{O}$ é admissível, pois pode atuar como fundente.

A presença de $\mathrm{Fe}_{2} \mathrm{O}_{3}$ também não é um problema, pois este composto vem sendo utilizado na preparação de vidros ferrofosfatos potencialmente indicados para a imobilização de rejeitos nucleares.

No entanto, $\mathrm{o} \mathrm{TiO}_{2}$ encontrado na composição da lama pode atuar como agente nucleante e dificultar a formação de uma estrutura amorfa.

Comparando as três lamas, observamos que a composição química da LV1 e da LV2, lamas fornecidas pela Alcoa Alumínio S.A., porém geradas em diferentes épocas (intervalo de 3 anos), é bem próxima, indicando que em um intervalo de 3 
anos não houve alteração significativa na composição do resíduo gerado. Este resultado é benéfico, pois sugere que a variação da composição química dessa lama em particular não é uma barreira para a aplicação desse resíduo.

Porém, na composição química da LV3, lama fornecida pela CBA, observamos variações consideráveis quando comparada a composição química da LV1 e LV2, principalmente em relação ao teor de $\mathrm{SiO}_{2}, \mathrm{Na}_{2} \mathrm{O}, \mathrm{Fe}_{2} \mathrm{O}_{3}, \mathrm{CaO}$ e $\mathrm{K}_{2} \mathrm{O}$. Essas variações não chegam a ser uma barreira que impeça a aplicação dessa lama no objetivo proposto nesse trabalho, porém ajustes na composição devem ser realizados.

Tabela 2: Determinação dos elementos que compõem a lama vermelha.

\begin{tabular}{c|ccc}
\hline \multicolumn{4}{c}{ \% em Mol } \\
\hline & LV1 & LV2 & LV3 \\
\hline $\mathrm{SiO}_{2}$ & $30,5 \pm 0,9$ & $28,5 \pm 0,7$ & $23,7 \pm 0,9$ \\
$\mathrm{Al}_{2} \mathrm{O}_{3}$ & $26,0 \pm 0,8$ & $24,7 \pm 0,8$ & $25,3 \pm 1,2$ \\
$\mathrm{Na}_{2} \mathbf{O}$ & $16,0 \pm 2,5$ & $16,3 \pm 1,9$ & $10,0 \pm 1,5$ \\
$\mathrm{Fe}_{2} \mathbf{O}_{3}$ & $15,5 \pm 2,8$ & $16,9 \pm 2,6$ & $25,2 \pm 2,0$ \\
$\mathbf{C a O}$ & $4,3 \pm 0,3$ & $4,1 \pm 0,6$ & $8,0 \pm 0,9$ \\
$\mathrm{TiO}_{2}$ & $3,5 \pm 0,1$ & $4,2 \pm 0,2$ & $5,3 \pm 0,3$ \\
$\mathbf{K}_{2} \mathbf{O}$ & $1,7 \pm 0,1$ & $2,0 \pm 0,1$ & $0,8 \pm 0,1$ \\
$\mathbf{B a O}$ & $0,7 \pm 0,0$ & $1,0 \pm 0,1$ & - \\
${ }^{*}$ Outros & $1,8 \pm 0,1$ & $2,3 \pm 0,1$ & $1,7 \pm 0,1$ \\
\hline
\end{tabular}

*Outros: $\mathrm{ZrO}_{2}, \mathrm{P}_{2} \mathrm{O}_{5}, \mathrm{Nb}_{2} \mathrm{O}_{5}, \mathrm{MnO}, \mathrm{SO}_{3}, \mathrm{CeO}_{2}, \mathrm{Er}_{2} \mathrm{O}_{3}, \mathrm{SrO}, \mathrm{Ga}_{2} \mathrm{O}_{3}, \mathrm{ZnO}$, e $\mathrm{Y}_{2} \mathrm{O}_{3}$.

No resultado de difratograma de raios $X$ da lama vermelha LV1, apresentado na Fig. 9, é possível observar que a lama possui estrutura cristalina. Porém, a identificação das fases que compõem essa estrutura cristalina é dificultada devido a grande quantidade de elementos presentes na composição da lama e indicados na Tab. 2. No entanto, algumas fases puderam ser identificadas. São elas: $\mathrm{Na}_{2} \mathrm{O}-\mathrm{Al}_{2} \mathrm{O}_{3}$ $\mathrm{TiO}_{2}-\mathrm{SiO}_{2}, \mathrm{Fe}_{2} \mathrm{O}_{3}, \mathrm{NaAlSiO} 4, \mathrm{SiO}_{2}$, e Na $\mathrm{Ti}_{5} \mathrm{O}_{12}$. 


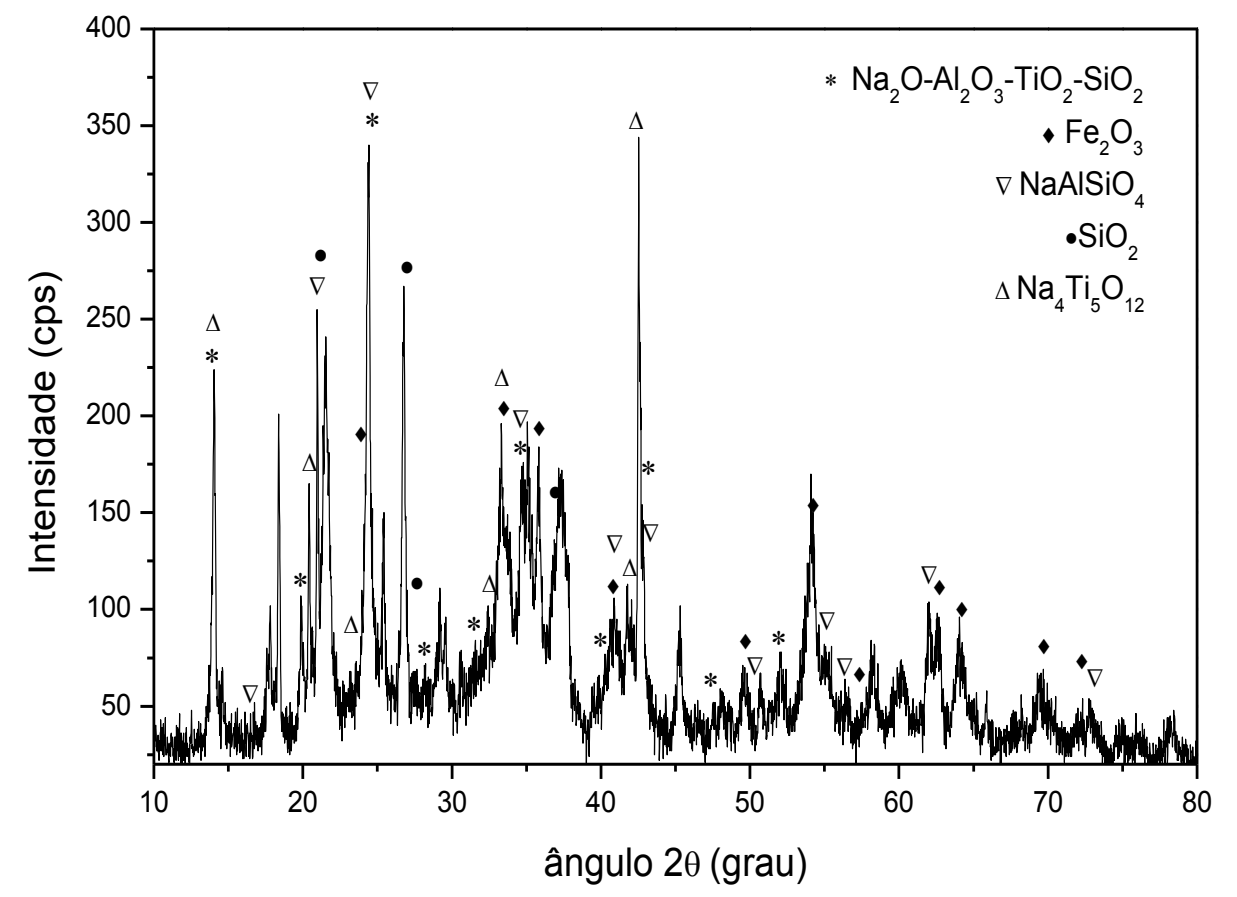

Figura 9: Difratograma de raios $X$ da lama vermelha LV1.

Na Fig. 10, são apresentados os difratogramas das lamas LV1, LV2 e LV3. Observamos que os espectros possuem alguma semelhança entre si e que os principais picos que puderam ser identificados na lama LV1 estão presentes nas lamas LV2 e LV3, mesmo que em menor intensidade.

No teste de perda ao fogo observa-se uma redução entre 1,2 e 2,7\% na massa das três lamas estudadas. Esta diferença pode ser proveniente da umidade adsorvida pelas mesmas e que foi volatizada durante a calcinação. Não houve mudança visual da coloração e morfologia das amostras após o teste. 


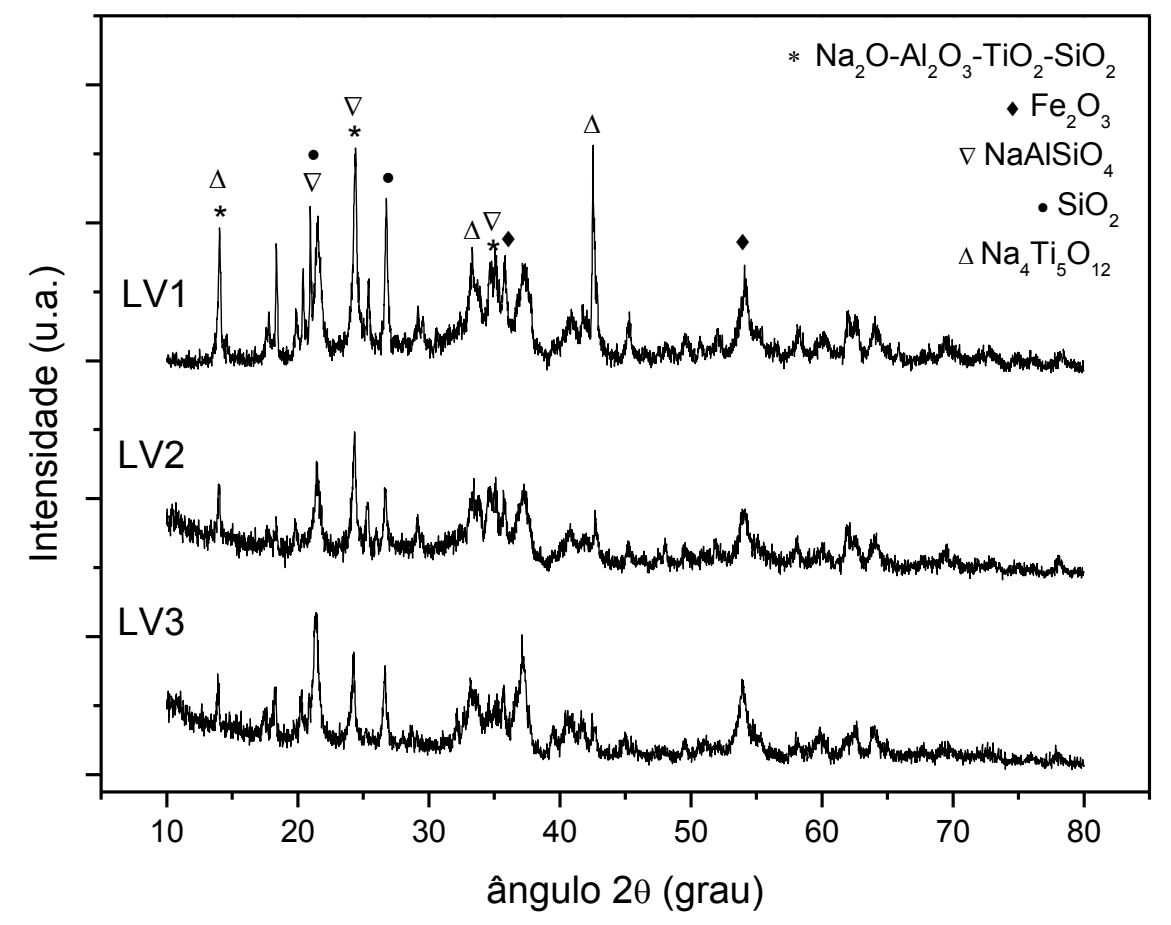

Figura 10: Difratogramas de raios $X$ das lamas LV1, LV2 e LV3.

\subsection{Materiais Produzidos}

Os materiais do grupo LS, grupo no qual a sílica foi incorporada a lama vermelha buscando a produção de materiais amorfos, foram analisados por difração de raios $X$ e os difratogramas obtidos são apresentados na Fig. 11. Observa-se que a partir do material 80L20S há uma evidente redução das fases cristalinas. No entanto, no material 60L40S, ainda há a presença de picos referentes à fase cristalina $\mathrm{Fe}_{3} \mathrm{O}_{4}$.

Nota-se que a intensidade dos picos referentes à fase cristalina $\mathrm{NaAlSiO}_{4}$, identificados na amostra 90L10S e na lama vermelha LV1, Fig. 9, diminui com o aumento do teor de sílica. Para o material 60L40S esses picos não são mais observados indicando a ausência desta fase. Observa-se também a existência de um halo na faixa entre 20 a $30^{\circ}$, o qual está relacionado à presença de fases amorfas. 


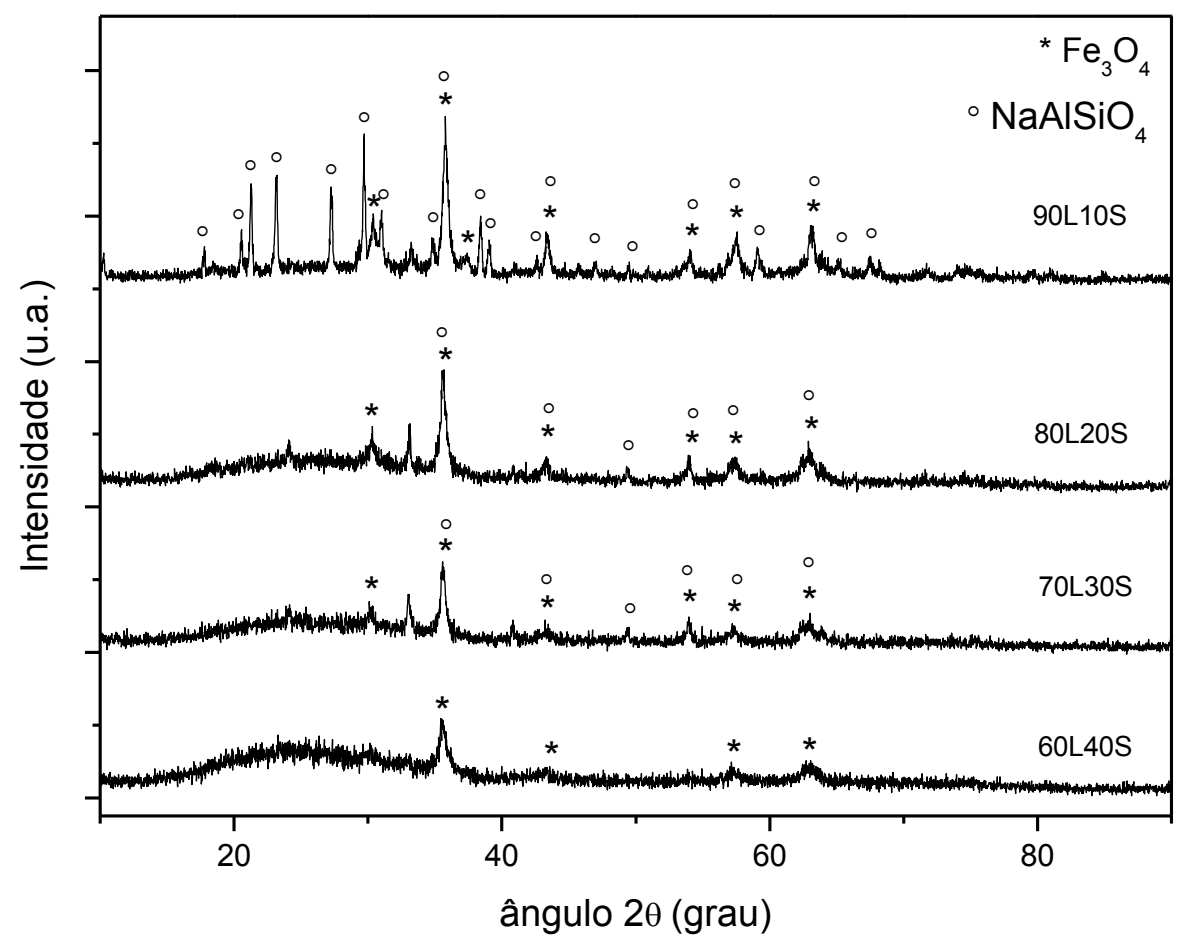

Figura 11: Difratogramas de raios $X$ dos materiais do grupo LS.

Tendo em vista a aplicação proposta neste trabalho e a diversidade de elementos presentes no rejeito nuclear, é interessante obter um material amorfo, para que seja possível acomodar um volume maior de rejeito, devido a sua estrutura, quando comparado a um material cristalino. Desta forma, considerando os difratogramas apresentados, o material 60L40S foi selecionado para a continuidade do trabalho.

$\mathrm{Na}$ Tab. 3 são apresentados os elementos que compõem os materiais do grupo LS, determinados por EDX, e as temperaturas nas quais foi possível fundir esse grupo de materiais.

O teor em mol de sílica presente no material 60L40S é cerca de $15 \%$ maior em relação ao material 80L20S. Este resultado ressalta a escolha do material 6OL40S como o mais adequado, pois o maior teor de sílica pode fornecer melhor durabilidade química ao material. Além disso, a redução no teor de alumina foi de apenas $6 \%$ e este elemento, assim como a sílica, pode reduzir a dissolução do material em água.

No entanto, observa-se que a incorporação de sílica à lama aumenta em $40^{\circ} \mathrm{C}$ a temperatura de fusão do material 6OL40S quando comparada aos valores 
referentes aos materiais 90L10S e 80L20S e, por esse motivo, não foram produzidos materiais com teor de sílica maior que $59.2 \% \mathrm{em}$ mol, pois a alta temperatura de fusão e viscosidade do material inviabilizaria o processo de produção comercial.

Tabela 3: Elementos constituintes dos materiais do grupo LS e temperatura de fusão para a preparação dos mesmos.

\begin{tabular}{c|cccc}
\hline & \multicolumn{4}{c}{ \% em mol } \\
\hline & $\mathbf{9 0 L 1 0 S}$ & $\mathbf{8 0 L 2 0 S}$ & $\mathbf{7 0 L 3 0 S}$ & $\mathbf{6 0 L 4 0 S}$ \\
\hline $\mathrm{SiO2}$ & 36,4 & 44,2 & 52,9 & 59,2 \\
$\mathrm{Al}_{2} \mathrm{O}_{3}$ & 23,5 & 21,1 & 18,7 & 17,3 \\
$\mathrm{Fe}_{2} \mathrm{O}_{3}$ & 15,2 & 13,8 & 11,1 & 9,3 \\
$\mathrm{Na}_{2} \mathrm{O}$ & 12,8 & 10,4 & 8,7 & 6,8 \\
$\mathrm{TiO}_{2}$ & 4,5 & 4,0 & 3,4 & 2,8 \\
$\mathrm{CaO}$ & 3,9 & 3,5 & 2,8 & 2,5 \\
$\mathrm{~K}_{2} \mathrm{O}$ & 1,5 & 1,3 & 1,1 & 0,9 \\
${ }^{*}$ Outros & 2,2 & 1,7 & 1,3 & 1,2 \\
\hline $\mathbf{T}_{\mathbf{f}}\left({ }^{\circ} \mathbf{C}\right)$ & 1.520 & 1.520 & 1.540 & 1.560 \\
\hline
\end{tabular}

*Outros: $\mathrm{ZrO}_{2}, \mathrm{P}_{2} \mathrm{O}_{5}, \mathrm{Nb}_{2} \mathrm{O}_{5}, \mathrm{MnO}, \mathrm{CeO}_{2}, \mathrm{SrO}, \mathrm{Ga}_{2} \mathrm{O}_{3}, \mathrm{ZnO}, \mathrm{Y}_{2} \mathrm{O}_{3}, \mathrm{WO}_{3}$ e $\mathrm{V}_{2} \mathrm{O}_{5}$.

Dando continuidade ao estudo do material 60L40S, foram realizados ajustes na composição desse material com o intuito de diminuir a sua temperatura de fusão sem reduzir o teor de lama utilizada. Para isso foram produzidos dois grupos de materiais denominados LSN e LSB. Ao grupo LSN foi adicionado sódio à composição base, mantendo-se a proporção entre lama vermelha e sílica enquanto que, ao grupo LSB foi adicionado boro à composição base reduzindo-se o teor de sílica.

Nas Fig. 12 (a) e (b) são apresentados os difratogramas de raios $X$ dos materiais produzidos nos grupos LSN e LSB. 


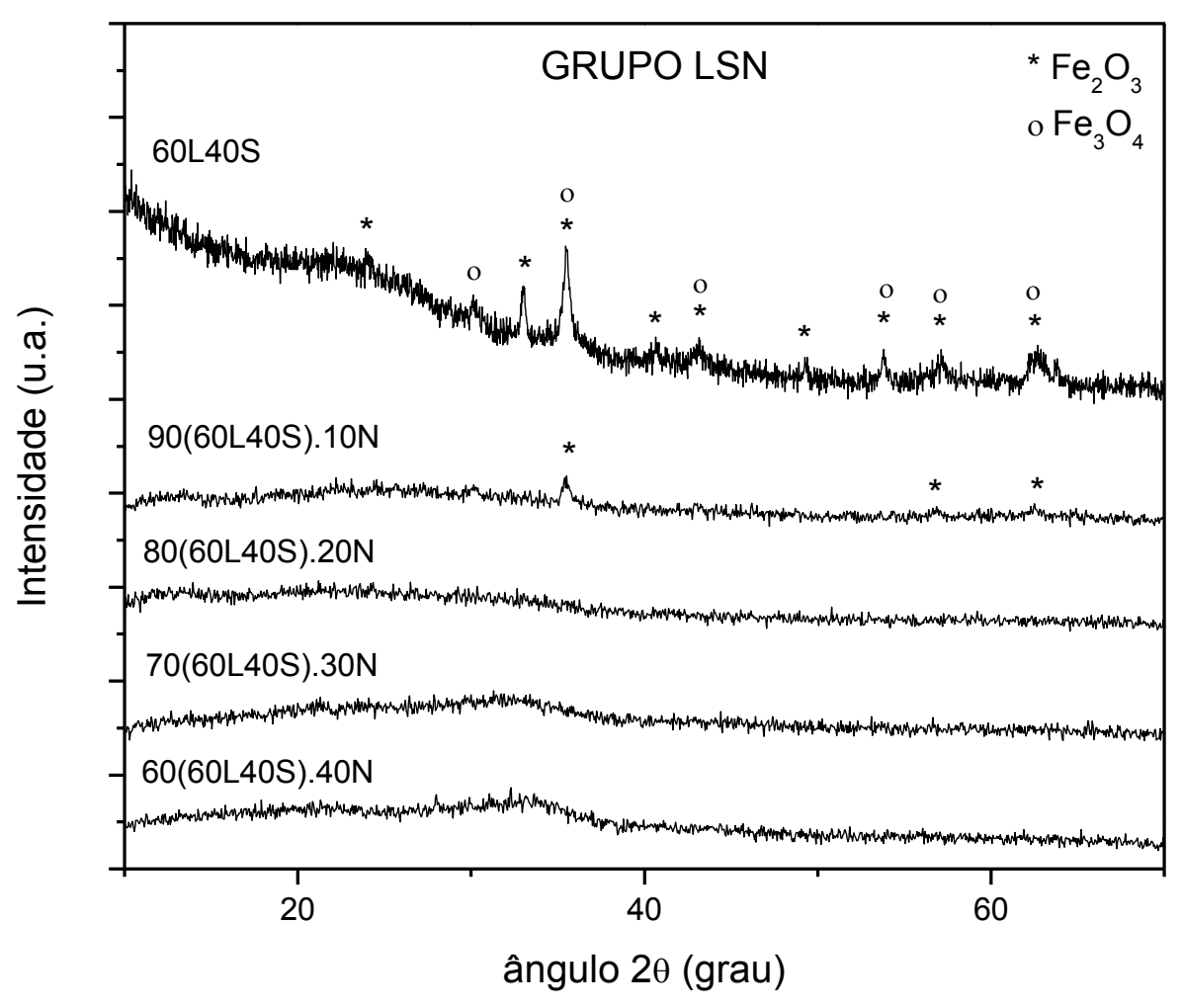

(a)

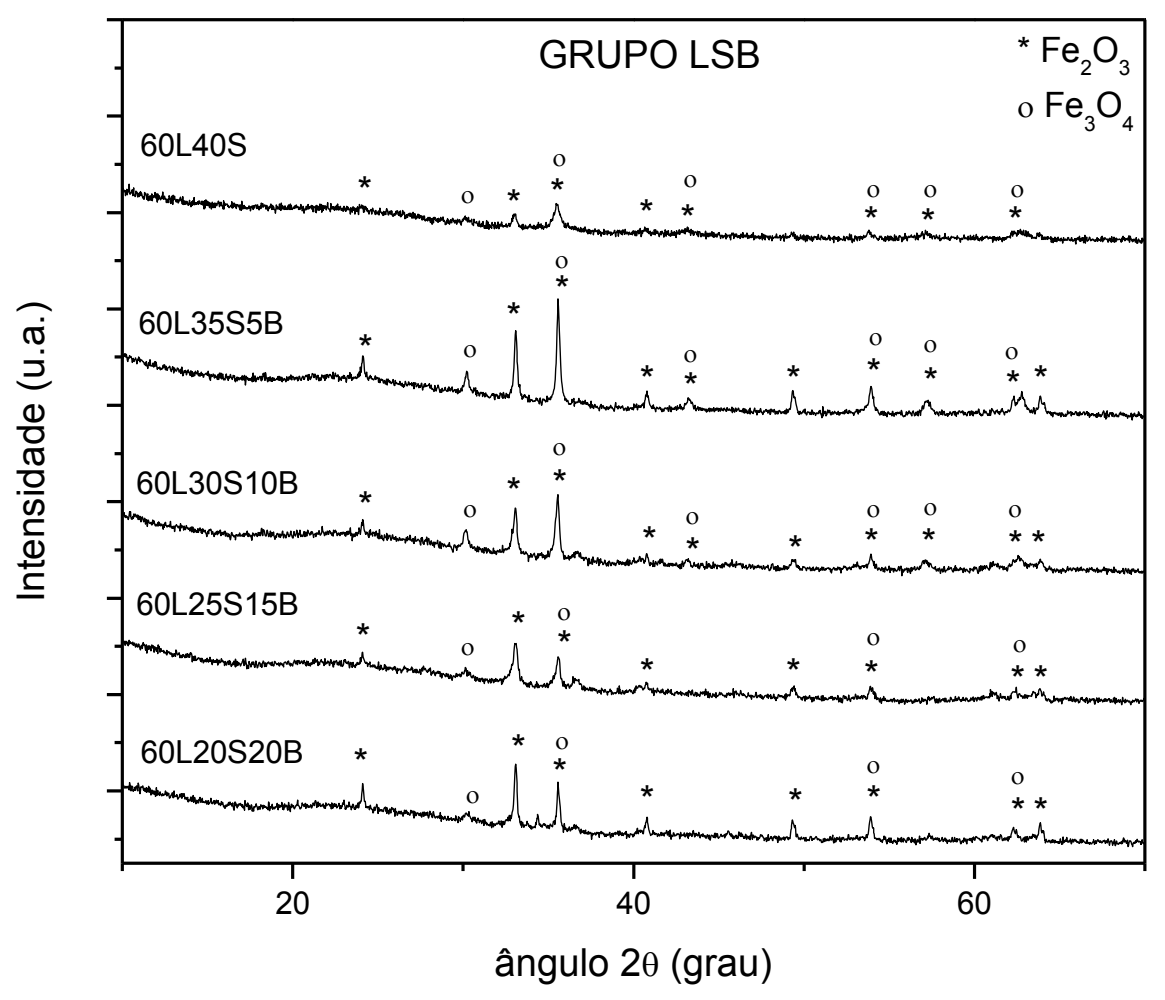

(b)

Figura 12: Difratogramas de raios $X$ dos materiais pertencentes aos grupos LSN (a) e LSB (b). 
Observa-se na Fig. 12 (a), uma notável diminuição dos picos referentes à presença de fases cristalinas a partir da amostra 90(60L40S).10N. Na amostra 80(60L40S).20N os picos não são mais observados. Isto indica que o $\mathrm{Na}$, que atua como um elemento modificador na produção de um vidro, também auxilia, neste caso, para a formação de um material amorfo facilitando a dissolução das fases cristalinas presentes na composição base.

Por outro lado, a adição de boro ao grupo LSB, Fig. 12 (b), favorece a cristalização dos materiais. Ainda que seja possível a visualização de halos, entre 20 e $30^{\circ}$, que indicam a presença de um percentual de fase amorfa nesses materiais, observa-se picos proeminentes a partir do difratograma correspondente ao material 60L35S5B em relação ao difratograma do material 60L40S.

Sendo assim, a adição do B prejudicou a formação de um material amorfo, intensificando os picos referentes a fases cristalinas presentes na composição base.

A dissolução dos materiais pertencentes aos grupos LSN e LSB em água destilada a $90^{\circ} \mathrm{C}$ foi estudada. Para isso, testes de lixiviação foram realizados durante o período de 14 dias em amostras preparadas na forma de pastilhas. Os resultados obtidos são apresentados nas Fig. 13 (a) e (b).

A dissolução do material 60(60L40S)·40N em água é significantemente maior quando comparada a dissolução dos demais materiais, e observou-se que o material foi completamente dissolvido após o terceiro dia de teste. Portanto, a curva de dissolução desse material não será apresentada.

As temperaturas indicadas na legenda da Fig. 13 (a) e (b) são as temperaturas necessárias para fundir cada um desses materiais. Nota-se que, a partir do material 80(60L40S) $20 \mathrm{~N}$, é possível reduzir consideravelmente a temperatura de fusão desses materiais, favorecendo, assim, o procedimento para a obtenção dos mesmos e justificando a incorporação de sódio à composição base 60L40S. Porém, salvo o material 90(60L40S) $10 \mathrm{~N}$, a adição de sódio aumenta significantemente a dissolução desses materiais em água, e este aumento não favorece a indicação dos mesmos para a aplicação indicada nesse trabalho. 


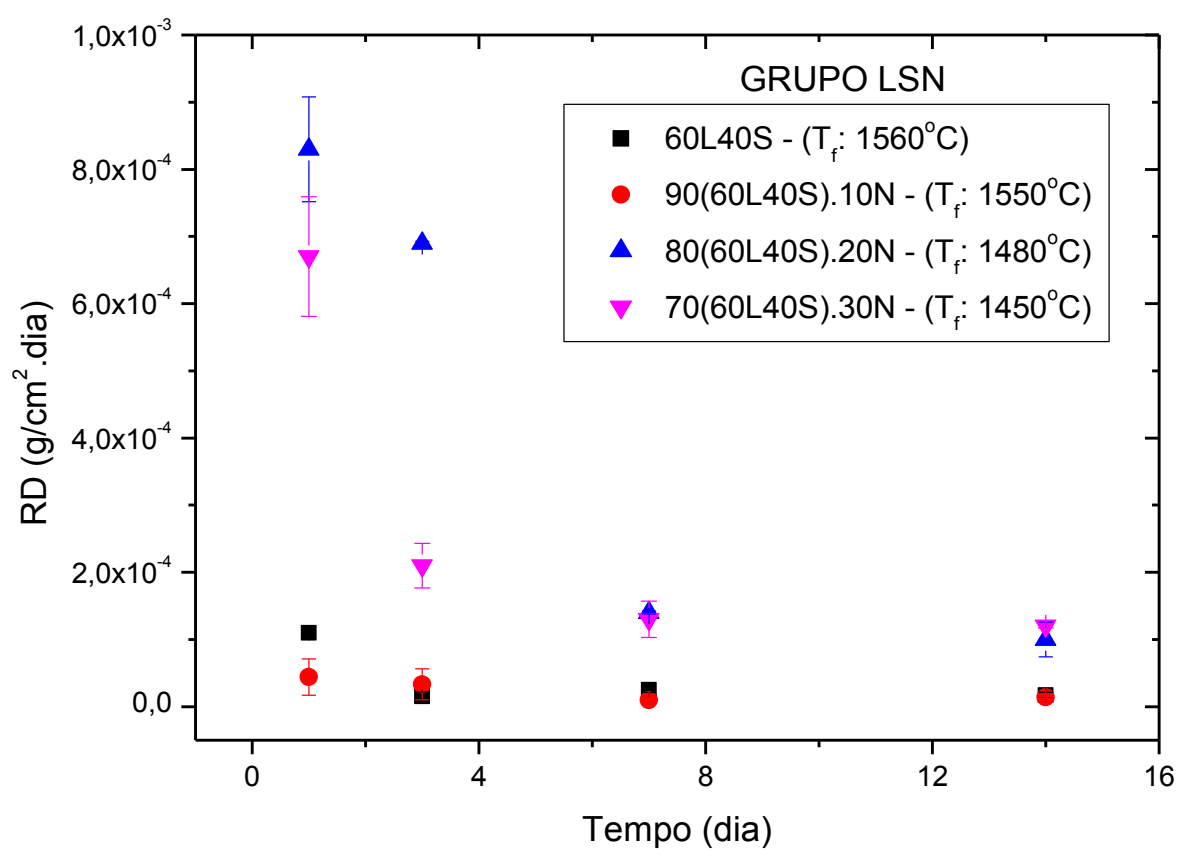

(a)

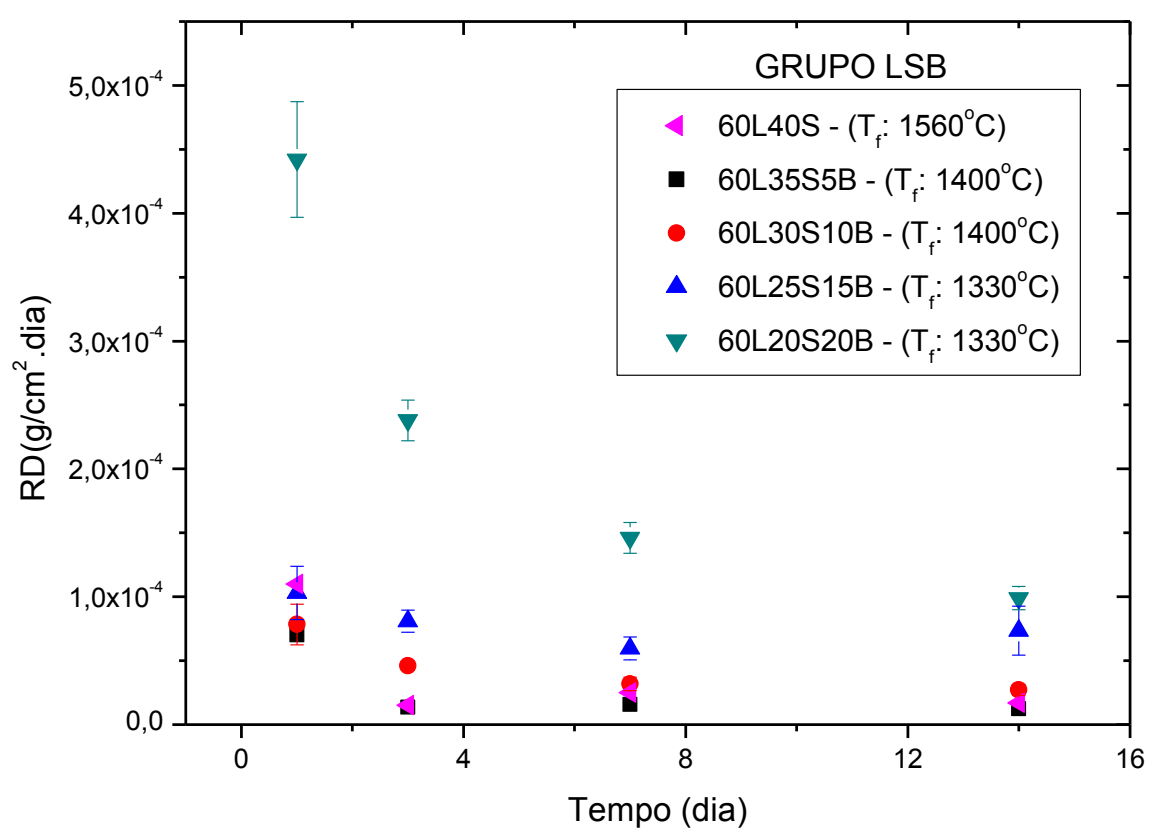

(b)

Figura 13: Razão de dissolução dos materiais dos grupos LSN (a) e LSB (b) em água destilada a $90^{\circ} \mathrm{C}$ por 14 dias.

Desta forma, apesar da incorporação de sódio atender a condição de reduzir a temperatura de fusão e contribuir para a formação de um material amorfo, a 
continuação do estudo dos materiais 80(60L40S) $20 \mathrm{~N}$ e $70(60 \mathrm{~L} 40 \mathrm{~S}) \cdot 30 \mathrm{~N}$ foi descartada por conta do aumento das suas taxas de dissolução em água.

A taxa de dissolução do material 90(60L40S)·10N é comparável a taxa da composição base 60L40S; no primeiro dia de teste é até mesmo inferior. No entanto, a temperatura necessária para a fusão desse material é apenas $10^{\circ} \mathrm{C}$ inferior a temperatura de fusão do material 60L40S. A pequena redução na temperatura de fusão não justifica a incorporação de 10\% em massa de sódio ao material 60L40S e a continuação do estudo do material 90(60L40S)·10N.

Portanto, dentre os materiais do grupo LSN, será continuado apenas o estudo do material $60 \mathrm{~L} 40 \mathrm{~S}$.

Na Fig. 13 (b) observa-se, com exceção do material 60L20S20B, taxas de dissolução comparáveis entre si e a redução significativa da temperatura de fusão, principalmente entre os materiais 60L40S, 60L35S5B e 60L30S10B. Porém, foi decidido continuar o estudo apenas do material 60L25S15B porque, embora apresente a maior taxa de dissolução quando comparado aos materiais 60L35S5B e 60L30S10B, apresenta, em compensação, a menor temperatura de fusão e, considerando o difratograma apresentado na Fig. 12 (b), possui um número menor de picos relacionados a fases cristalinas, com menor intensidade, além de um halo que indica a presença de uma fase amorfa.

Sendo assim, dentre os materiais do grupo LSB, apenas o estudo do material 60L25S15B será continuado.

Análises térmicas diferenciais foram realizadas em amostras dos materiais 60L40S e 60L25S15B e os resultados são apresentados na Fig. 14.

Observa-se que, nas condições desta análise, não há a presença de reações exotérmicas que possam ser identificadas como cristalização da fase amorfa presente nesses materiais e reações endotérmicas que indiquem a fusão das fases cristalinas existentes. Porém, para o material 60L40S há uma pequena variação na curva em torno de $803^{\circ} \mathrm{C}$, a qual foi considerada como a possível $\mathrm{T}_{\mathrm{g}}$ do material.

Para verificar essa hipótese foi realizada a análise de dilatometria para tentar identificar por outra técnica a $\mathrm{T}_{\mathrm{g}}$ da amostra 60L40S. O resultado obtido é apresentado na Fig. 15. 


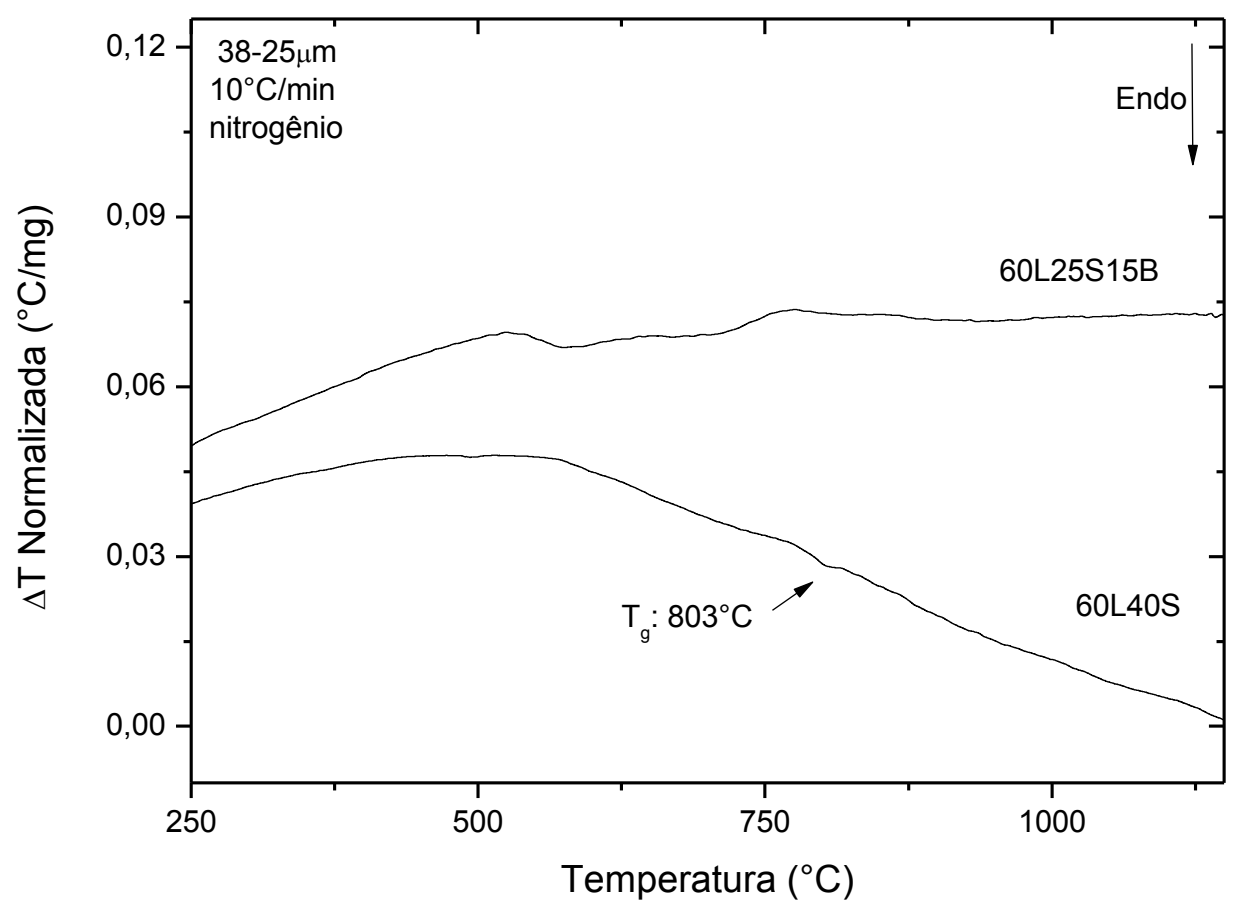

Figura 14: analise térmica diferencial dos materiais 60L40S e 60L25S15B, com granulometria entre $38-25 \mu \mathrm{m}$, realizada a $10^{\circ} \mathrm{C} / \mathrm{min}$ em atmosfera de nitrogênio.

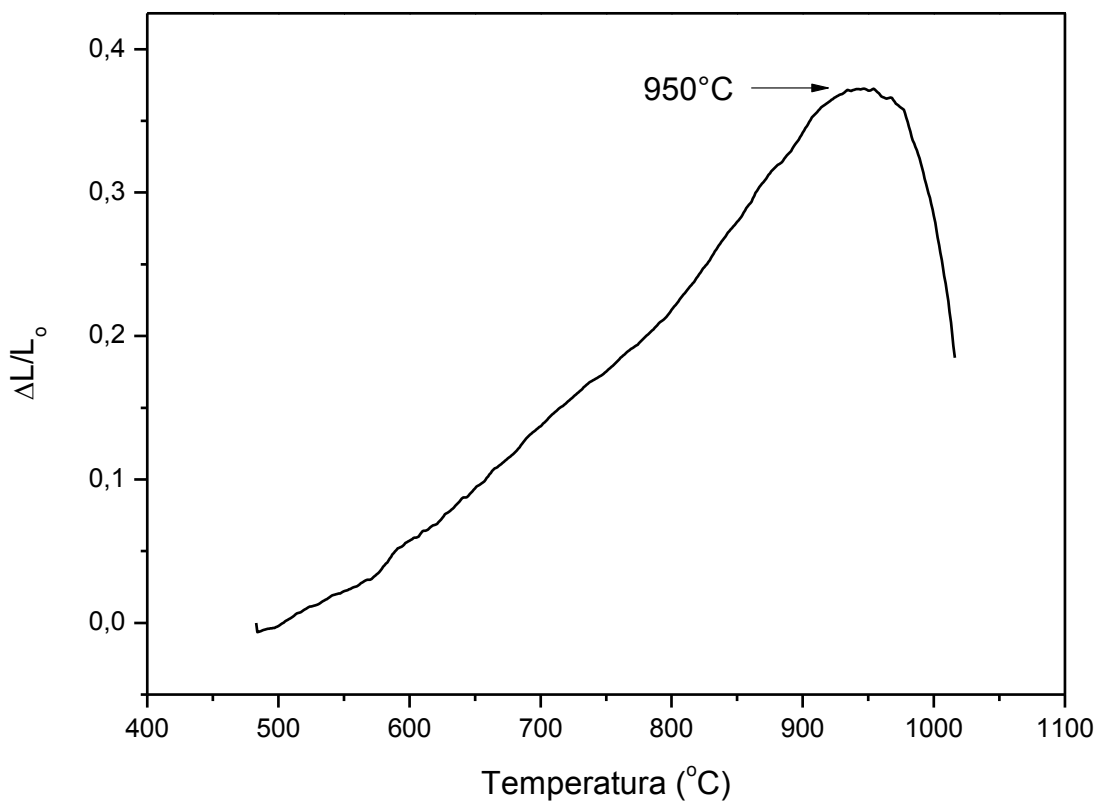

Figura 15: Dilatometria do material 60L40S. 
Observa-se na Fig. 15 que, com esta análise não foi possível identificar a faixa de temperatura de transição vítrea da amostra 60L40S, visto que não há uma variação significativa na inclinação da curva obtida. Porém, é possível observar em torno de $950^{\circ} \mathrm{C}$ o ponto de amolecimento da amostra.

Considerando o resultado de DRX apresentado na Fig. 11, a única fase cristalina presente nesse material é a magnetita, cuja temperatura de fusão é aproximadamente $1600^{\circ} \mathrm{C}$. Logo, o amolecimento observado em $950^{\circ} \mathrm{C}$ deve ser referente ao ponto de amolecimento dilatométrico da fase amorfa, visto que, a temperatura de fusão da fase cristalina existente é consideravelmente mais alta.

Na Fig. 16 (a) é apresentada a micrografia da superfície externa do material 60L40S obtida por microscopia eletrônica de varredura. Observa-se a presença de formações esféricas na superfície do material 60L40S que foram atribuídas à separação de fase nesse material, principalmente por conta da sua morfologia. 0 diâmetro da fase esférica é de aproximadamente $220 \mathrm{~nm}$ e os elementos que constituem essa fase e a matriz foram determinados por EDS e são apresentados nas Fig. 16 (b) e (c), respectivamente. De acordo com os espectros, observamos que as duas regiões são formadas basicamente pelos mesmos elementos e o pico referente ao $\mathrm{Na}$ é o único que apresenta uma ligeira diferença de intensidade, sendo mais intenso na região da matriz.

A superfície externa do material 60L25S15B também foi observada por microscopia eletrônica de varredura e, de acordo com a imagem obtida e apresentada na Fig. 17 (a), observamos a presença de diversas estruturas na superfície do material. As regiões marcadas com os números 4, 7 e 8 podem representar os cristais identificados no difratograma desse material, Fig. 12 (b). Essa possibilidade se deve ao fato dessas estruturas apresentarem formas geométricas comuns em cristais. 


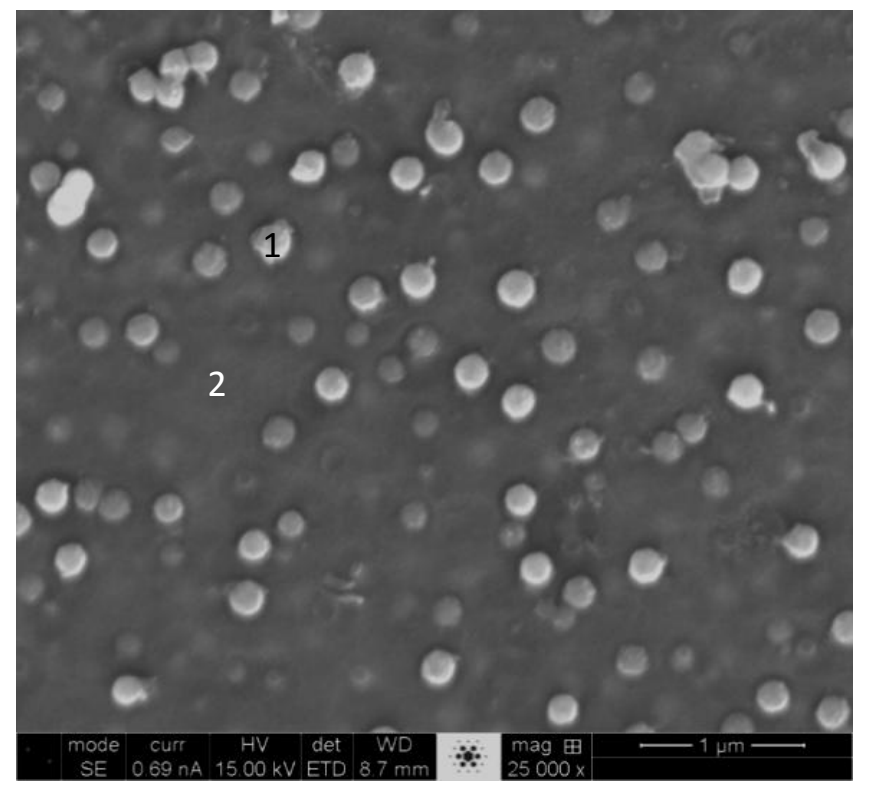

(a)

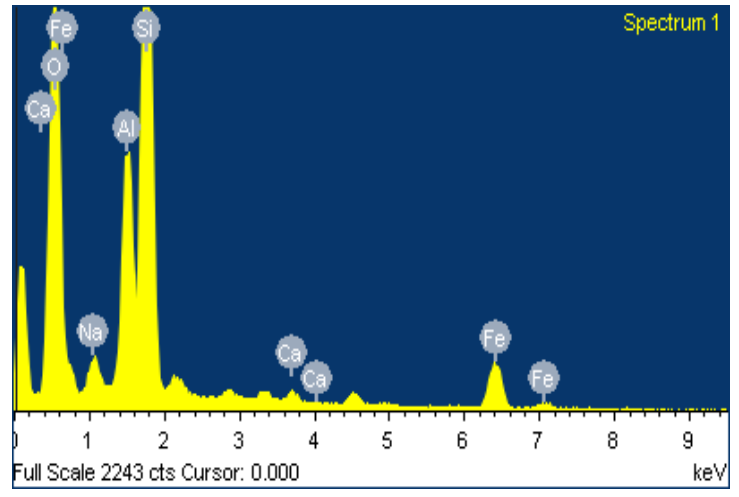

(b)

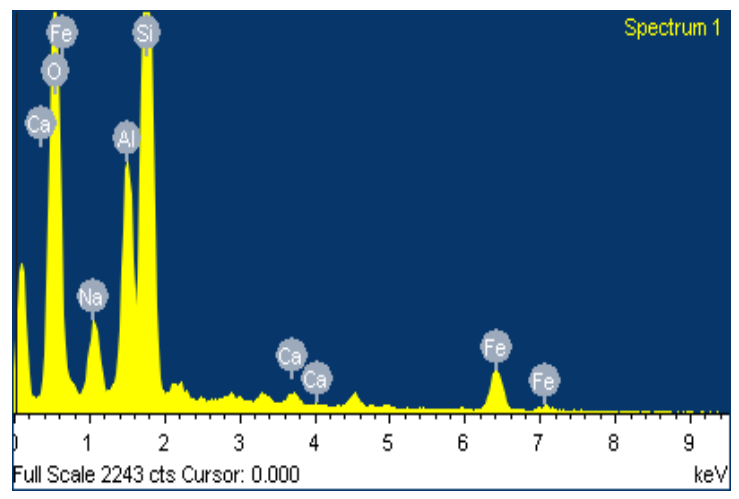

(c)

Figura 16: Microscopia eletrônica de varredura da superfície externa do material 60L40S (a), e os espectros obtidos por EDS para identificar os elementos constituintes da fase esférica (b) e da matriz (c). 


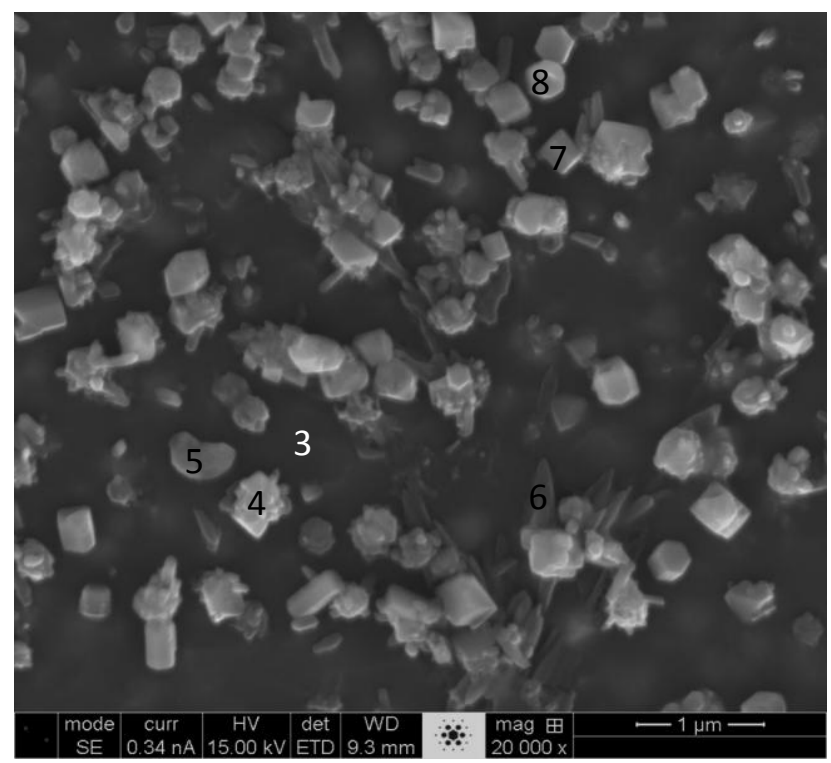

(a)

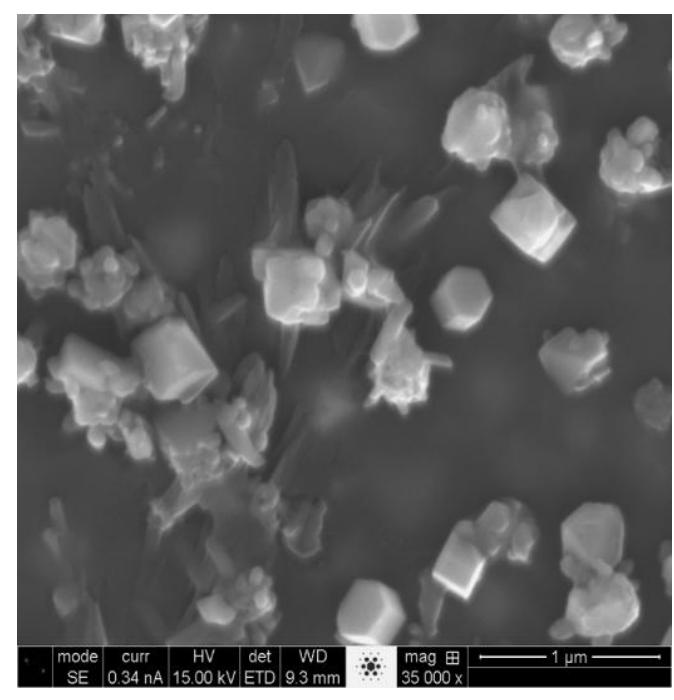

(b)

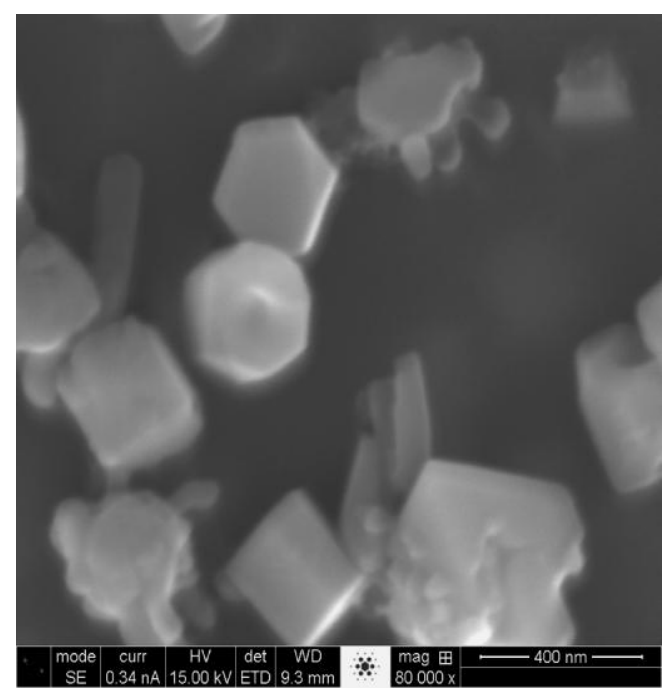

(c)

Figura 17: Microscopia eletrônica de varredura da superfície externa do material 60L25S15B (a), (b) e (c).

Os elementos que constituem a matriz e as diversas estruturas observadas e numeradas de 3 a 8 na Fig. 17 (a) foram determinados por EDS e os espectros são apresentados nas Fig. 18 (a) a 18 (f), conforme a sequência de numeração adotada. De acordo com os espectros, observamos que, assim como ocorre no material 60L40S, não é possível destacar uma região que seja composta preferencialmente 
por um determinado elemento ou uma região onde a ausência de algum elemento seja notada.

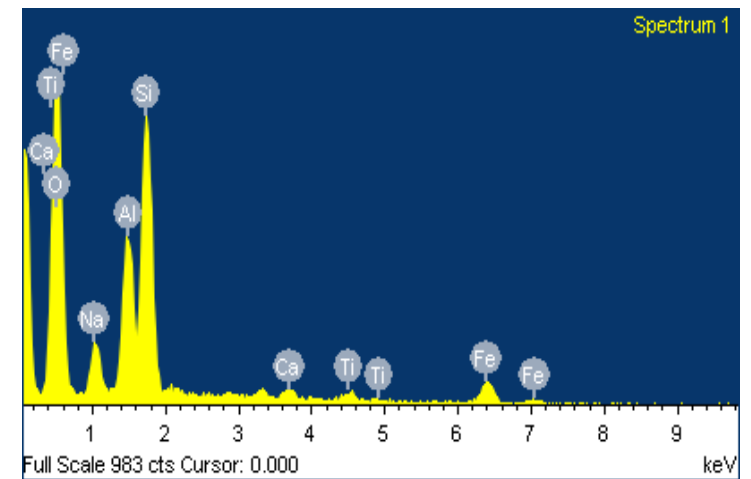

(a)

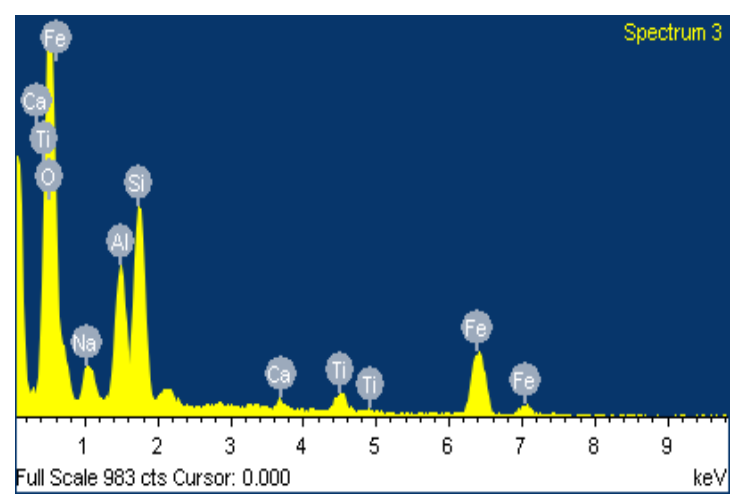

(c)

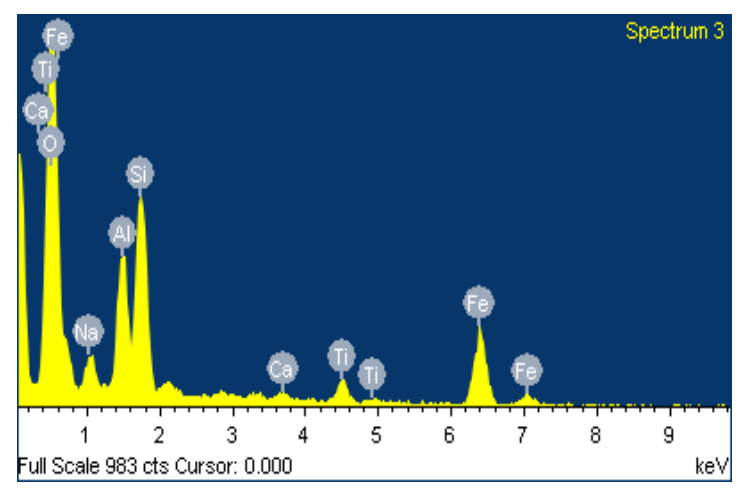

(e)

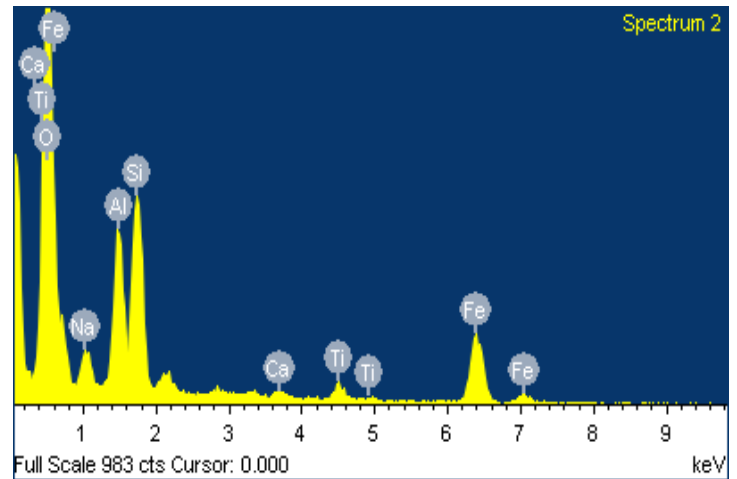

(b)

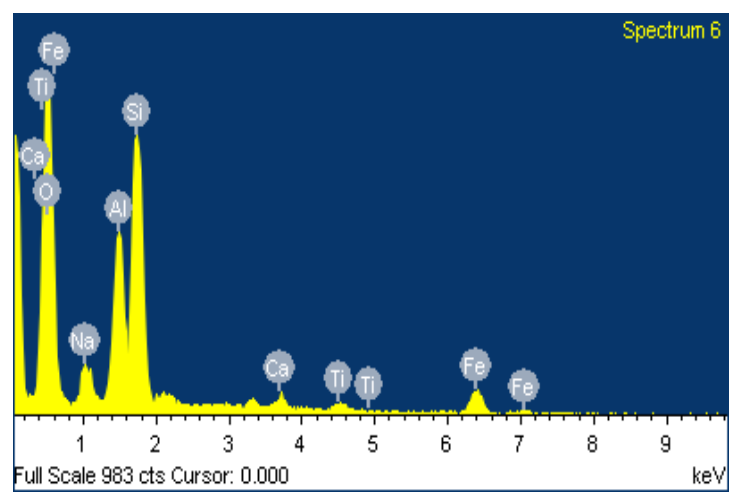

(d)

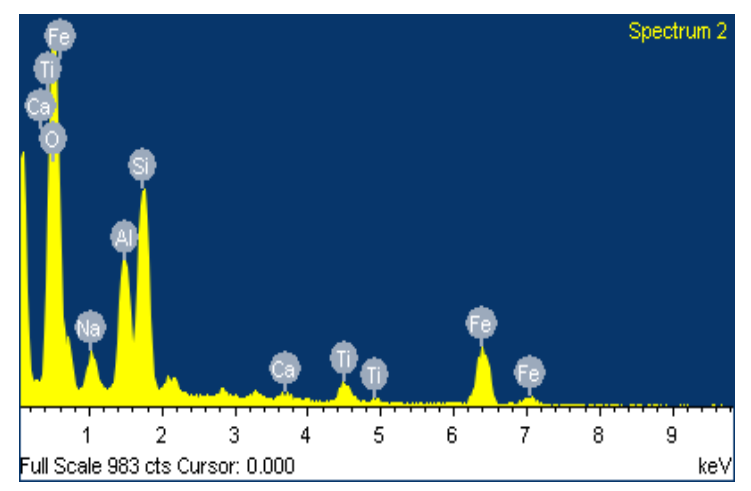

(f)

Figura 18: espectros obtidos por EDS, referente ao material 60L25S15B, para identificar os elementos constituintes da matriz (a) e das regiões numeradas de 3 a 8 na Fig. 10 (a), espectros (b) a (f). 
Sendo assim, todas as regiões marcadas na microscopia são constituídas por todos os principais elementos presentes na composição química do material e, apenas podemos destacar, que nos espectros apresentados nas Fig. 18 (a) e (d) referentes as regiões marcadas com os números 3 e 6 na Fig. 17 (a) há uma maior diferença de intensidade entre os picos referentes aos elementos Al e Si e um pico de Fe de menor intensidade quando comparados aos espectros obtidos nas outras regiões do material. Isso indica que a matriz e a região 6, que é uma região que pode estar mais relacionada a matriz e não a uma formação que indique a presença de algum cristal ou separação de fase, podem apresentar um maior teor de Si, em relação ao teor de $\mathrm{Al}$, e menor teor de Fe, quando comparadas as outras regiões.

As regiões numeradas nas micrografias da superfície dos materiais 60L40S e 60L25S15B, Fig. 6 (a) e Fig. 17 (a) foram analisadas por EDS também no modo quali-quantitativo para estimar o teor de cada elemento nas diferentes regiões.

De acordo com os resultados obtidos e apresentados na Tab. 4 foi observado que as regiões 1 e 2 do material 60L40S são constituídas principalmente de Si. Esse resultado reforça a hipótese que a região esférica, região 1, esteja relacionada à separação de fase do material, pois de acordo com o resultado de DRX dessa amostra, Fig. 11, as fases cristalinas presentes nesse material são as fases $\mathrm{Fe}_{3} \mathrm{O}_{4} \mathrm{e}$ $\mathrm{NaAlSiO}_{4}$. Sendo assim, a fase esférica estaria relacionada às fases cristalinas presentes nesse material se fossem rica em Fe.

Analisando os teores dos elementos $\mathrm{Na}$, Fe e Al, normalizados em função do teor de Si de cada região, observa-se que esses elementos estão presentes na região 1 na ordem $\mathrm{Na}$, Fe e $\mathrm{Al}$, considerando uma ordem crescente de concentração. Além disso, o teor de Fe é cerca de 2 vezes maior quando comparado ao teor de $\mathrm{Na}$ e o teor de Al é cerca de 4 vezes maior. Logo, podemos considerar a região 1 como uma região pobre em Na quando comparado ao teor de Fe e principalmente de Al.

Por outro lado, na região 2, os teores de $\mathrm{Na}$ e Fe encontrados são similares entre si e o teor de Al é cerca de duas vezes maior quando comparado ao teor dos demais elementos na mesma região.

Considerando que, dentre as regiões 1 e 2, o teor de Al presente são similares e que a região 1 é significantemente pobre em $\mathrm{Na}$, espera-se que a região 
1, ou seja, as formações esféricas presentes na superfície do material 60L40S, sejam menos lixiviadas durante o teste de lixiviação em água, pois possuem a menor concentração de $\mathrm{Na}$, elemento conhecido como pouco resistente ao ataque da água.

Tabela 4: Teor estimado de cada elemento presente nas regiões visualizadas nas superfícies dos materiais 60L40S e 60L25S15B, numeradas de 1 a 8, e mostradas nas Fig. 9 (a) e 10 (a).

\begin{tabular}{c|cc|cccccc}
\hline \multicolumn{10}{c}{$\%$ At. } \\
\hline & $\mathbf{6 0 L 4 0 S}$ & \multicolumn{7}{c}{$\mathbf{6 0 L 1 5 S 2 5 B}$} \\
\hline & $\mathbf{1}$ & $\mathbf{2}$ & $\mathbf{3}$ & $\mathbf{4}$ & $\mathbf{5}$ & $\mathbf{6}$ & $\mathbf{7}$ & $\mathbf{8}$ \\
\hline $\mathbf{S i}$ & 56,0 & 54,8 & 47,0 & 32,5 & 32,7 & 47,6 & 32,5 & 35,5 \\
$\mathbf{A l}$ & 22,9 & 20,9 & 25,2 & 23,3 & 21,4 & 26,1 & 21,2 & 22,2 \\
$\mathbf{F e}$ & 13,6 & 11,5 & 10,5 & 29,0 & 29,9 & 11,0 & 29,5 & 26,0 \\
$\mathbf{N a}$ & 6,1 & 11,2 & 12,9 & 10,3 & 9,6 & 11,0 & 11,1 & 10,5 \\
$\mathbf{C a}$ & 1,4 & 1,6 & 2,3 & 1,3 & 1,5 & 2,5 & 1,4 & 1,4 \\
$\mathbf{T i}$ & - & - & 2,1 & 3,5 & 4,9 & 1,8 & 4,2 & 4,4 \\
$\mathbf{A l} / \mathbf{S i}$ & $\mathbf{0 , 4}$ & $\mathbf{0 , 4}$ & $\mathbf{0 , 5}$ & $\mathbf{0 , 7}$ & $\mathbf{0 , 6}$ & $\mathbf{0 , 6}$ & $\mathbf{0 , 6}$ & $\mathbf{0 , 6}$ \\
$\mathbf{F e} / \mathbf{S i}$ & $\mathbf{0 , 2}$ & $\mathbf{0 , 2}$ & $\mathbf{0 , 2}$ & $\mathbf{0 , 9}$ & $\mathbf{0 , 9}$ & $\mathbf{0 , 2}$ & $\mathbf{0 , 9}$ & $\mathbf{0 , 7}$ \\
$\mathbf{N a} / \mathbf{S i}$ & $\mathbf{0 , 1}$ & $\mathbf{0 , 2}$ & $\mathbf{0 , 3}$ & $\mathbf{0 , 3}$ & $\mathbf{0 , 3}$ & $\mathbf{0 , 2}$ & $\mathbf{0 , 3}$ & $\mathbf{0 , 3}$ \\
\hline
\end{tabular}

Em relação ao material 60L25S15B observamos que, embora existam diferentes estruturas na superfície desse material, os teores de $\mathrm{Na}$ e Al presentes em cada região são comparáveis. A região 3 , que representa a matriz do material, e a região 6 , possuem composições químicas bastante similares na sua totalidade. Essas regiões, quando comparadas as áreas marcadas como 4, 5, 7 e 8 são ricas em Si e pobres em Fe.

Analisando o resultado obtido para as áreas 4, 5, 7 e 8, apesar de apresentarem diferentes estruturas morfológicas, possuem composições químicas similares e opostas às composições das áreas 3 e 6 em relação aos elementos Fe e 
Si; as quatro regiões são ricas em Fe e pobres em Si quando comparadas as áreas 3 e 6. 


\subsection{Adição de BaO, SrO E $\mathrm{ZrO}_{2}$ nos Materiais 60L40S e 60L25S15B (Grupo LSR)}

Nas Fig. 19 (a) e (b) são apresentados os difratogramas dos materiais produzidos no grupo LSR. Observamos que a adição dos óxidos de bário, estrôncio e zircônio nos materiais 60L40S e 60L25S15B favorece a cristalização dos mesmos, porém essa cristalização não deve ser total, pois os halos entre 20 e $30^{\circ}$ que indicam a presença de fase amorfa no difratograma desses materiais sem a adição dos três óxidos, Fig. 12 (a) e (b), ainda estão presentes após a adição.

Não foi possível identificar por meio do programa convencionalmente utilizado para a indexação de picos em difratogramas de raios X, programa (SearchMath), as fases cristalinas presentes nos materiais sem a adição de B, Fig. 19 (a), e alguns picos presentes nos materiais 90(60L25S15B).10R e 85(60L25S15B).15R, Fig. 19 (b).

Buscamos então obter alguma informação sobre os elementos constituintes dessas fases por meio da análise de EDS realizada simultaneamente com a obtenção de imagens da superfície desses materiais por microscopia eletrônica de varredura e, assim, auxiliar a identificação das fases cristalinas. A intenção era visualizar as possíveis fases cristalinas presentes na superfície do material, realizar uma análise de EDS limitada à área da fase e, sabendo os elementos que constituem essas fases, limitar ao máximo o número de elementos possíveis durante a tentativa de identificar os picos presentes nos difratogramas desses materiais. Mas como será apresentado a seguir, a análise de EDS não auxiliou nessa questão.

Os picos cuja identificação foi possível são relacionados às fases $\mathrm{Fe}_{2} \mathrm{O}_{3}$, $\mathrm{Fe}_{3} \mathrm{O}_{4}, \mathrm{SrFe}_{2} \mathrm{O}_{5}$ e $\mathrm{ZrO}_{2}$, Fig. 19 (b). 


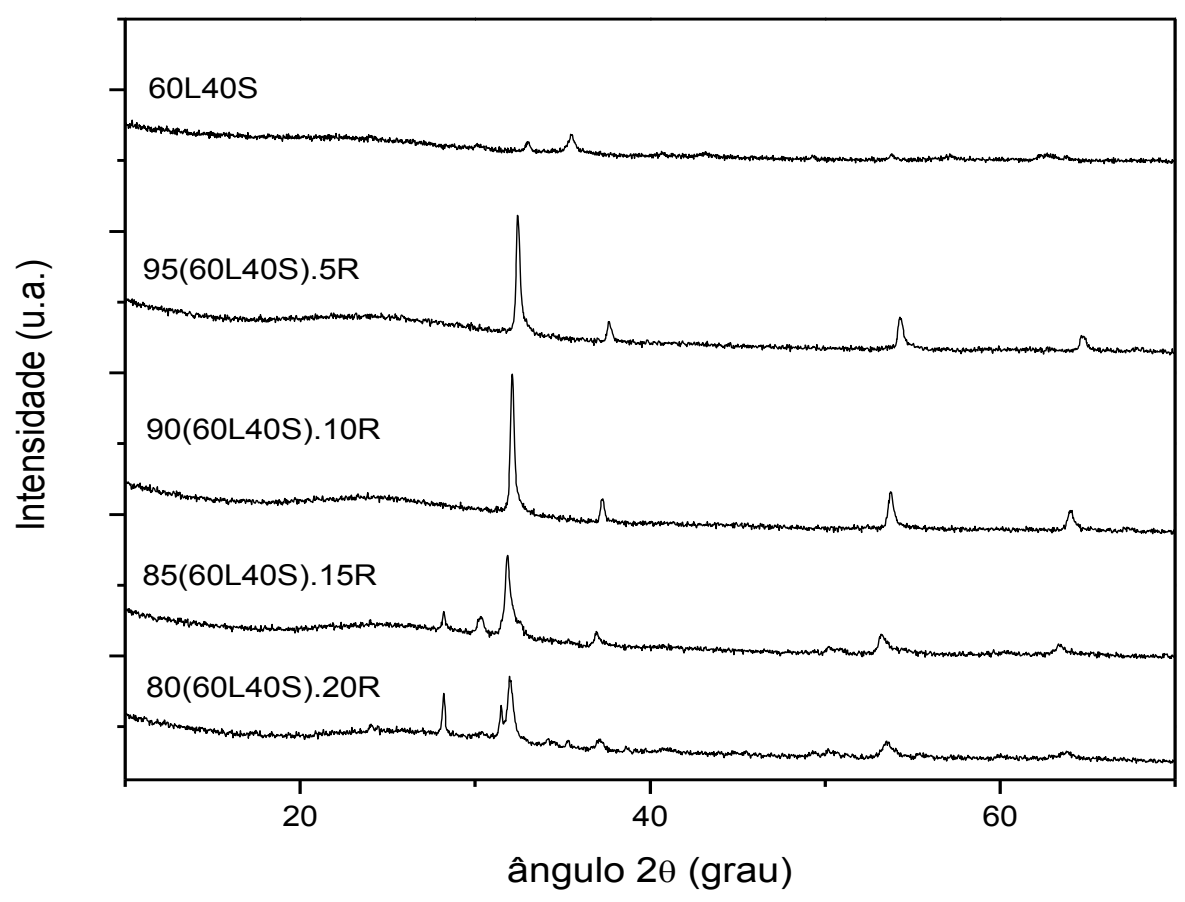

(a)

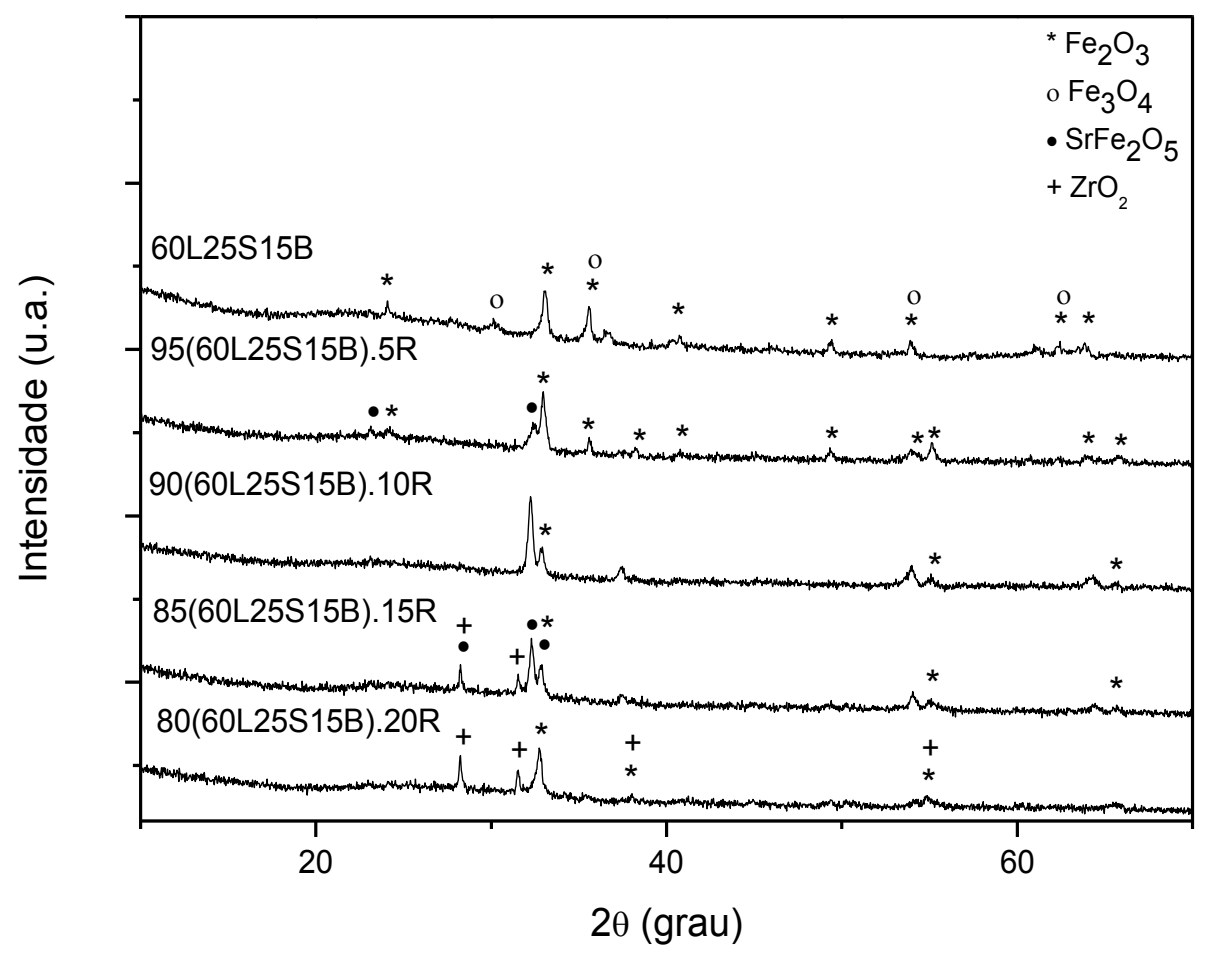

(b)

Figura 19: Difratogramas de raios $X$ dos materiais 60L40S (a) e 60L25S15B (b) adicionado de $\mathrm{BaO}, \mathrm{SrO}$ e $\mathrm{ZrO}_{2}$ (Grupo LSR). 
As curvas das análises térmicas realizadas nos materiais do grupo LSR são apresentadas nas Fig. 20 (a) e (b).

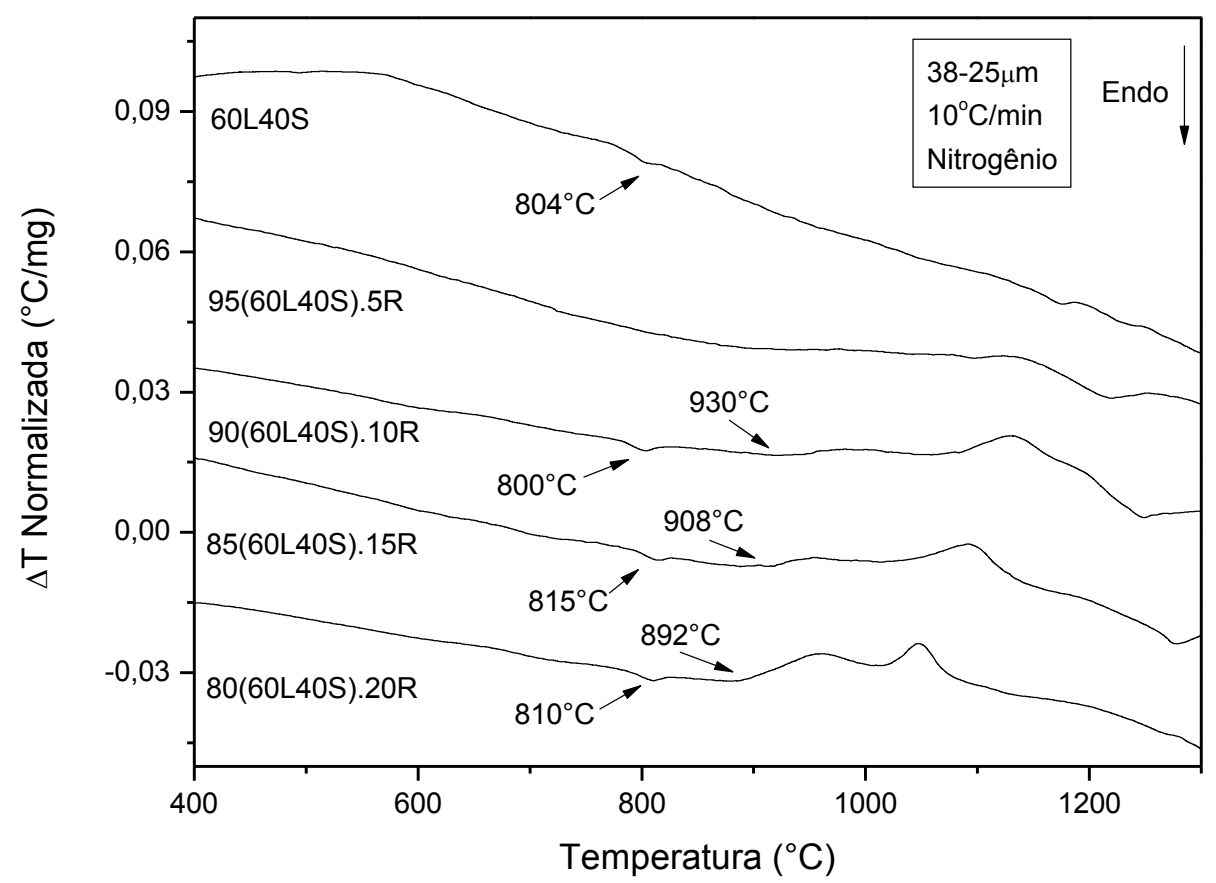

(a)

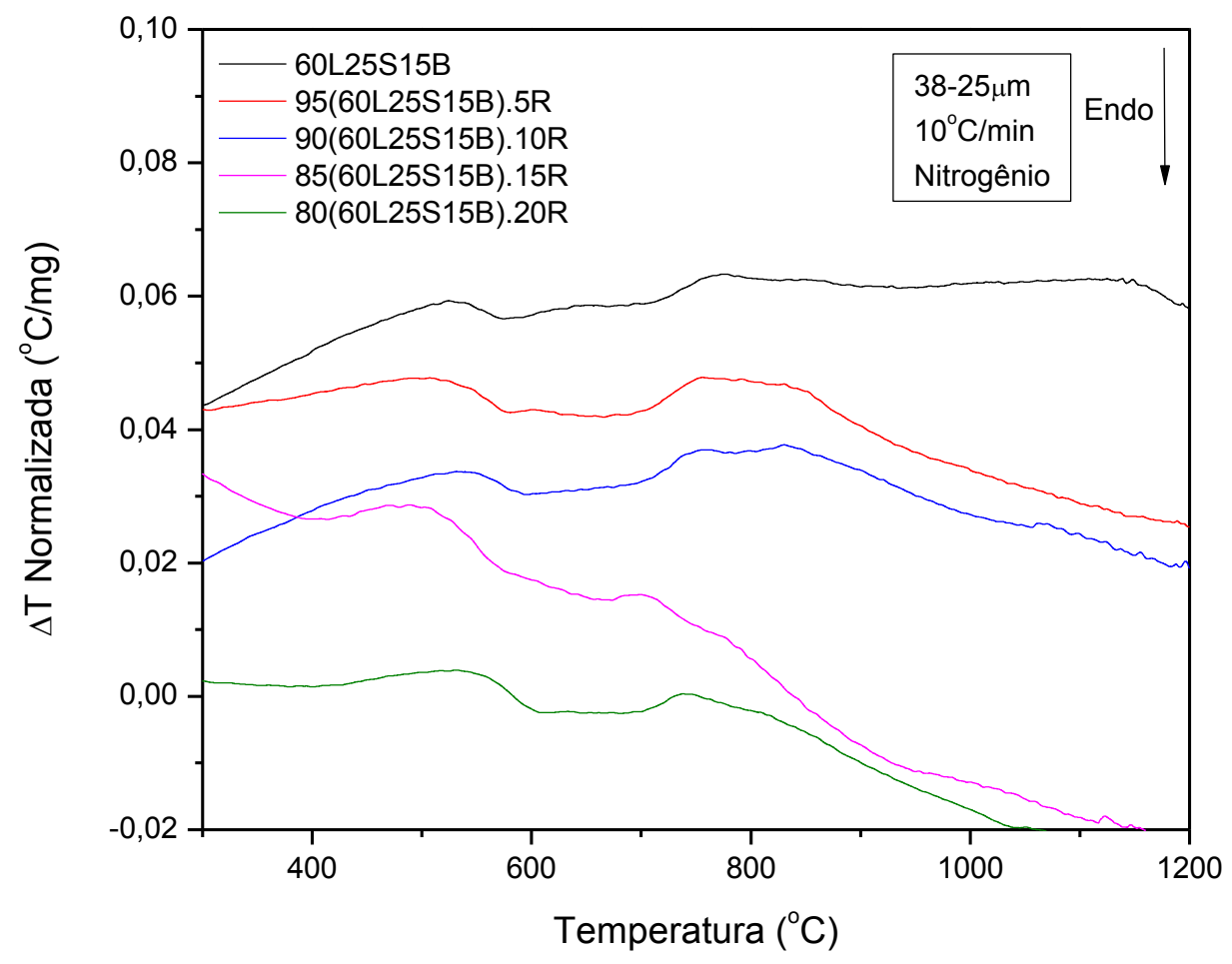

(b)

Figura 20: analise térmica diferencial dos materiais produzidos no grupo LSR, (a) sem adição de B, (b) com adição de boro. 
Foram observadas algumas variações exotérmicas na Fig. 20 (a) com início em torno de $930^{\circ} \mathrm{C}$, para o material $90(60 \mathrm{~L} 40 \mathrm{~S}) 10 \mathrm{R}, 908^{\circ} \mathrm{C}$ para o material $85(60 \mathrm{~L} 40 \mathrm{~S}) \cdot 15 \mathrm{R}$ e $892^{\circ} \mathrm{C}$ para o material $80(60 \mathrm{~L} 40 \mathrm{~S}) \cdot 20 \mathrm{R}$. Essas variações exotérmicas podem estar relacionadas à cristalização das fases amorfas presentes nesses materiais. As variações entre $800^{\circ} \mathrm{C}$ e $815^{\circ} \mathrm{C}$, presentes em todas as curvas apresentadas na Fig.20 (a), foram atribuídas à $T_{g}$ de cada material.

As curvas apresentadas na Fig. 20 (b) são mais complexas para serem analisadas, pois as variações ocorridas não são muito definidas e isto dificulta a interpretação. Essa análise foi repetida em diferentes condições de granulometria e taxa de aquecimento e, em nenhuma dessas condições, foi possível obter alguma informação significativa sobre o comportamento das propriedades físicas e químicas desses materiais quando submetidos a um programa controlado de temperatura. Desta forma, a análise térmica diferencial, técnica importante e amplamente utilizada na caracterização de vidros, infelizmente não é a mais adequada para a caracterização desse grupo de materiais.

Testes de lixiviação foram realizados nos materiais do grupo LSR preparados na forma de pastilha e em particulado. Quando na forma de particulado a água destilada utilizada nos testes foi analisada por ICP. Os resultados dos testes de lixiviação dos materiais sem adição de B são apresentados na Fig. 21 (a) e dos materiais com adição de B na Fig. 22 (a). Os resultados das análises por ICP da água utilizada nos testes dos materiais sem adição de B são apresentados nas Fig. 21 (b) e (c) e dos materiais com adição de B nas Fig. 22 (b), (c) e (d).

Na Fig. 21 (a) observa-se que, de acordo com a dissolução dos materiais 95(60L40S)·5R e 90(60L40S)·10R, o acréscimo de até 10\% em massa da mistura contendo $\mathrm{BaO}, \mathrm{SrO}$ e $\mathrm{ZrO}_{2}$, não potencializa a dissolução do material 60L40S. Aliás, essa adição tornou o material menos suscetível à água, pois as taxas de dissolução dos materiais 95(60L40S) $5 \mathrm{R}$ e 90(60L40S) 10R são menores em comparação ao material 60L40S. A partir do material $85(60 \mathrm{~L} 40 \mathrm{~S}) \cdot 15 \mathrm{R}$ observa-se um aumento na dissolução.

De acordo com a análise da água utilizada nos testes, é possível observar na Fig. 21 (b) que a fração de lixiviação dos elementos $\mathrm{Na}$, Si e Al é maior para o material 60L40S quando comparado aos materiais 95(60L40S) $5 \mathrm{R}$ e 80(60L40S) $20 \mathrm{R}$, e apresenta um comportamento crescente durante o tempo de 
teste enquanto a lixiviação desses elementos nos outros materiais parece se estabilizar. Em todos os materiais o $\mathrm{Na}$ é o elemento com maior fração de lixiviação.

Na Fig. 21 (c) é observada a fração de lixiviação dos elementos $\mathrm{Ba}$, Sr e Zr adicionados aos materiais 95(60L40S)·5R e 80(60L40S) 20R. Nos dois materiais investigados o Sr apresenta a maior fração de lixiviação dentre os elementos mencionados e a maior lixiviação ocorre para o material 95(60L40S)·5R.

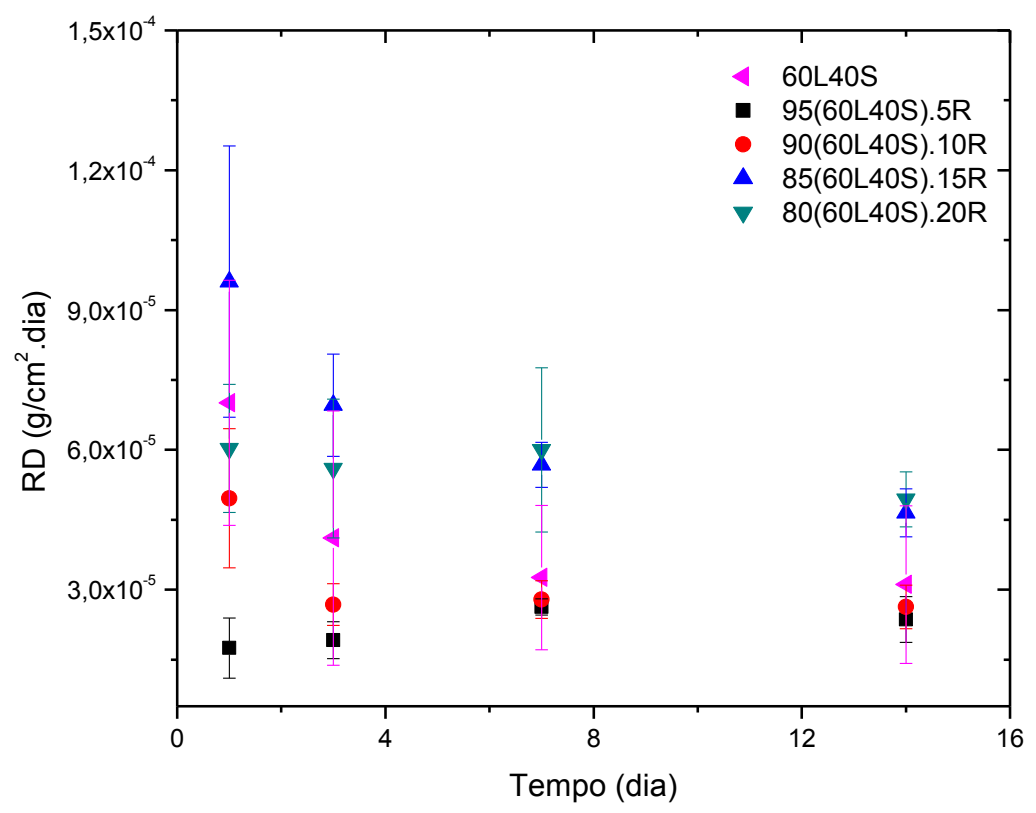

(a)

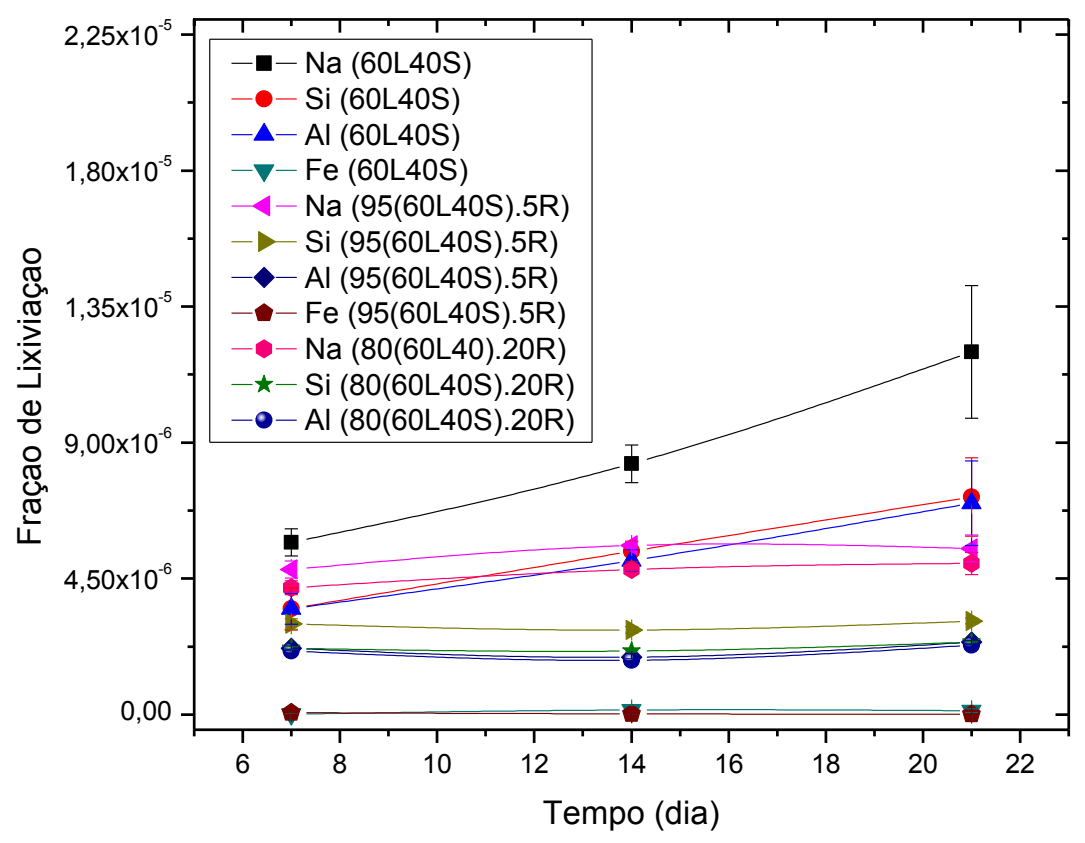

(b) 


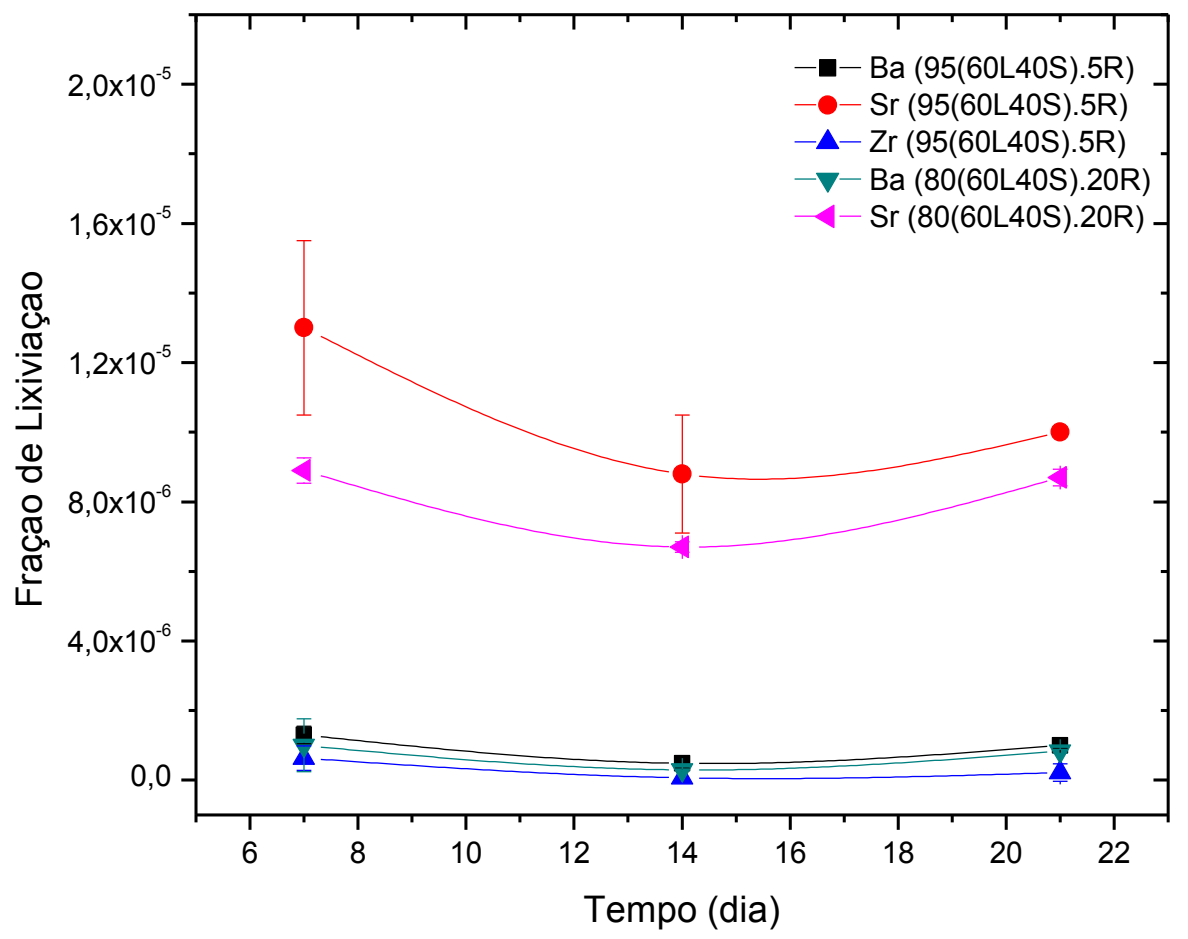

(c)

Figura 21: Razão de dissolução dos materiais do grupo LSR, sem adição de $\mathrm{B}$, em água destilada a $90^{\circ} \mathrm{C}$ por 14 dias (a), análise por ICP da água utilizada nos testes de lixiviação (b) e (c).

Observa-se na Fig. 22 (a) que a adição de $\mathrm{BaO}$, SrO e $\mathrm{ZrO}_{2}$ no material 60L25S15B compromete a durabilidade do material aumentando a taxa de dissolução do mesmo em água. Este efeito é observado desde o material 95(60L25S15B) 5R.

Na Fig. 22 (b) são apresentados os resultados da análise da água utilizada no teste de lixiviação. Observa-se que a lixiviação do B e da Si no material 60L25S15B é consideravelmente maior em relação aos mesmos elementos nos demais materiais.

Na Fig. 22 (c) são apresentados os mesmos resultados da Fig. 22 (b), porém sem os elementos B e Si do material 60L25S15B para melhor visualização das curvas obtidas. Nesta figura foi observado que a lixiviação dos elementos $\mathrm{B}, \mathrm{Na}, \mathrm{Si}$ e Al presentes no material 95(60L25S15B) 5R apresenta um comportamento crescente durante o teste enquanto que a lixiviação dos mesmos elementos 
presentes nos demais materiais parece assumir um comportamento mais estável. Observa-se também que, com exceção do material 80(60L25S15B)20R, o B apresenta a maior fração de lixiviação mesmo quando comparado ao $\mathrm{Na}$.

A lixiviação dos elementos $\mathrm{Ba}, \mathrm{Sr}$, e $\mathrm{Zr}$ adicionados aos materiais 95(60L25S15B)·5R e 80(60L25S15B)'20R é apresentada na Fig. 22 (d). Foi observado que o elemento $\mathrm{Sr}$ novamente apresenta a maior fração de lixiviação quando comparado aos demais, porém, diferentemente do que ocorre nos materiais sem adição de B, Fig. 21 (c), esta fração é maior para o material 80(60L40S) 20R.

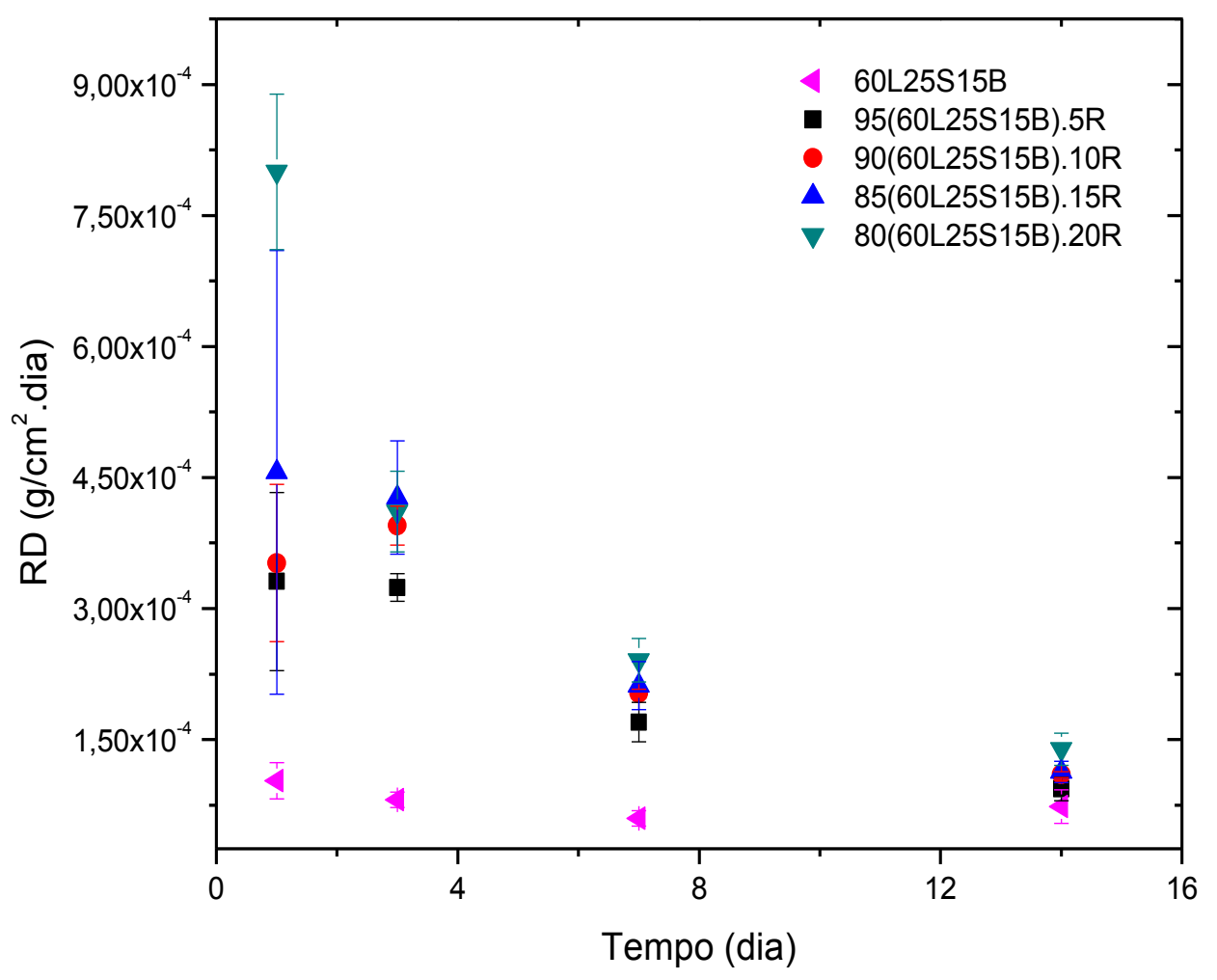

(a) 


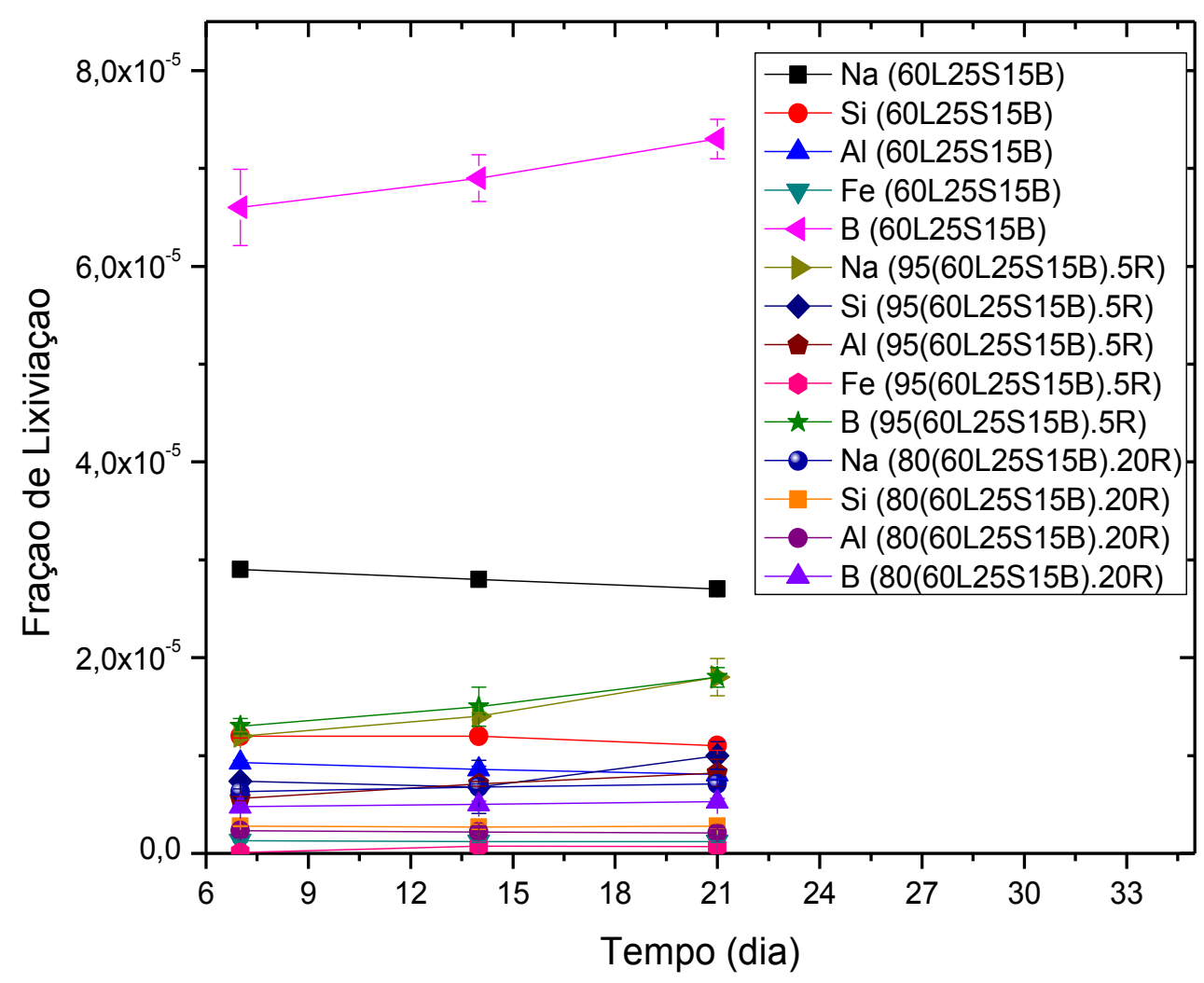

(b)

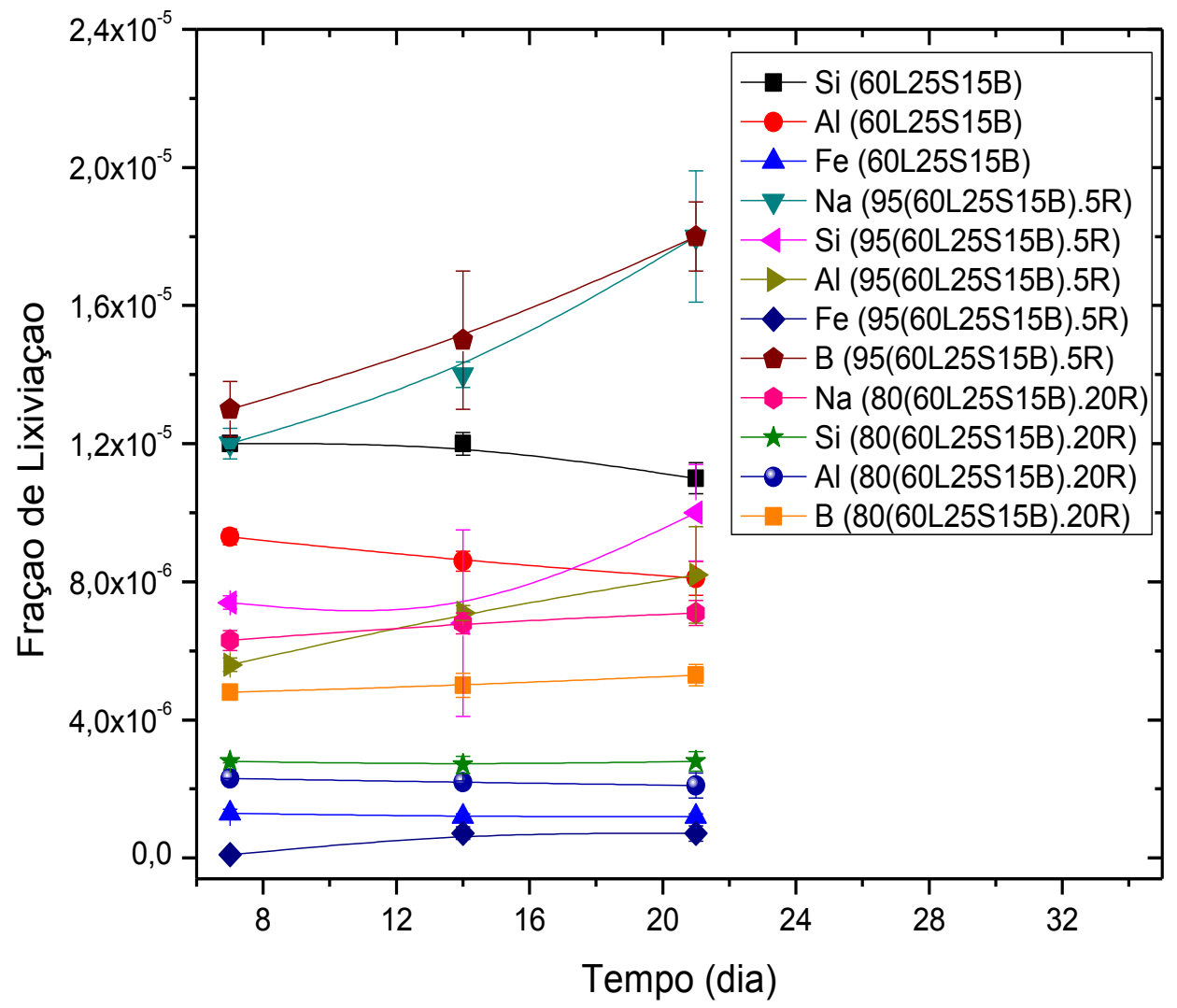

(c) 


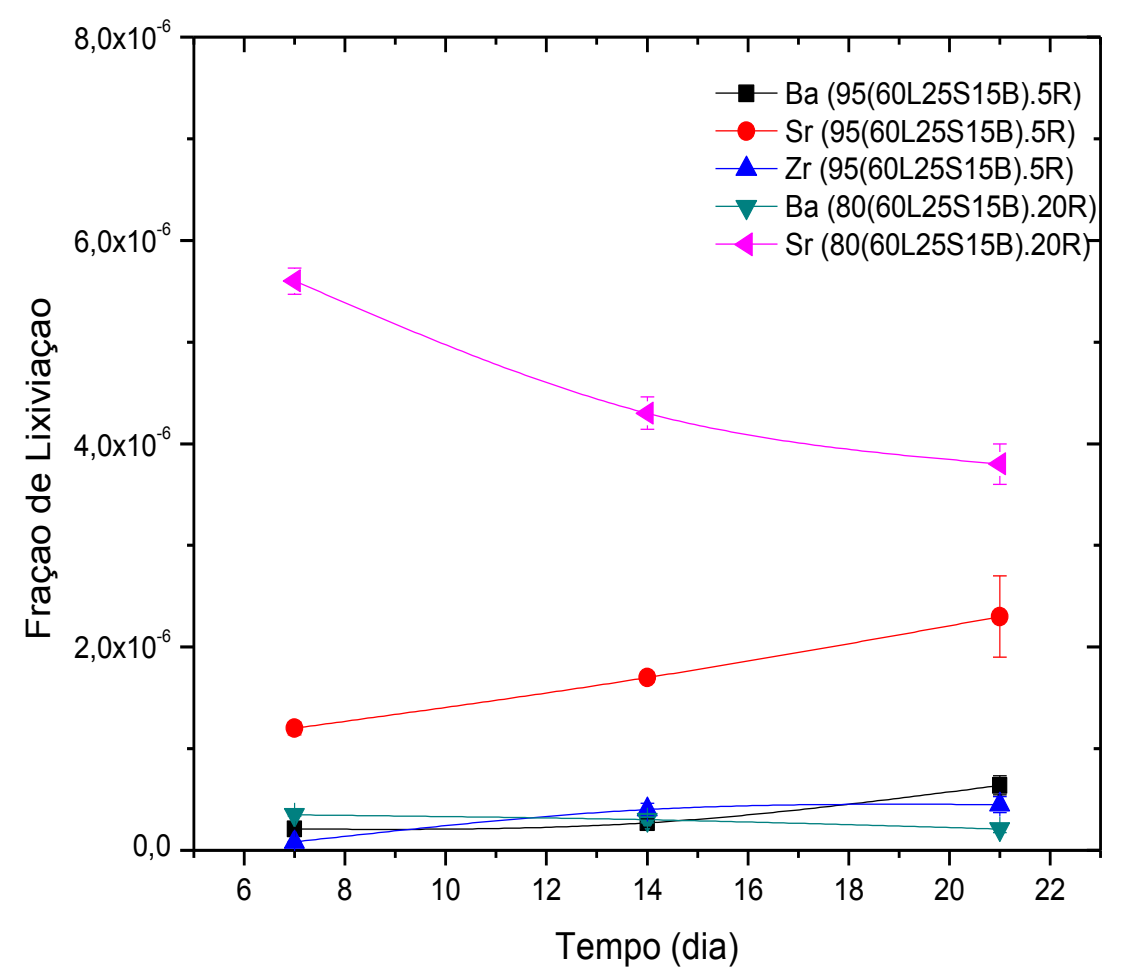

(d)

Figura 22: Razão de dissolução dos materiais do grupo LSR, com adição de $\mathrm{B}$, em água destilada a $90^{\circ} \mathrm{C}$ por 14 dias (a), análise por ICP da água utilizada nos testes de lixiviação (b), (c) e (d).

As amostras do grupo LSR, sem adição de B, utilizadas no teste de lixiviação em forma de particulados foram analisadas, após o teste de lixiviação, por difração de raios $X$ para verificar se houve alguma modificação no padrão de difração dessas amostras por conta de uma possível solubilidade em água das fases presentes nesses materiais. Os resultados obtidos são apresentados nas Fig. 23 (a) e (b).

Observa-se na Fig. 23 (a) que, após 7, 14 e 21 dias de testes de lixiviação não é possível identificar nenhuma alteração nos picos referentes a fases cristalinas presentes no material 95(60L40S)·5R. Porém, é possível observar que o halo presente em torno de $20^{\circ}$ e $30^{\circ}$ se tornou menos acentuado com o decorrer do teste. Isto pode indicar que a fase amorfa presente nesse material é a fase mais suscetível ao ataque da água.

$\mathrm{Na}$ Fig. 23 (b) observamos que com o decorrer do teste de lixiviação no material 80(60L40S) 20R há uma diminuição na intensidade dos picos localizados 
em $28^{\circ}$ e $32^{\circ}$, e há o surgimento de um novo pico em torno de $30^{\circ}$. É possível observar também que o halo existente entre $20^{\circ}$ e $30^{\circ}$ se torna menos relevante com o decorrer do teste de lixiviação.

Esse resultado pode indicar que ambas as fases presentes nesse material, fases amorfa e cristalina, passam por alguma alteração quando em contato com água.

Nas Fig. 24 (a) a 24 (i) são apresentadas as micrografias obtidas da superfície externa dos materiais do grupo LSR, sem adição de B, antes e após o teste de lixiviação. A superfície do material 60L40S antes do teste de lixiviação é mostrada nas Fig. 24 (a) e após o teste nas Fig. 24 (b) e (c), em detalhe. A superfície do material 95(60L40S)·5R antes do teste é mostrada na Fig. 24 (d) e após nas Fig. 24 (e) e (f). Na Fig. 24 (g) é mostrada a superfície do material 80(60L40S) 20R antes do teste e nas Fig. 24 (h) e (i) é mostrada a superfície desse mesmo material após o teste de lixiviação.

Observa-se nas Fig. 24 (a), (d) e (g) que os três materiais analisados possuem superfícies semelhantes, ou seja, a adição de $\mathrm{BaO}, \mathrm{SrO}$ e $\mathrm{ZrO}_{2}$ não altera a estrutura morfológica superficial desses materiais e a separação de fase continua ocorrendo mesmo após a adição desses três óxidos.

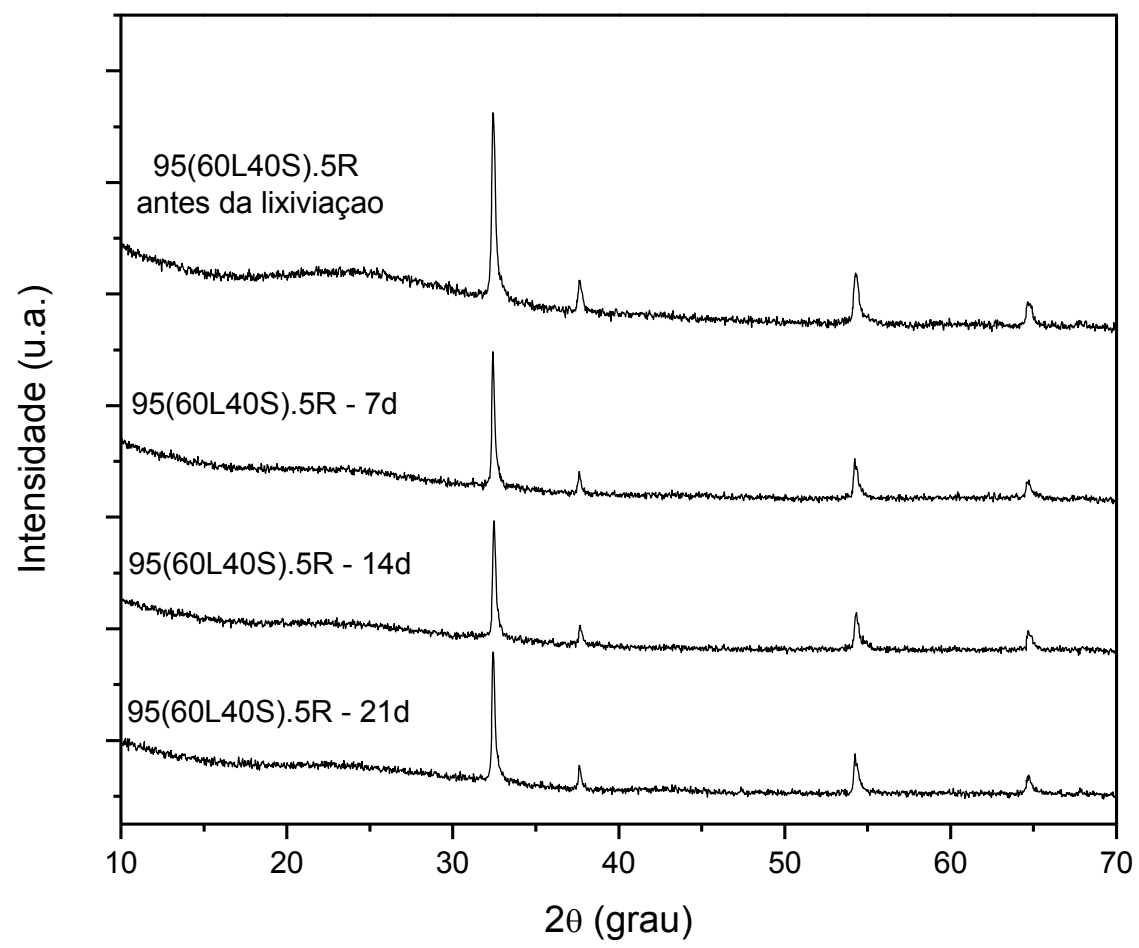

(a) 


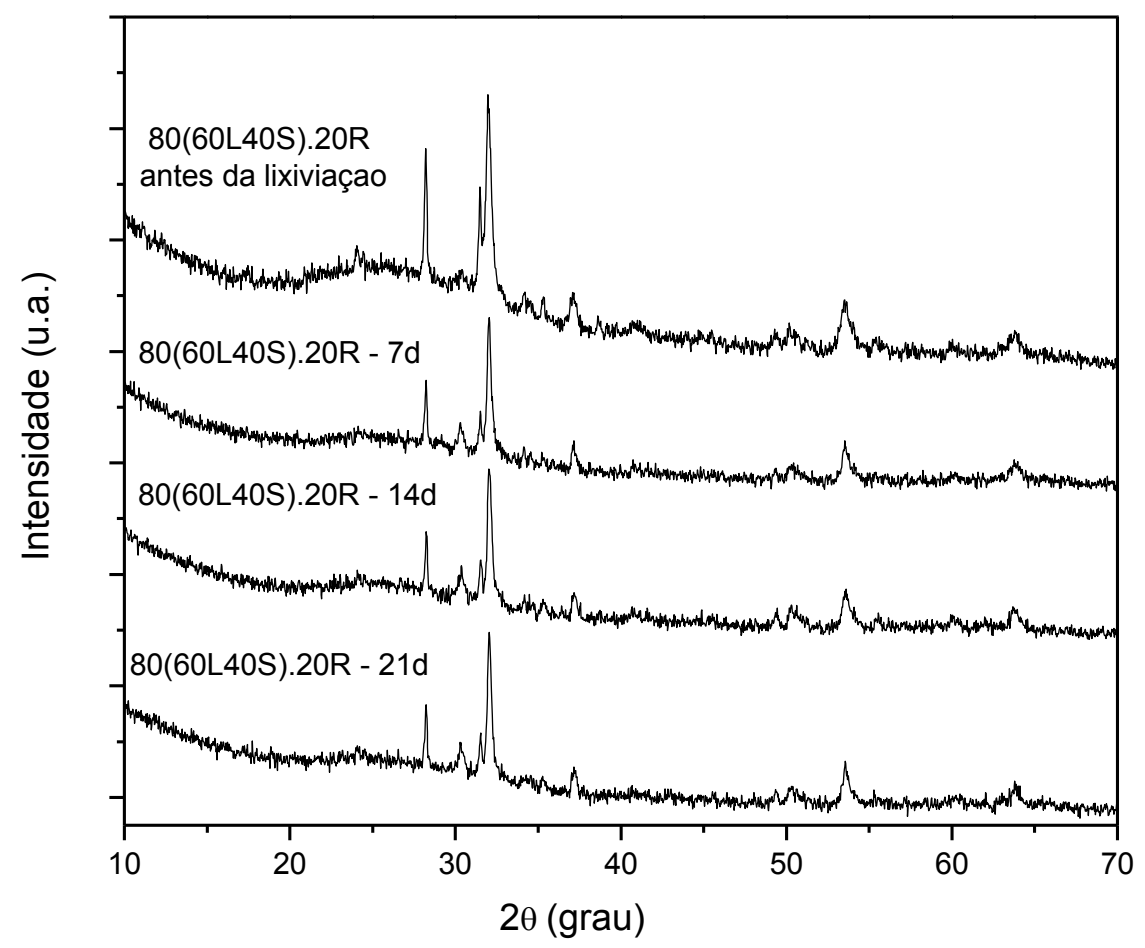

(b)

Figura 23: Difração de raios $X$ das amostras do grupo LSR, (a) sem adição de $B$, (b) com adição de B, em forma de particulados, antes e após serem utilizadas nos testes de lixiviação.

Nas Fig. 24 (b), (c), (e), (f), (h) e (i) foi observado que, após o teste de lixiviação, as formações esféricas na superfície dos materiais são melhor visualizadas e, considerando que, diferentemente do que ocorre com as amostras sem o teste de lixiviação, não foi necessário o ataque em HF para essa visualização, apenas o ataque em água, indicando que a matriz desses materiais é mais suscetível à água quando comparada às formações esféricas. 


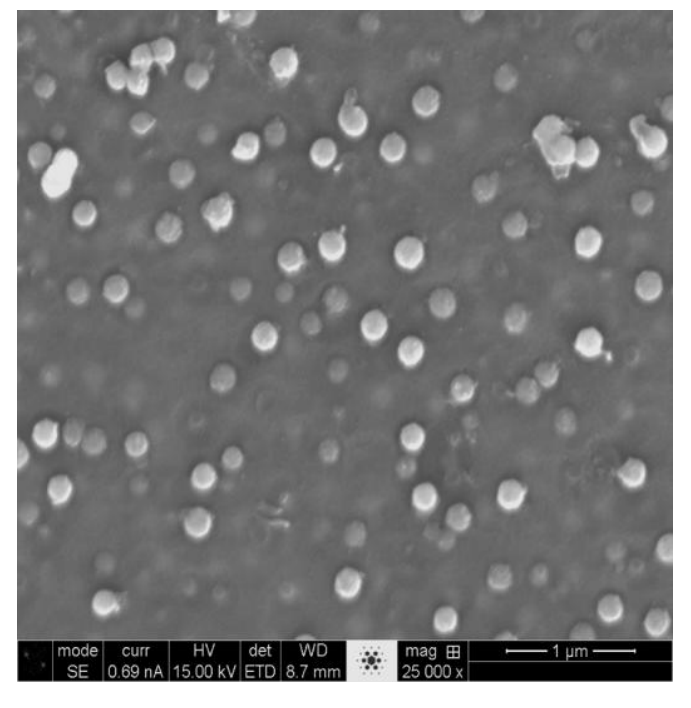

(a)

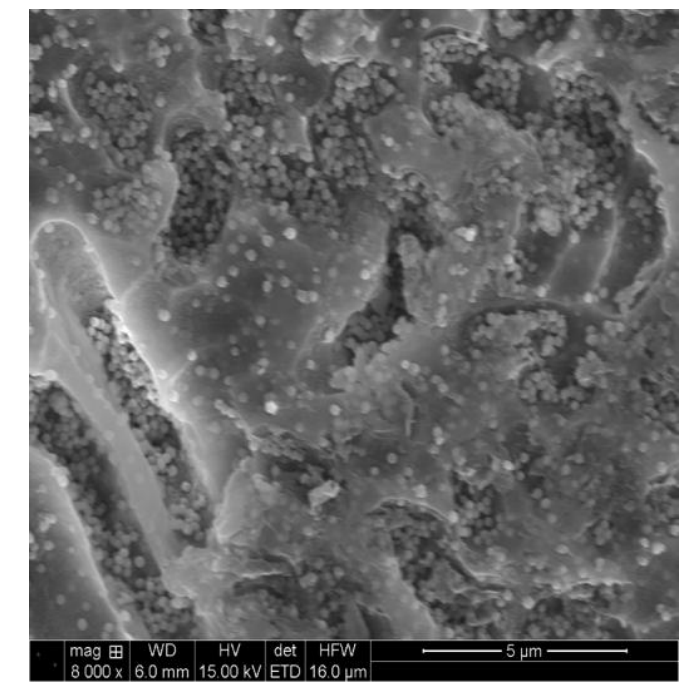

(b)

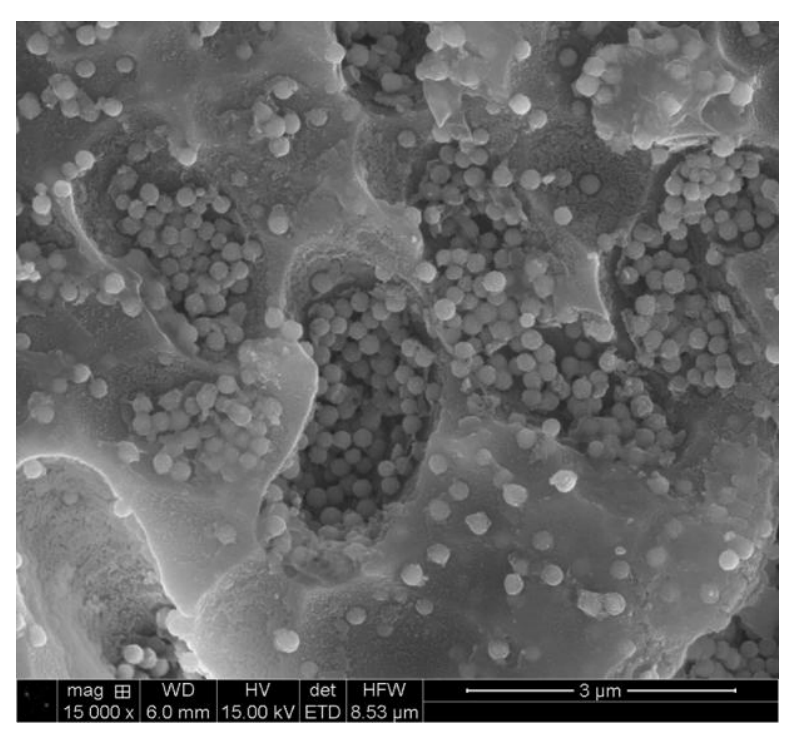

(c) 


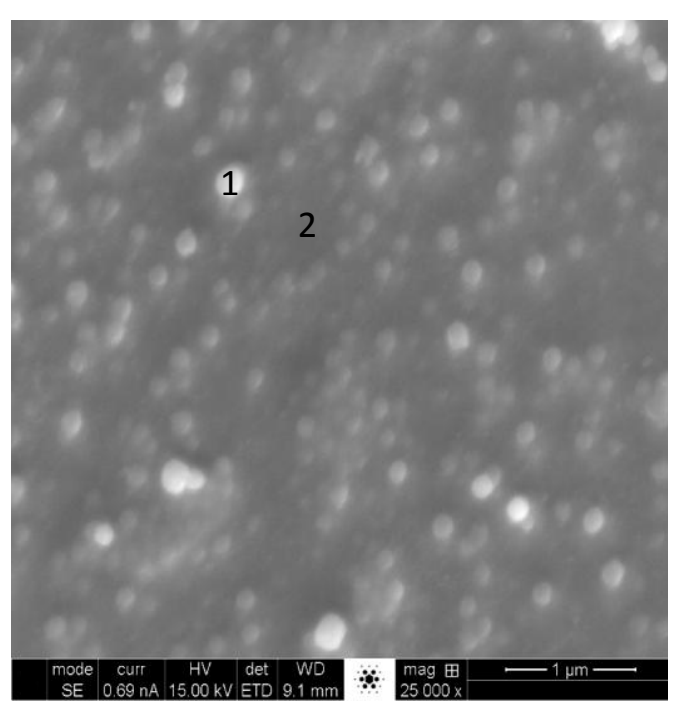

(d)

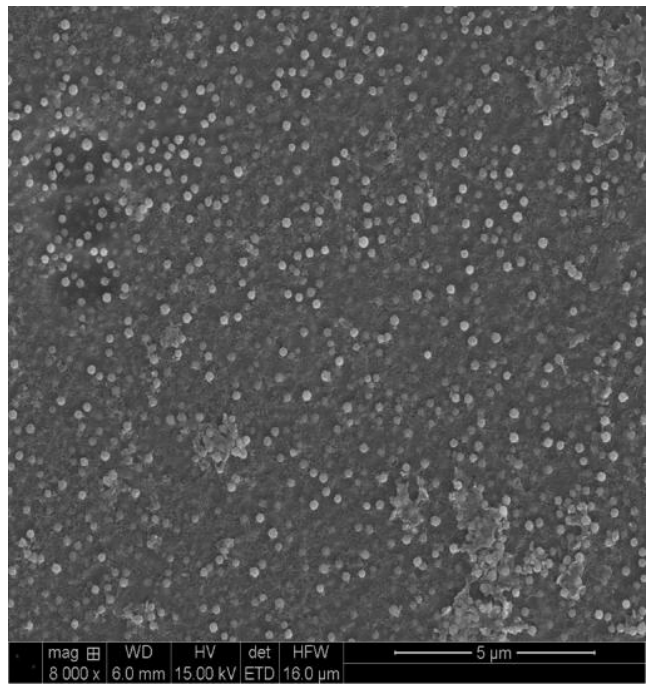

(e)

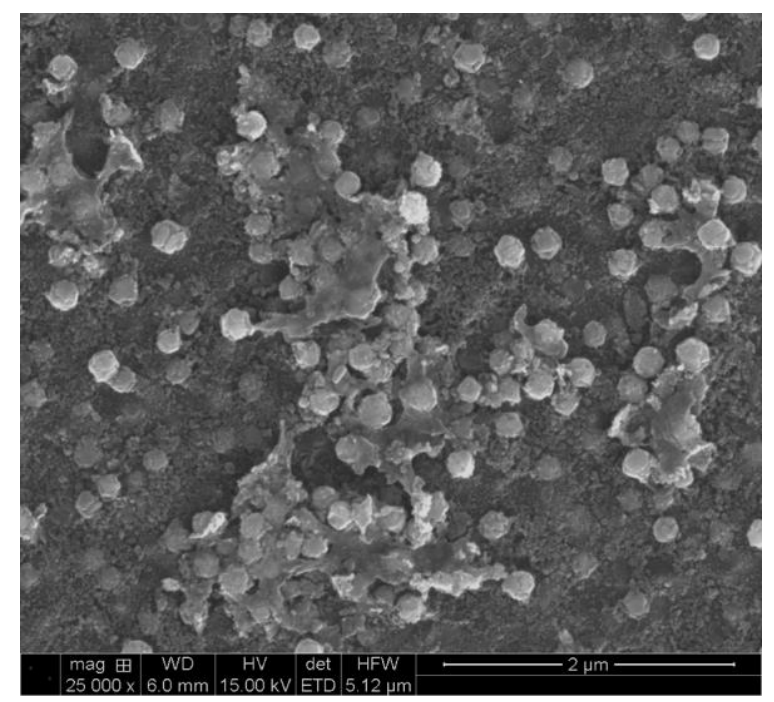

(f)

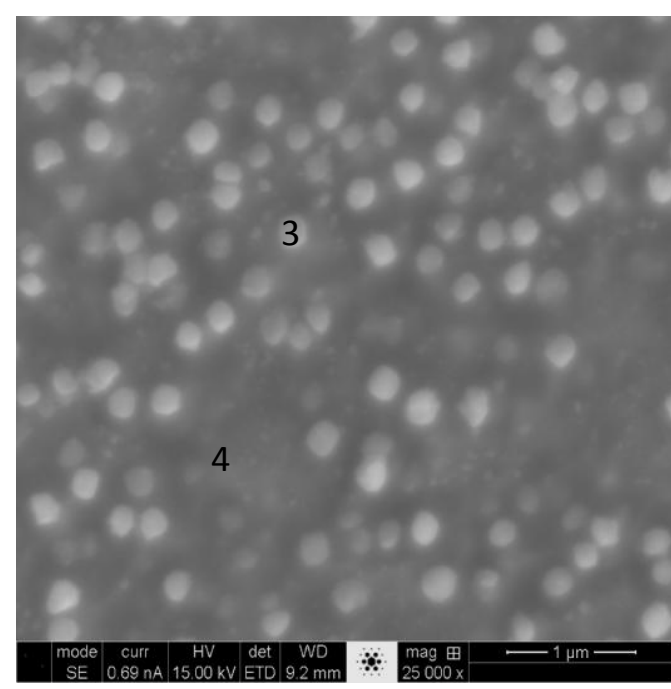

(g)

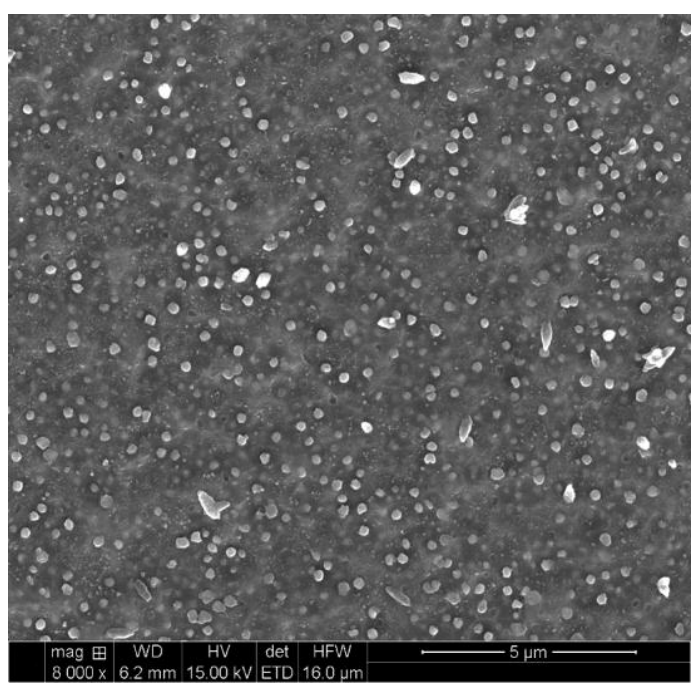

(h) 


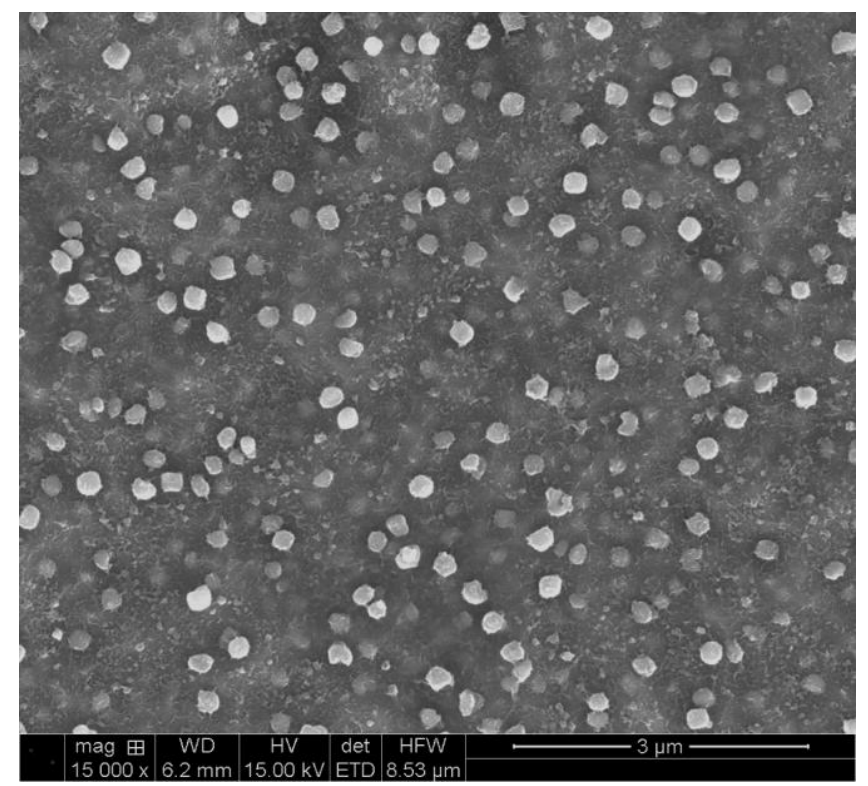

(i)

Fig. 24: Micrografias das superfícies dos materiais do grupo LSR, polidas e atacadas em HF6\%, sem adição de B: (a) 60L40S, (d) 95(60L40S)5'R e (g) 80(60L40S) 20R. Micrografias das superfícies dos materiais do grupo LSR, sem adição de B, após imersão em água destilada a $90^{\circ} \mathrm{C}$ por 14 dias: (b) e (c) 60L40S, (e) e (f) $95(60 L 40 S) 5 \cdot R$, e (h) e (i) $80(60 L 40 S) \cdot 20 R$.

Nas Fig. 25 (a) a 25 (k) são apresentadas as micrografias da superfície externa dos materiais do grupo LSR, com adição de boro, antes e após o teste de lixiviação. A superfície do material 60L25S15B antes do teste de lixiviação é mostrada nas Fig. 25 (a) e após o teste nas Fig. 25 (b) e (c). A superfície do material 95(60L25S15B)·5R antes do teste é mostrada nas Fig. 25 (d) e (f), em detalhe, e após o teste nas Fig. 25 (e) e (g). Nas Fig. 25 (h) e (j) é mostrada a superfície do material 80(60L25S15B) 20R antes do teste, e após o teste nas Fig. 25 (i) e (k).

Foi observado que a adição de $\mathrm{BaO}, \mathrm{SrO}$ e $\mathrm{ZrO}_{2}$ não causa alterações relevantes na superfície do material 95(60L25S15B)·5R, quando comparado ao material 60L25S15B, e após o teste de lixiviação a superfície se manteve sem grandes alterações. Porém, comparando a superfície do material 80(60L25S15B)·20R às superfícies dos materiais 60L25S15B e 95(60L25S15B)·5R observa-se a aglomeração das estruturas constituintes dessa superfície.

Alterações na superfície do material 80(60L25S15B)·20R também podem ser observadas após o teste de lixiviação quando comparada à superfície do mesmo 
material sem ser submetido a este teste, porém essa alteração pode estar relacionada ao fato que a amostra que não foi submetida ao teste de lixiviação foi atacada em HF, Fig. 25 (h), e esse ataque pode ter sido mais agressivo à superfície do material, talvez por conta do tempo de exposição ao ácido, em comparação ao ataque da água ocorrido no teste de lixiviação.

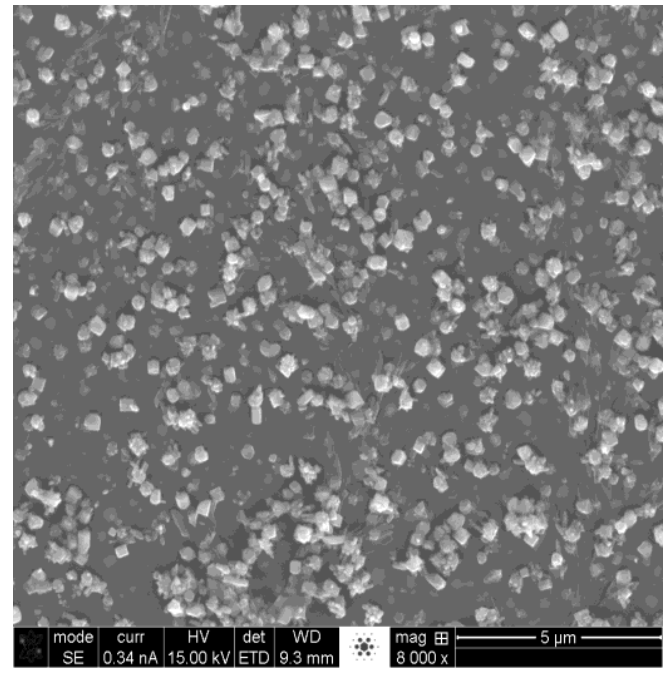

(a)

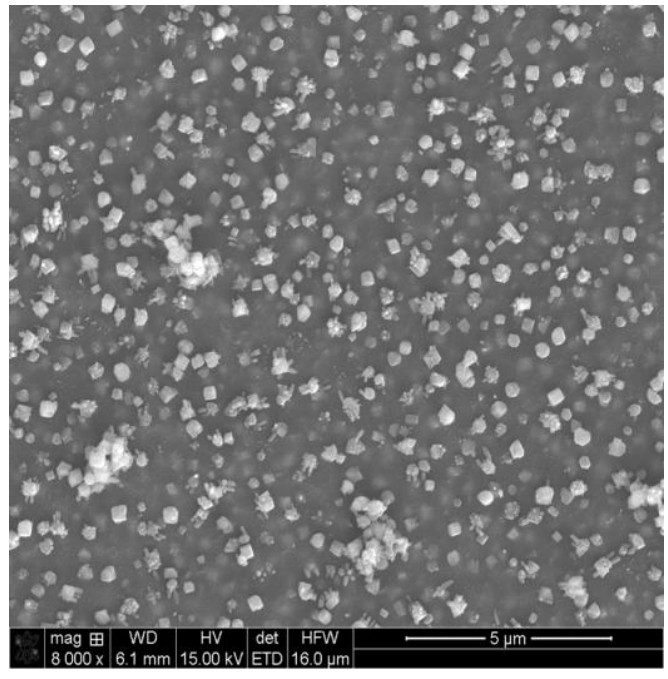

(b)

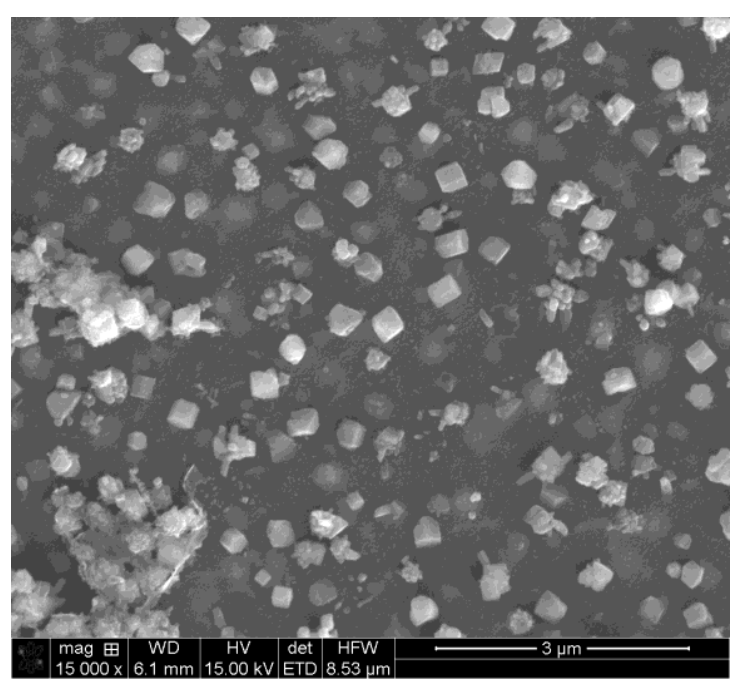

(c) 


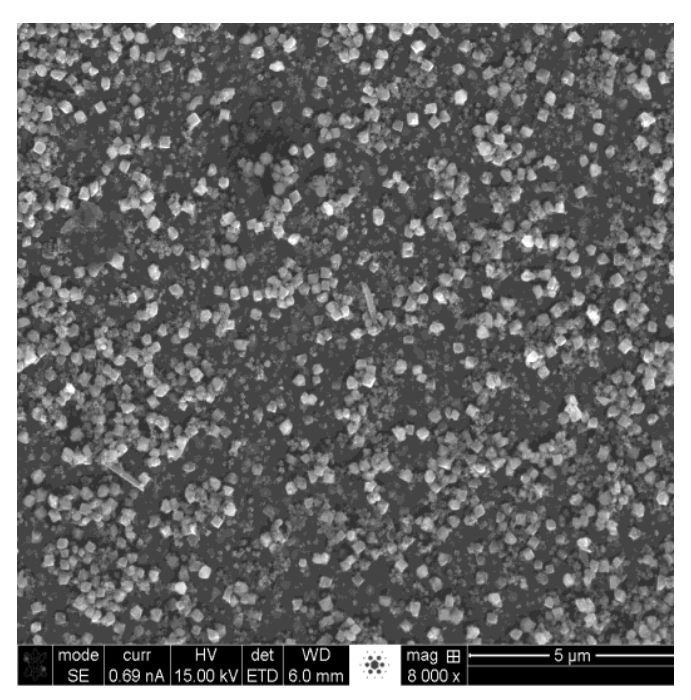

(d)

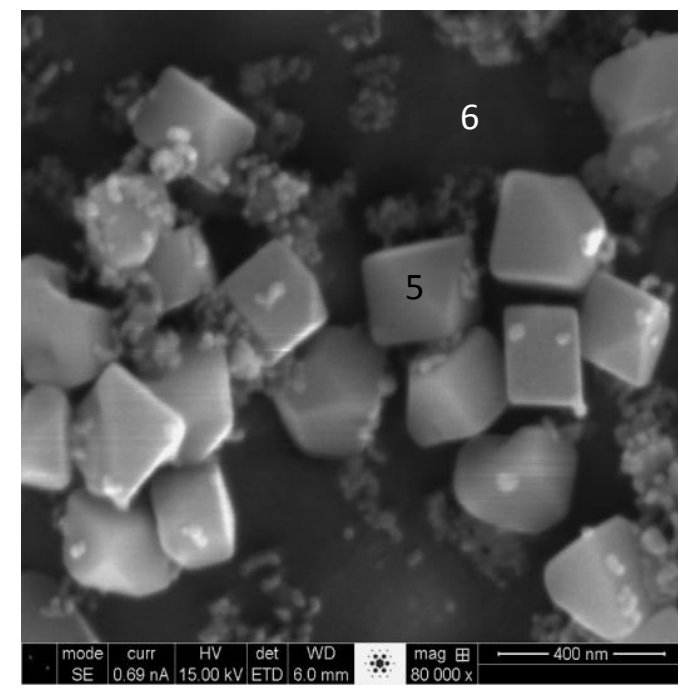

(f)

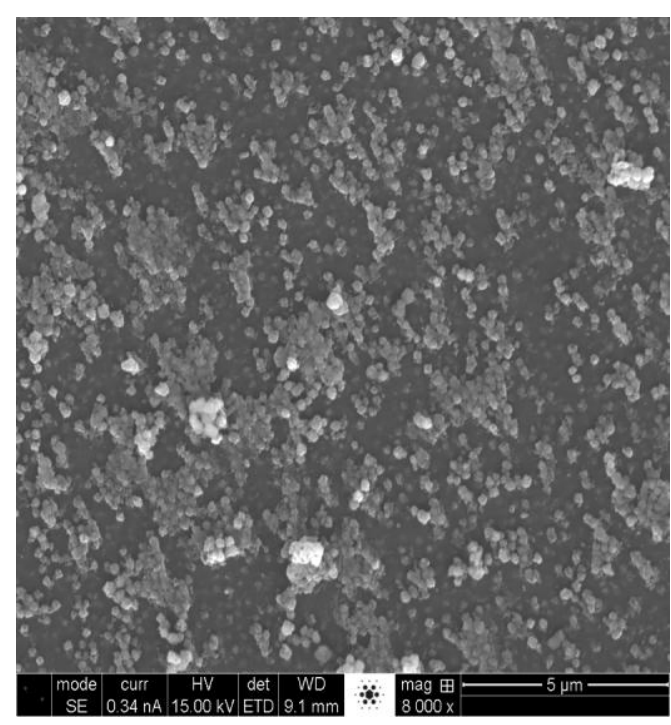

(h)

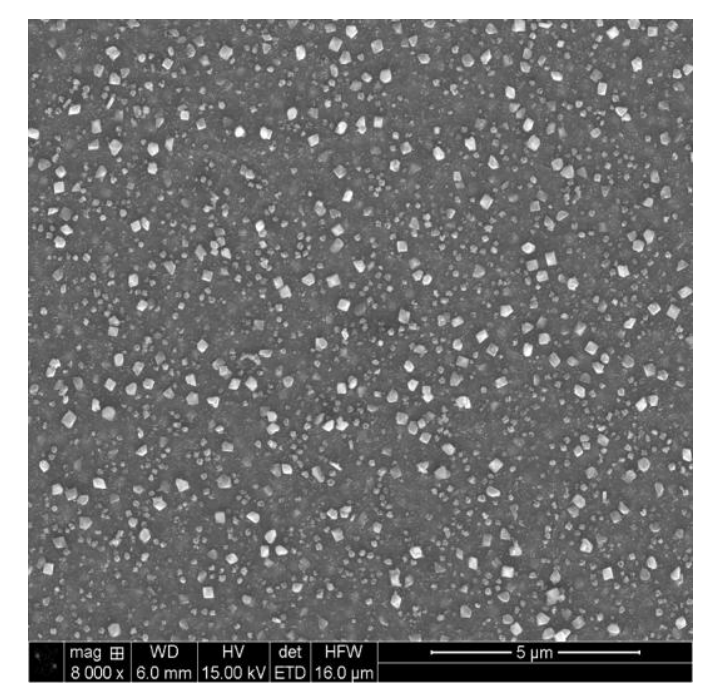

(e)

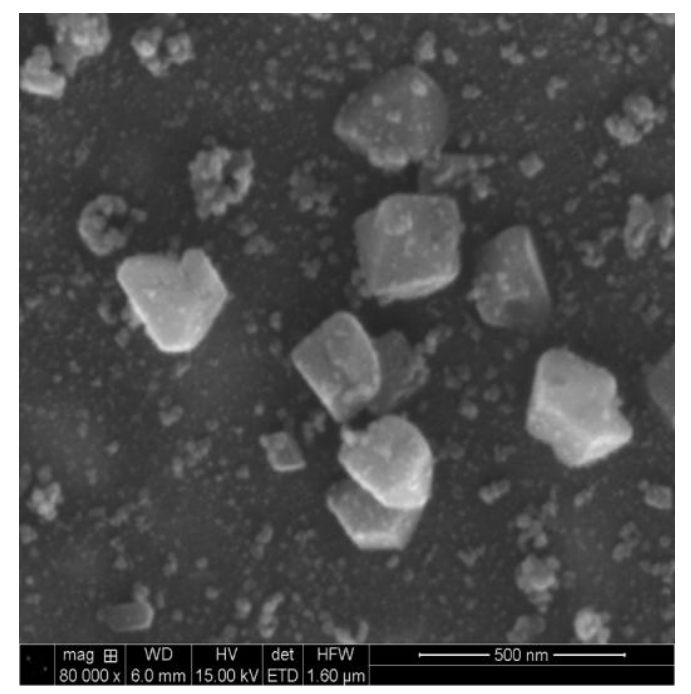

(g)

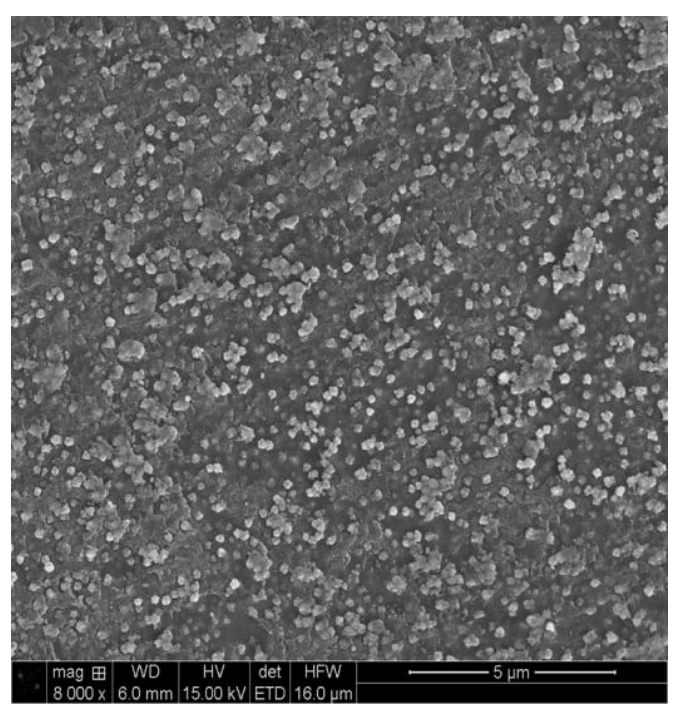

(i) 


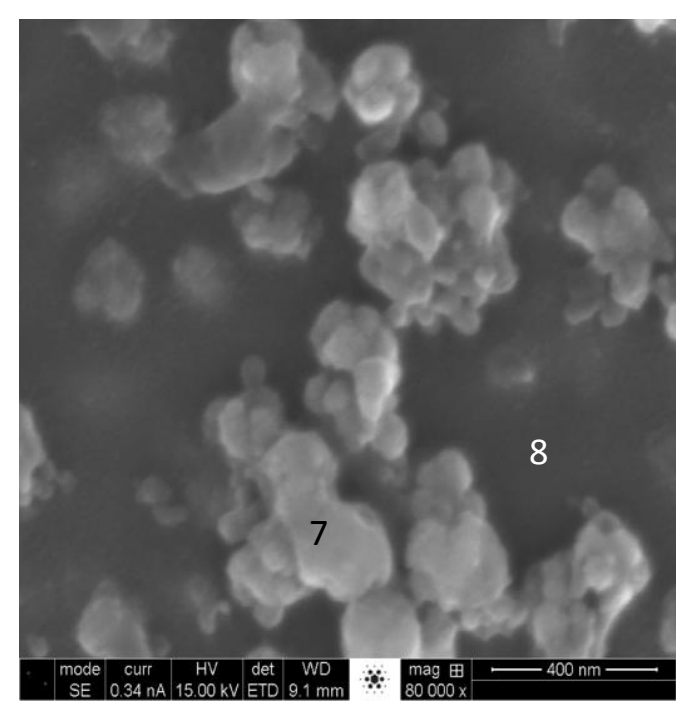

(j)

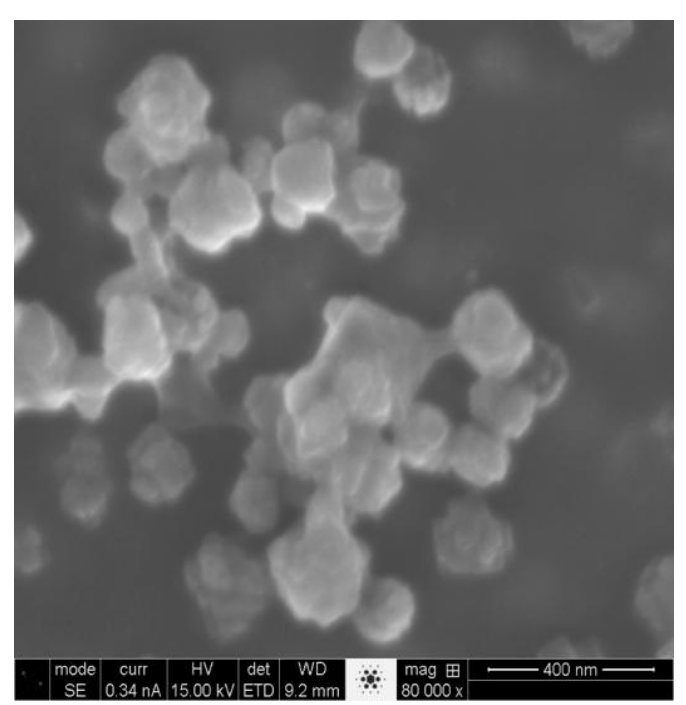

$(k)$

Fig. 25: Micrografias das superfícies dos materiais do grupo LSR, com adição de B, polidas e atacadas com HF6\%: (a) 60L25S15B, (d) e (f) 95(60L25S15B).5R, (h) e (j) 80(60L25S15B) 20R. Micrografias das superfícies dos materiais do grupo LSR, com adição de B, após imersão em água destilada a $90^{\circ} \mathrm{C}$ por 14 dias: (b) e (c) 60L25S15B, (e) e (g) 95(60L25S15B)·5R, (i) e (k) 80(60L25S15B)'20R.

As regiões numeradas na superfície dos materiais do grupo LSR e apresentadas nas Fig. 24 e 25 foram analisadas por EDS durante a obtenção das imagens por microscopia eletrônica de varredura. Os espectros obtidos são apresentados nas Fig. 26 (a) a 26 (h), seguindo a ordem numérica adotada nas micrografias.

Na Fig. 26 (a) observamos o espectro obtido na região numerada como 1 , formação esférica, na superfície do material 95(60L40S)·5R e na Fig. 26 (b) 0 espectro da região 2, matriz. Ambas as regiões são mostradas na Fig. 24 (d).

De acordo com os espectros, as duas regiões são constituídas por todos os elementos presentes na composição desse material sendo que, na região 2, o pico referente ao elemento $\mathrm{Al}$ é ligeiramente mais intenso quando comparado ao pico referente a esse elemento na região 1. 


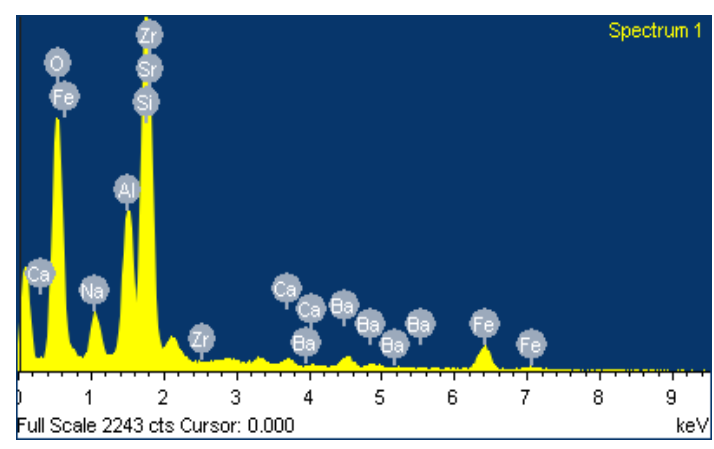

(a)

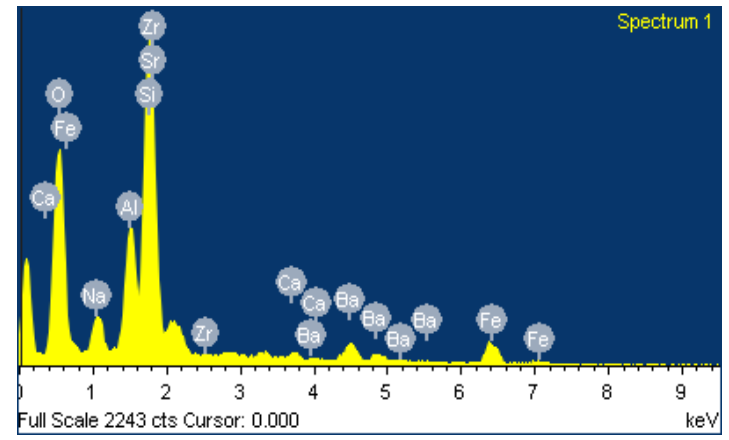

(c)

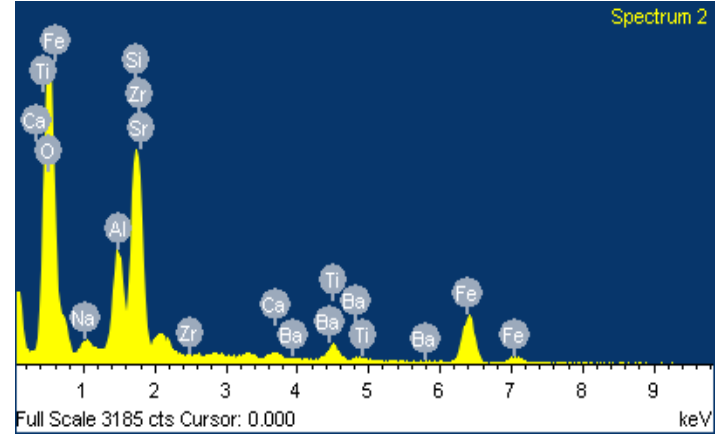

(e)

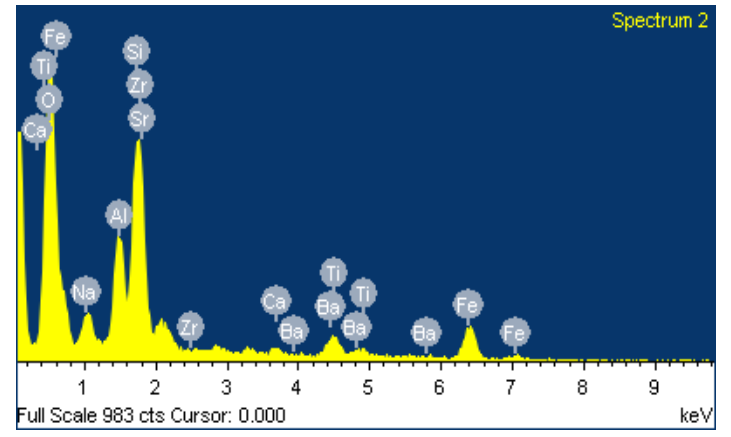

(g)

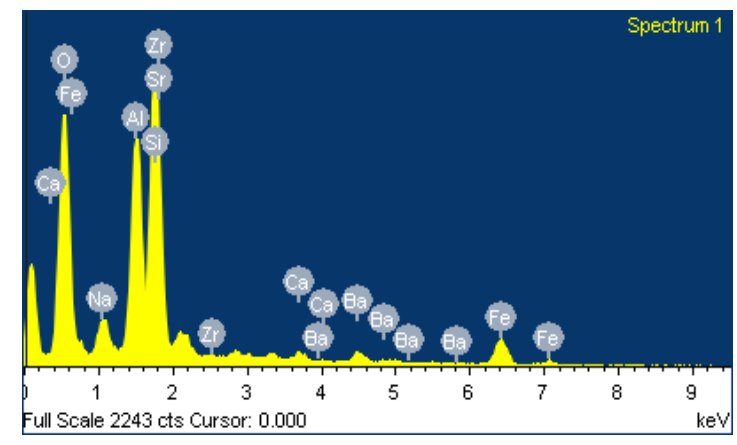

(b)

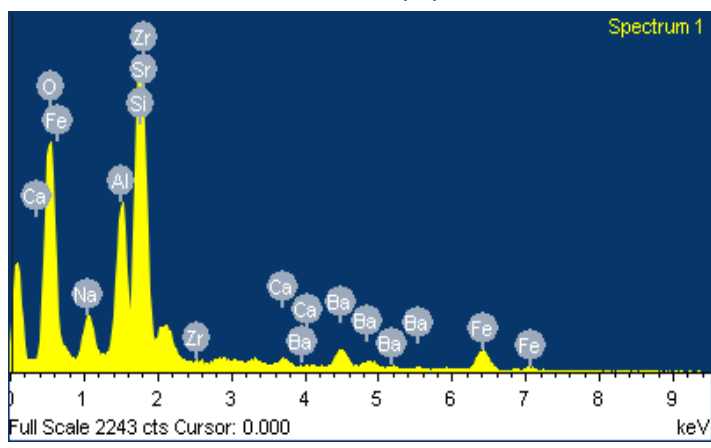

(d)

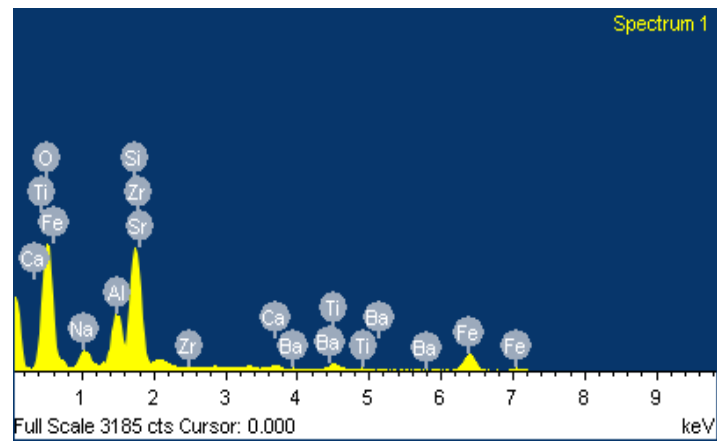

(f)

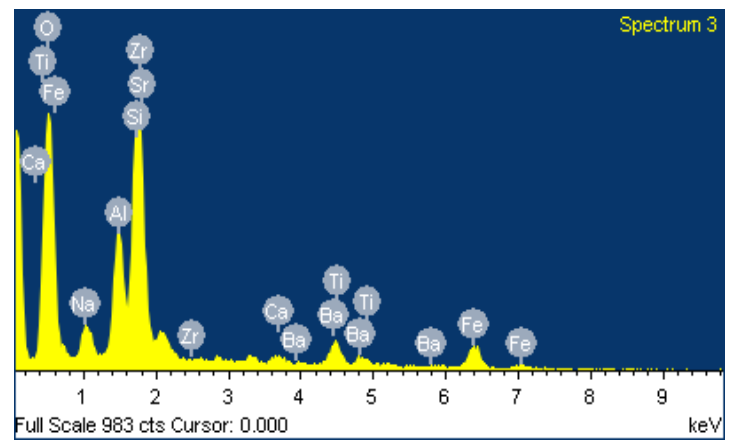

(h)

Figura 26: espectros obtidos por EDS das regiões numeradas de 1 a 8 nas micrografias de superfície dos materiais do grupo LSR. (a) e (b): regiões 1 e 2 do material 95(60L40S)·5R, respectivamente. (c) e (d): regiões 3 e 4 do material 80(60L40S) $20 \mathrm{R}$, respectivamente. (e) e (f): regiões 5 e 6 do material 95(60L25S15B)·5R, respectivamente. (g) e (h): regiões 7 e 8 do material 80(60L25S15B) $20 \mathrm{R}$, respectivamente. 
Nos espectros apresentados nas Fig. 26 (c) e (d) das regiões numeradas como 3, formação esférica, e 4, matriz, do material 80(60L40S)20R, Fig. 24 (g), observamos novamente a presença de todos os elementos constituintes desse material nas duas regiões.

Considerando os espectros das regiões marcadas como 5 , formações cúbicas, e 6, matriz, na superfície do material 95(60L25S15B) 5R, Fig. 25 (f), o mesmo verificado nas regiões analisadas anteriormente se repete, Fig. 26 (e) e (f), assim como nas regiões numeradas como 7 e 8 na superfície do material 80(60L25S15B).20R, Fig. 25 (j), de acordo com os espectros apresentados nas Fig. 26 (g) e (h).

As regiões numeradas nas microscopias dos materiais do grupo LSR foram analisadas por EDS também no modo quali-quantitativo e o teor dos elementos constituintes de cada fase foi estimado. Os resultados obtidos são apresentados na Tab. 5.

Tabela 5: Teor estimado de cada elemento presente nas regiões visualizadas nas superfícies dos materiais do grupo LSR, numeradas de 1 a 8, e mostradas nas

Fig. 17 (d) e (g), e 18 (f) e (j).

\begin{tabular}{c|ccccccccc}
\hline & \multicolumn{10}{|c}{ \% At. } \\
\hline 95(60L40S)·5R & $\mathbf{S i}$ & $\mathbf{A l}$ & $\mathbf{F e}$ & $\mathbf{N a}$ & $\mathbf{C a}$ & $\mathbf{Z r}$ & $\mathbf{B a}$ & $\mathbf{S r}$ & $\mathbf{T i}$ \\
Região 1 & 53,4 & 20,7 & 9,5 & 10,6 & 1,5 & 2,2 & 2,0 & - & - \\
Região 2 & 45,6 & 30,1 & 10,5 & 8,3 & 1,6 & 2,2 & 1,7 & - & - \\
80(60L40S)·20R & $\mathbf{S i}$ & $\mathbf{A l}$ & $\mathbf{F e}$ & $\mathbf{N a}$ & $\mathbf{C a}$ & $\mathbf{Z r}$ & $\mathbf{B a}$ & $\mathbf{S r}$ & $\mathbf{T i}$ \\
\hline Região 3 & 50,4 & 19,1 & 9,8 & 10,3 & 1,5 & 3,7 & 4,0 & 1,4 & - \\
Região 4 & 47,9 & 22,3 & 8,9 & 10,1 & 1,5 & 4,0 & 3,9 & 1,5 & - \\
\hline 95(60L25S15B)·5R & $\mathbf{S i}$ & $\mathbf{A l}$ & $\mathbf{F e}$ & $\mathbf{N a}$ & $\mathbf{C a}$ & $\mathbf{Z r}$ & $\mathbf{B a}$ & $\mathbf{S r}$ & $\mathbf{T i}$ \\
\hline Região 5 & 41,7 & 19,8 & 24,6 & 4,2 & 1,8 & 2,3 & 0,7 & 1,0 & 3,8 \\
Região 6 & 45,1 & 18,9 & 17,9 & 10,7 & 1,6 & 1,7 & 0,8 & 0,5 & 2,8 \\
$\mathbf{8 0 ( 6 0 L 2 5 S 1 5 B ) \cdot 2 0 R}$ & $\mathbf{S i}$ & $\mathbf{A l}$ & $\mathbf{F e}$ & $\mathbf{N a}$ & $\mathbf{C a}$ & $\mathbf{Z r}$ & $\mathbf{B a}$ & $\mathbf{S r}$ & $\mathbf{T i}$ \\
Região 7 & 37,5 & 20,0 & 16,8 & 10,6 & 1,8 & 3,4 & 3,1 & 4,2 & 2,6 \\
Região 8 & 42,5 & 21,4 & 11,1 & 9,9 & 2,0 & 3,0 & 4,3 & 3,9 & 1,9 \\
\hline
\end{tabular}


Nas Fig. 27 (a) a 27 (i) são apresentadas as micrografias obtidas das superfícies internas dos materiais do grupo LSR após um corte transversal. As imagens mostradas nas Fig. 27 (a), (b) e (c) são dos materiais 60L40S, 95(60L40S)·5R e 80(60L40S) 20R, respectivamente. Observa-se a presença de formações esféricas nas superfícies internas desses materiais, assim como foram observadas nas superfícies externas dos mesmos, Fig. 24 (a), (d) e (g). Como mencionado anteriormente, essas formações foram atribuídas a uma separação de fase e, de acordo com as micrografias apresentadas, essa separação ocorre em todo o volume do material.

Nas Fig. 27 (d), (e) e (f) são apresentadas as imagens das superfícies de corte transversal (região interna) dos materiais 60L25S15B, 95(60L25S15B)·5R e 80(60L25S15B) 20R, respectivamente. Foi observado que, assim como ocorre na superfície externa desses materiais, Fig. 25 (a), (d) e (h), há a presença de pequenas estruturas em toda a superfície interna dos três materiais investigados, porém no material $80(60 \mathrm{~L} 25 \mathrm{~S} 15 \mathrm{~B}) \cdot 20 \mathrm{R}$ observa-se também a presença de estruturas maiores, Fig. 27(g), (h) e (i), que foram analisadas por EDS para a determinação dos elementos constituintes.

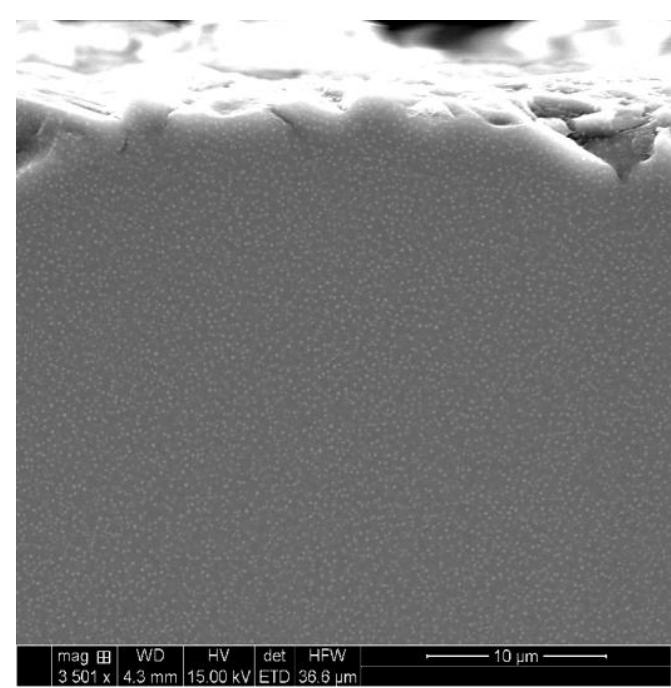

(a)

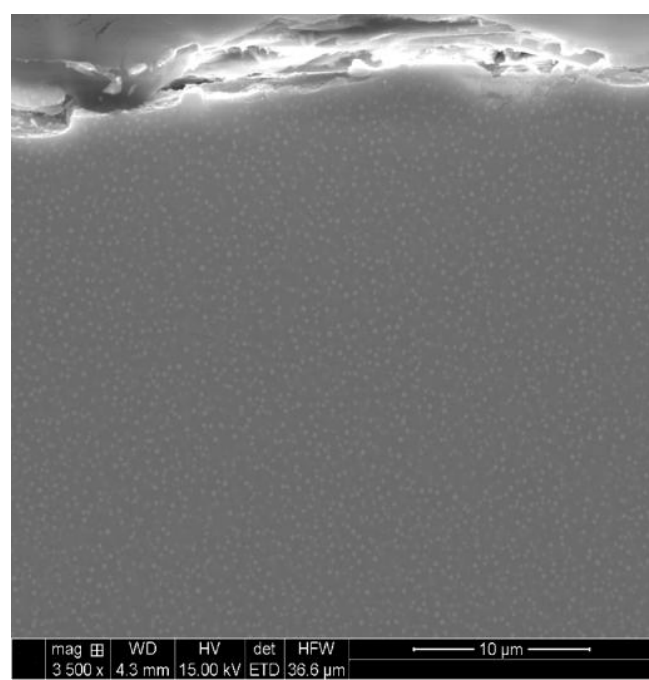

(b) 


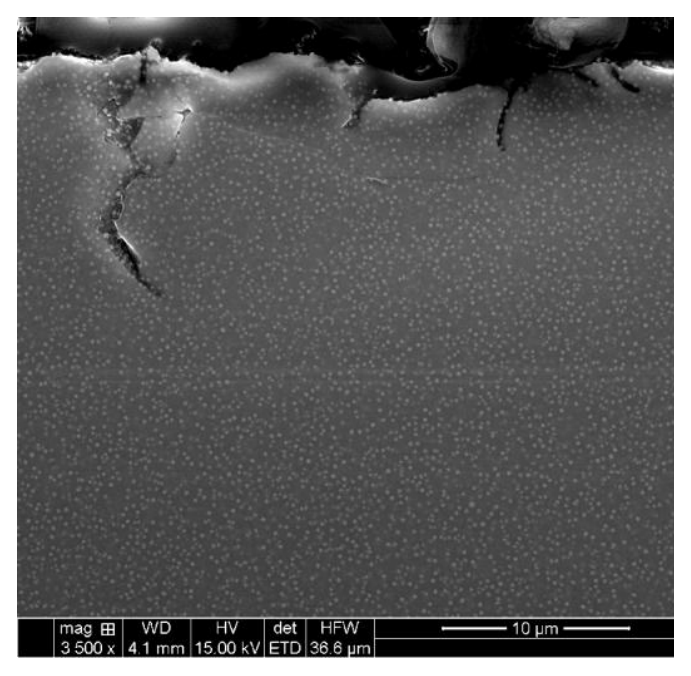

(c)

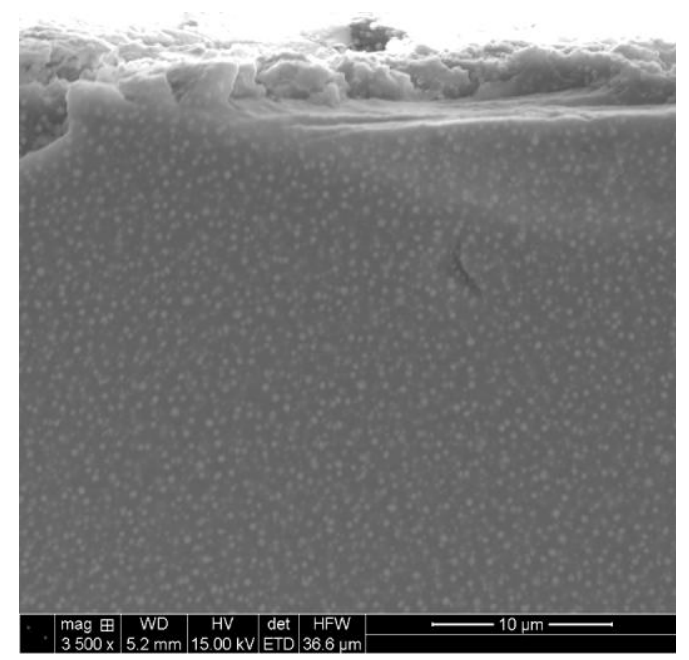

(e)

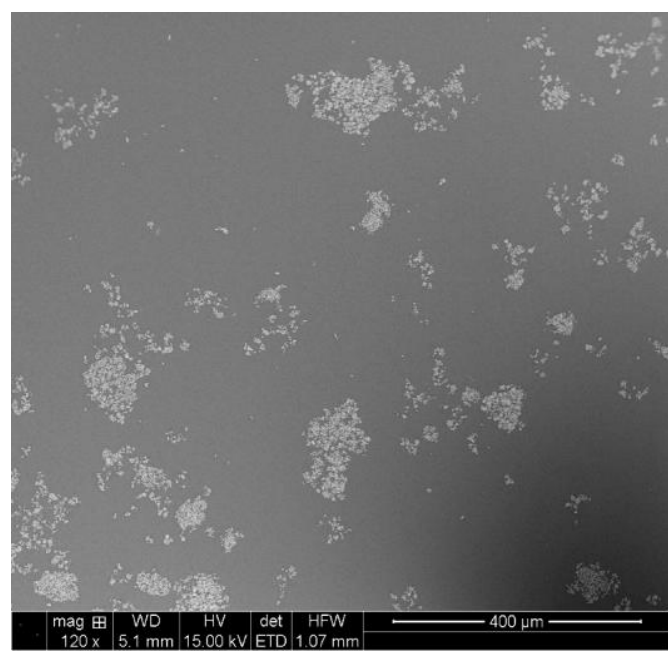

(g)

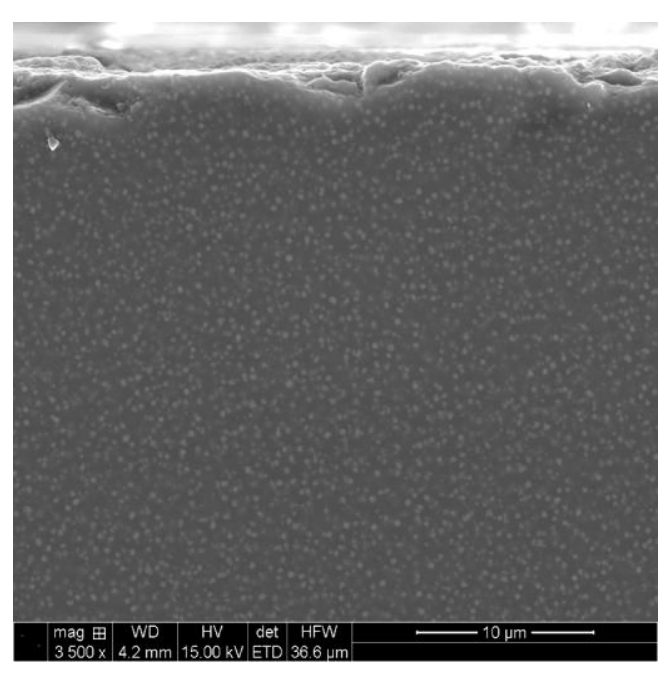

(d)

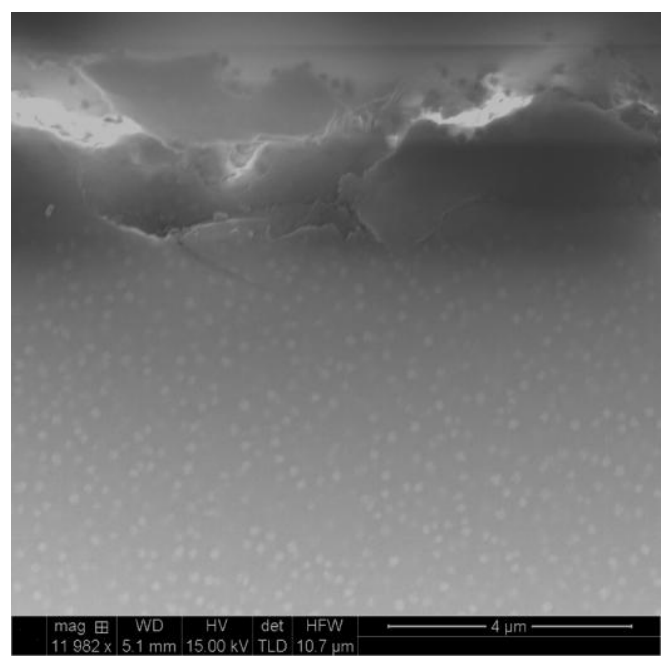

(f)

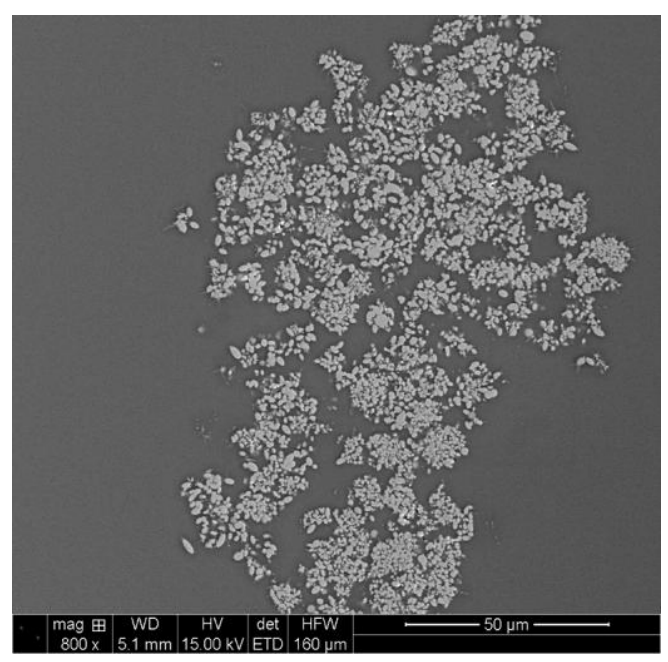

(h) 


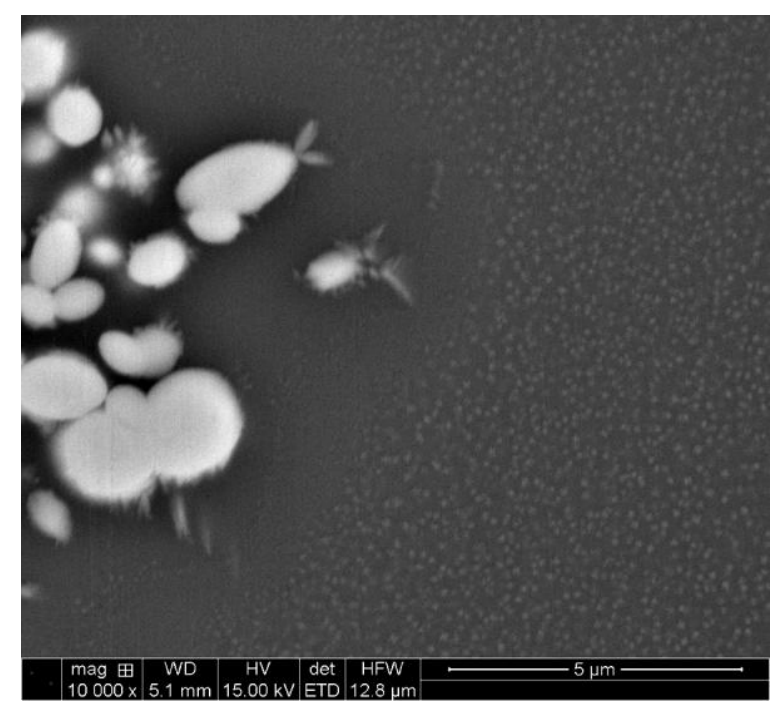

(i)

Fig. 27: Micrografias das superfícies internas dos materiais do grupo LSR, polidas e atacadas com HF6\%, com adição de B: (a) 60L40S, (b) 95(60L40S)·5R, (c) 80(60L40S)·20R, e sem adição de B: (d) 60L25S15B, (e) 95(60L25S15B)·5R, (f), (g), (h) e (i) $80(60 \mathrm{~L} 25 \mathrm{~S} 15 \mathrm{~B}) \cdot 20 \mathrm{R}$.

De acordo com o resultado da análise de EDS realizada nas partículas grandes encontradas no volume do material $80(60 \mathrm{~L} 25 \mathrm{~S} 15 \mathrm{~B}) \cdot 20 \mathrm{R}$, estas são constituídas principalmente de $\mathrm{Zr}$ que provavelmente precipitou durante 0 resfriamento do material ou que não se dissolveu durante o processo de aquecimento para a fusão do material. O espectro obtido e o teor estimado de cada elemento dessas partículas são apresentados na Fig. 28 e na Tab. 6.

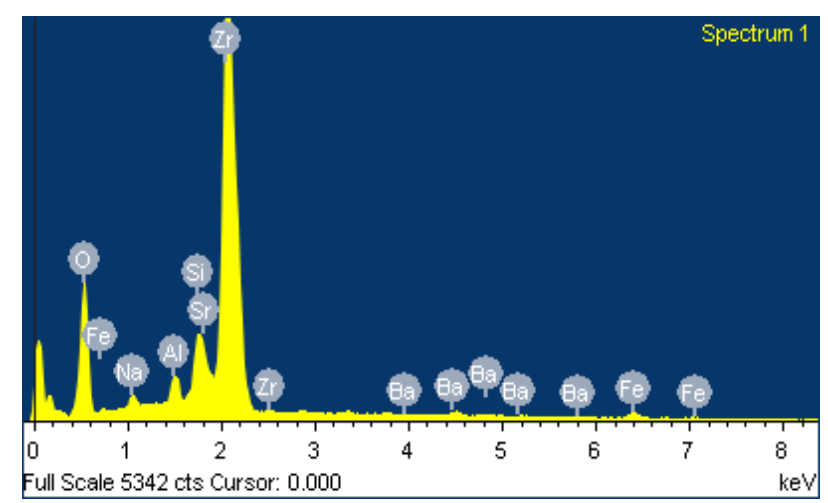

Figura 28: espectro obtido por meio da análise de EDS realizada nas partículas grandes encontradas no volume do material 80(60L25S15B)·20R, Fig. 27 (i). 
Tabela 6: Elementos constituintes das partículas encontradas no volume do material 80(60L25S15B)20R.

\begin{tabular}{c|ccccccc}
\hline & $\mathbf{Z r}$ & $\mathbf{S i}$ & $\mathbf{A l}$ & $\mathbf{F e}$ & $\mathbf{N a}$ & $\mathbf{S r}$ & $\mathbf{B a}$ \\
\hline \% At. & 73,8 & 9,5 & 5,8 & 4,1 & 3,8 & 1,8 & 1,2 \\
\hline
\end{tabular}




\subsection{Adição Individual de $\mathrm{BaO}, \mathrm{SrO}_{2}$ e $\mathrm{ZrO}_{2}$ no Material 60L40S (Grupo LSO)}

A Tab. 7 apresenta os elementos constituintes dos materiais do quinto grupo, grupo LSO. Neste grupo, os óxidos de $\mathrm{Ba}, \mathrm{Sr}$ e $\mathrm{Zr}$ foram adicionados ao material 60L40S individualmente e o efeito discreto dessa adição de nas propriedades térmicas e estruturais desse material foi investigado.

A produção de materiais com adição maior que 8,6\% em massa de $\mathrm{ZrO}_{2}$ foi impossibilitada devido a alta temperatura de fusão necessária para a produção do mesmo.

TABELA 7: Elementos constituintes dos materiais do grupo LSO.

\begin{tabular}{|c|c|c|c|c|c|c|c|c|}
\hline & \multicolumn{8}{|c|}{$\%$ em Massa } \\
\hline & $\mathrm{SiO}_{2}$ & $\mathrm{Al}_{2} \mathrm{O}_{3}$ & $\mathrm{Fe}_{2} \mathrm{O}_{3}$ & $\mathrm{Na}_{2} \mathrm{O}$ & $\mathrm{BaO}$ & SrO & $\mathrm{ZrO}_{2}$ & Outros \\
\hline 60L40S & 52,9 & 18,7 & 14,9 & 7,6 & - & - & - & 5,9 \\
\hline $95(60 \mathrm{~L} 40 \mathrm{~S}) \cdot 5 \mathrm{Ba}$ & 46,2 & 20,5 & 16,6 & 3,8 & 9,0 & - & - & 3,9 \\
\hline $90(60 \mathrm{~L} 40 \mathrm{~S}) \cdot 10 \mathrm{Ba}$ & 46,6 & 18,4 & 13,3 & 4,3 & 13,8 & - & - & 3,6 \\
\hline $85(60 \mathrm{~L} 40 \mathrm{~S}) \cdot 15 \mathrm{Ba}$ & 43,6 & 18,6 & 12,4 & 3,9 & 17,8 & - & - & 3,7 \\
\hline $80(60 \mathrm{~L} 40 \mathrm{~S}) \cdot 20 \mathrm{Ba}$ & 37,5 & 16,5 & 13,8 & 2,7 & 24,3 & - & - & 5,2 \\
\hline $95(60 \mathrm{~L} 40 \mathrm{~S}) \cdot 5 \mathrm{Sr}$ & 53,5 & 18,1 & 13,4 & 4,5 & - & 5,3 & - & 5,2 \\
\hline $90(60 \mathrm{~L} 40 \mathrm{~S}) \cdot 10 \mathrm{Sr}$ & 53,5 & 16,5 & 12,1 & 3,9 & - & 9,1 & - & 4,9 \\
\hline $85(60 \mathrm{~L} 40 \mathrm{~S}) \cdot 15 \mathrm{Sr}$ & 52,1 & 15,7 & 11,1 & 3,4 & - & 13,1 & - & 4,6 \\
\hline $80(60 \mathrm{~L} 40 \mathrm{~S}) \cdot 20 \mathrm{Sr}$ & 50,8 & 17,4 & 9,4 & 3,2 & - & 15,3 & - & 3,9 \\
\hline $95(60 L 40 S) \cdot 5 Z r$ & 57,3 & 15,1 & 12,6 & 4,5 & - & - & 5,7 & 4,8 \\
\hline $90(60 \mathrm{~L} 40 \mathrm{~S}) \cdot 10 \mathrm{Zr}$ & 52,8 & 15,5 & 13,8 & 4,7 & - & - & 8,6 & 4,6 \\
\hline
\end{tabular}

Outros*: $\mathrm{CaO}, \mathrm{TiO}_{2}, \mathrm{~K}_{2} \mathrm{O}, \mathrm{Nb}_{2} \mathrm{O}_{5}, \mathrm{MnO}$.

Nos difratogramas de raios $X$ apresentados nas FIG. 29 (a) e (b), observamos a presença das fases cristalinas $\mathrm{Fe}_{2} \mathrm{O}_{3}$ e $\mathrm{Fe}_{3} \mathrm{O}_{4}$ nas amostras adicionadas de $\mathrm{BaO}$ e $\mathrm{SrO}$ individualmente, sendo que, com o aumento do teor desses elementos a fase remanescente é a fase $\mathrm{Fe}_{3} \mathrm{O}_{4}$. Adições acima de $15 \%$ em massa de cada elemento contribuem para a formação de uma estrutura amorfa. 


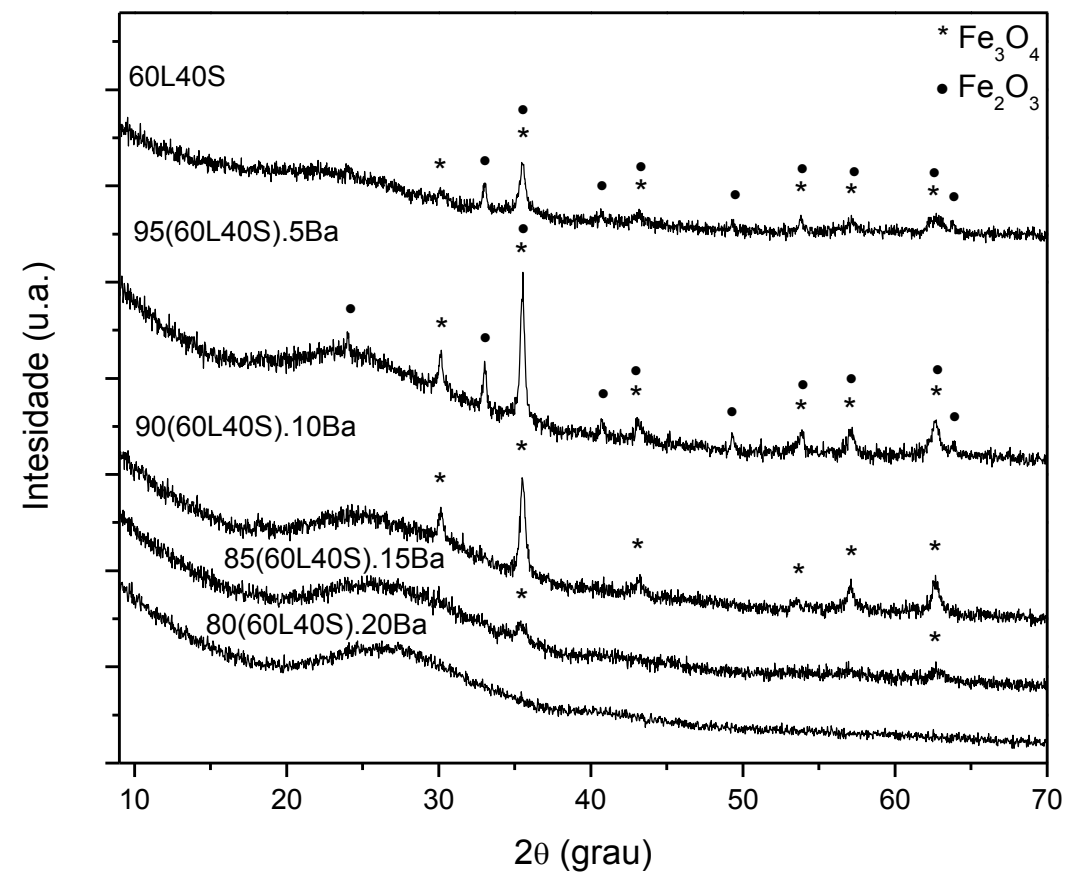

(a)

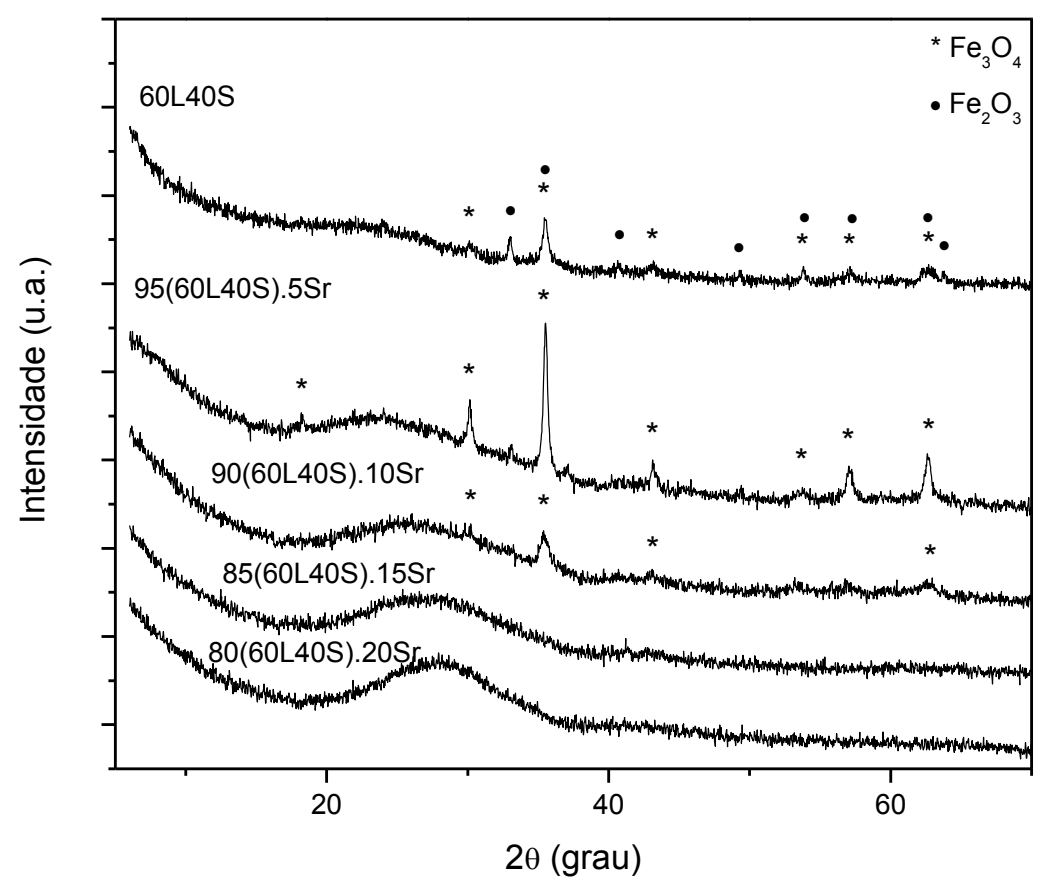

(b) 


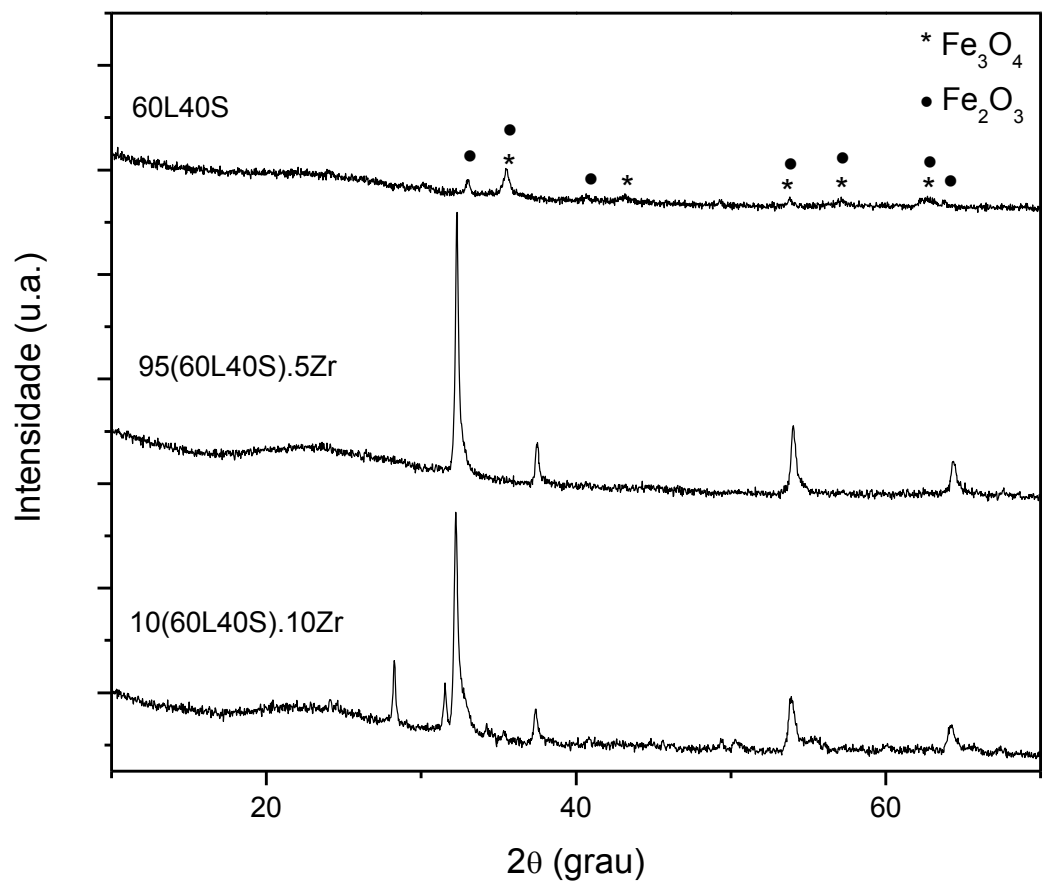

(c)

FIGURA 29: Difratogramas de raios $X$ da amostra 60L40S com adição individual de $\mathrm{BaO}, \mathrm{SrO}, \mathrm{ZrO}_{2}$ na sua composição, grupo LSO.

Na Fig. 29 (c) observamos que, embora haja halos que indicam a presença de uma fase amorfa residual, a adição individual de óxido de zircônio à composição base contribui para a formação de uma estrutura cristalina. Não foi possível identificar as fases cristalinas referentes aos picos observados nos difratogramas.

Os resultados das análises térmicas realizadas nos materiais do grupo LSO são apresentados nas Fig. 30 (a), (b) e (c).

É possível observar picos exotérmicos que indicam a cristalização do material a partir das amostras 90(60L40S) 10Ba, (Fig. 30 (a)), e 95(60L40S) 5Sr, (Fig. 30 (b)). O início da cristalização tende a ocorrer em temperaturas cada vez mais baixas, de acordo com o aumento do teor de cada óxido adicionado.

A temperatura de $1300^{\circ} \mathrm{C}$ não foi suficiente para a observação de picos endotérmicos que indicassem a fusão das fases cristalinas formadas durante a medida.

Observa-se também uma variação nas curvas apresentadas nas Fig. 30 (a) e (b) em torno de $812^{\circ} \mathrm{C}, 800^{\circ} \mathrm{C}, 675^{\circ} \mathrm{C}, 660^{\circ} \mathrm{C}$ e $650^{\circ} \mathrm{C}$. Essas variações foram relacionadas a $\mathrm{T}_{\mathrm{g}}$ de cada material. 


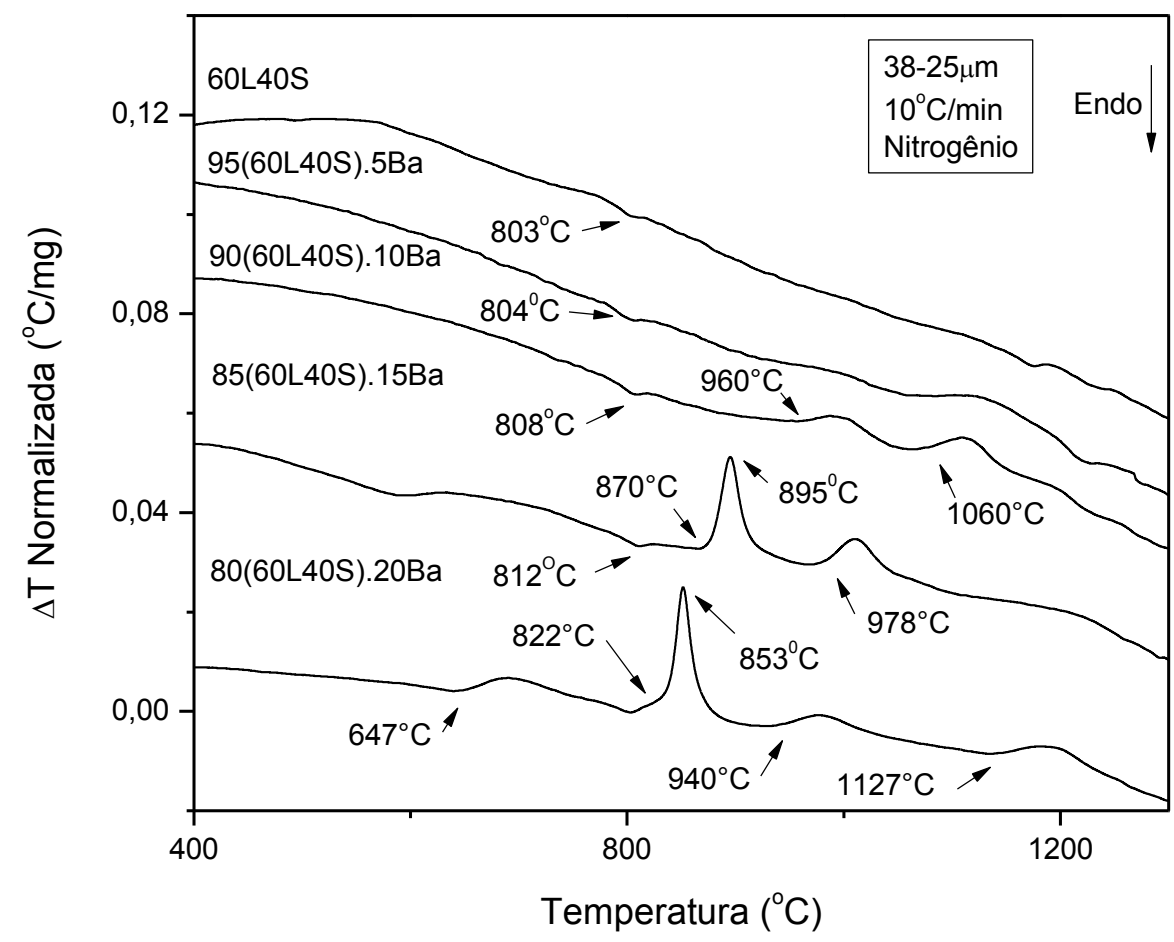

(a)

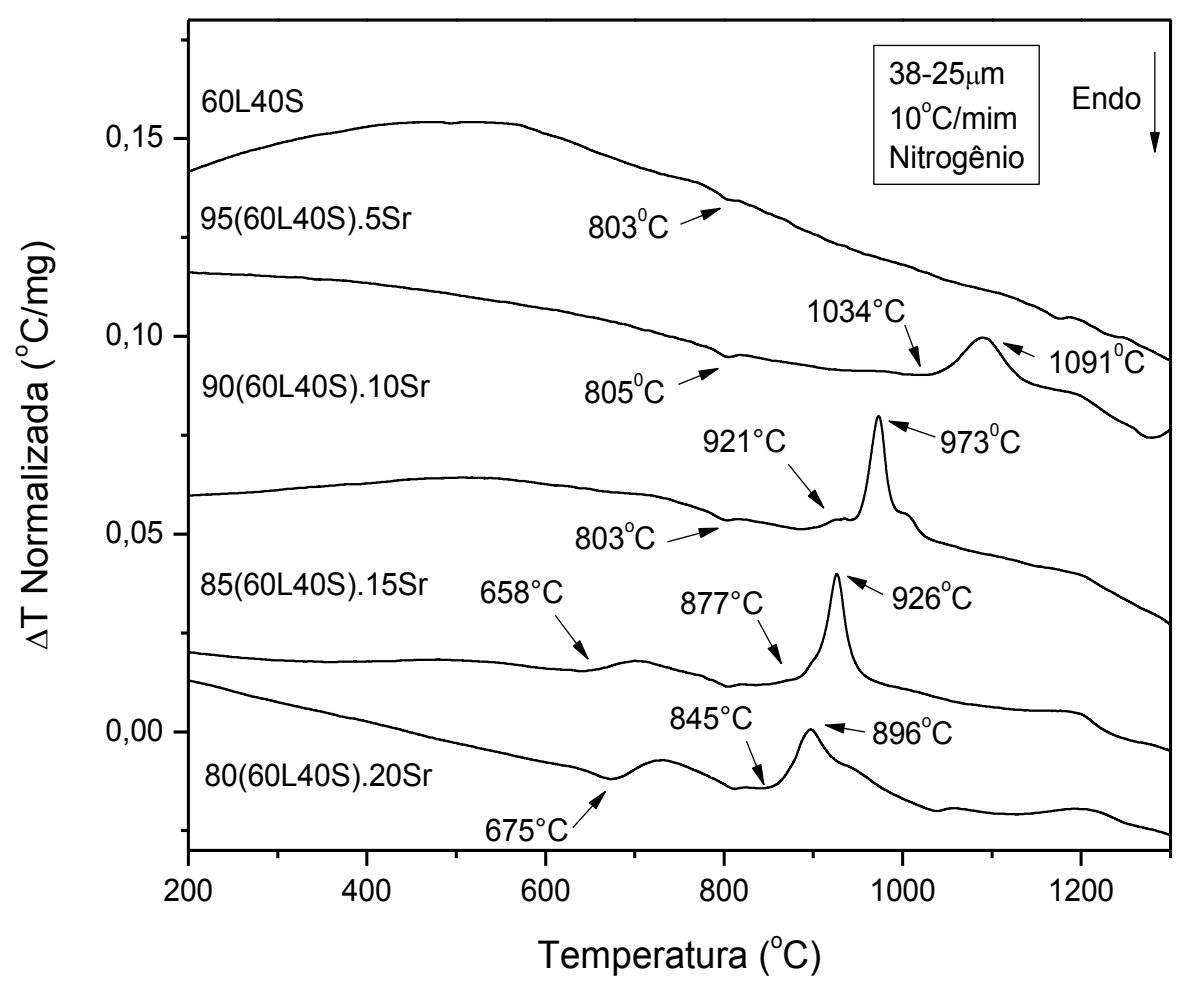

(b) 


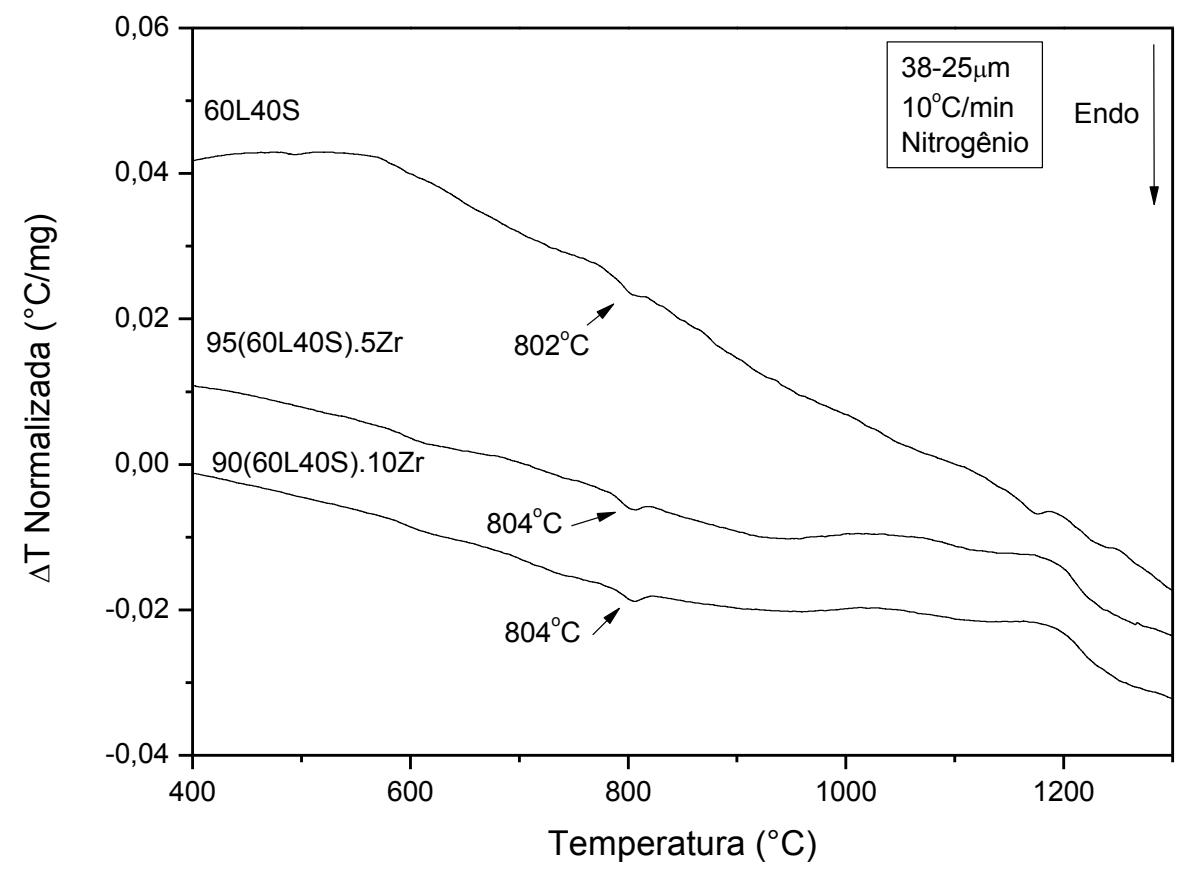

(c)

FIGURA 30: Análise térmica dos materiais do grupo LSO.

Na Figura 30 (c) observamos que, para as amostras com adição de $\mathrm{ZrO}_{2}$, não foi possível obter informações que digam respeito à cristalização ou fusão de alguma fase cristalina formada no material durante a análise, porém observa-se uma variação em torno de $800^{\circ} \mathrm{C}$ nas curvas apresentadas. Essas variações podem estar relacionadas à $T_{g}$ da fase amorfa residual presente nesses materiais.

Novas análises térmicas foram realizadas nas amostras 80(60L40S) 20Ba e 85(60L40S) $15 \mathrm{Sr}$ com o intuito de obter mais informações sobre o processo de cristalização desses materiais.

Foram escolhidas essas amostras dentre as opções de materiais produzidos porque os picos de cristalização ocorridos e mostrados nas Fig. 30 (a) e (b) são mais proeminentes em relação aos picos dos demais materiais e, para esse tipo de estudo, é necessário que o pico de cristalização da amostra durante a análise térmica seja acentuado. Além disso, sabe-se que a condição ideal para se obter informações válidas sobre o processo de cristalização de um material, tais como, faixa de temperatura de nucleação, temperatura de máxima nucleação, energia de ativação para a cristalização, fração de cristalização, determinação do tipo preferencial de cristalização (superficial ou volumétrica), por meio de análises térmicas diferencial é que o material possua um processo fácil e simples de 
cristalização, ou seja, é necessário que o material se cristalize facilmente nas condições fornecidas durante a análise de DTA, que seja possível detectar com facilidade essa cristalização na curva resultante e que, preferencialmente, seja cristalizada apenas uma única fase.

Nas curvas de DTA das amostras selecionadas, 80(60L40S) 20Ba e 85(60L40S) 15Sr, Fig. 30 (a) e (b), observamos que há indícios de mais de uma fase sendo cristalizada durante a análise. No entanto, os picos relacionados a essas cristalizações são isolados e há uma diferença considerável entre a área dos mesmos. Isso indica que há uma fase se cristalizando preferencialmente em cada um desses materiais e, como os picos são separados, a cristalização de cada fase nas condições aplicadas tende a ser um processo menos dependente das outras cristalizações.

Essas características apresentadas pelos materiais $80(60 \mathrm{~L} 40 \mathrm{~S}) \cdot 20 \mathrm{Ba}$ e 85(60L40S) 15Sr durante a análise térmica, asseguram que, mesmo não tendo a condição ideal, é possível estimar de forma satisfatória algumas informações sobre o processo de cristalização desses materiais por meio da análise térmica diferencial.

$\mathrm{Na}$ Fig. 31 (a) são apresentados os resultados das análises de DTA realizadas no material $80(60 \mathrm{~L} 40 \mathrm{~S}) \cdot 20 \mathrm{Ba}$ com diferentes granulometrias. Observa-se que, mesmo com a variação na granulometria das amostras, o pico de cristalização principal ocorre na mesma faixa de temperatura. Isso indica que o mecanismo de cristalização que ocorre nessa amostra em relação a essa fase é preferencialmente volumétrico.

Uma amostra do material 80(60L40S) $20 \mathrm{Ba}$, com granulometria entre 38 e 25 $\mu \mathrm{m}$, foi tratada termicamente utilizando a mesma taxa de aquecimento utilizada no DTA $\left(30^{\circ} \mathrm{C} / \mathrm{min}\right)$, até as temperaturas de $800^{\circ} \mathrm{C}, 930^{\circ} \mathrm{C}$ e $1050^{\circ} \mathrm{C}$ e, após esses tratamentos, foi analisada por difração de raios $X$ para verificar se as variações observadas nessas curvas, principalmente até $800^{\circ} \mathrm{C}$ e $1050^{\circ} \mathrm{C}$, são referentes a formação de uma fase cristalina e, se sim, as quais fases são referentes. Os resultados obtidos são apresentados na Fig. 31 (b).

Observa-se que a variação na curva de DTA existente após a temperatura de $800^{\circ} \mathrm{C}$, Fig. 31 (b), é referente ao processo de cristalização da fase $\beta$-hexacelsiana e essa fase se cristaliza durante a análise de DTA independente da granulometria adotada. Após $930^{\circ} \mathrm{C}$ observa-se que o pico existente é referente a cristalização da 
fase $\mathrm{K}_{6} \mathrm{Ba}_{4} \mathrm{Al}_{2} \mathrm{Si}_{3} \mathrm{O}_{8}$, e da mudança da fase $\beta$-hexacelsiana para as fases hexacelsiana e celsiana.

Essa amostra também foi tratada isotermicamente a $850^{\circ} \mathrm{C}$ por 150 horas. Observa-se no resultado obtido e apresentado na Fig. 31 (c) que, após um tratamento isotérmico longo, a fase remanescente é a fase celsiana.

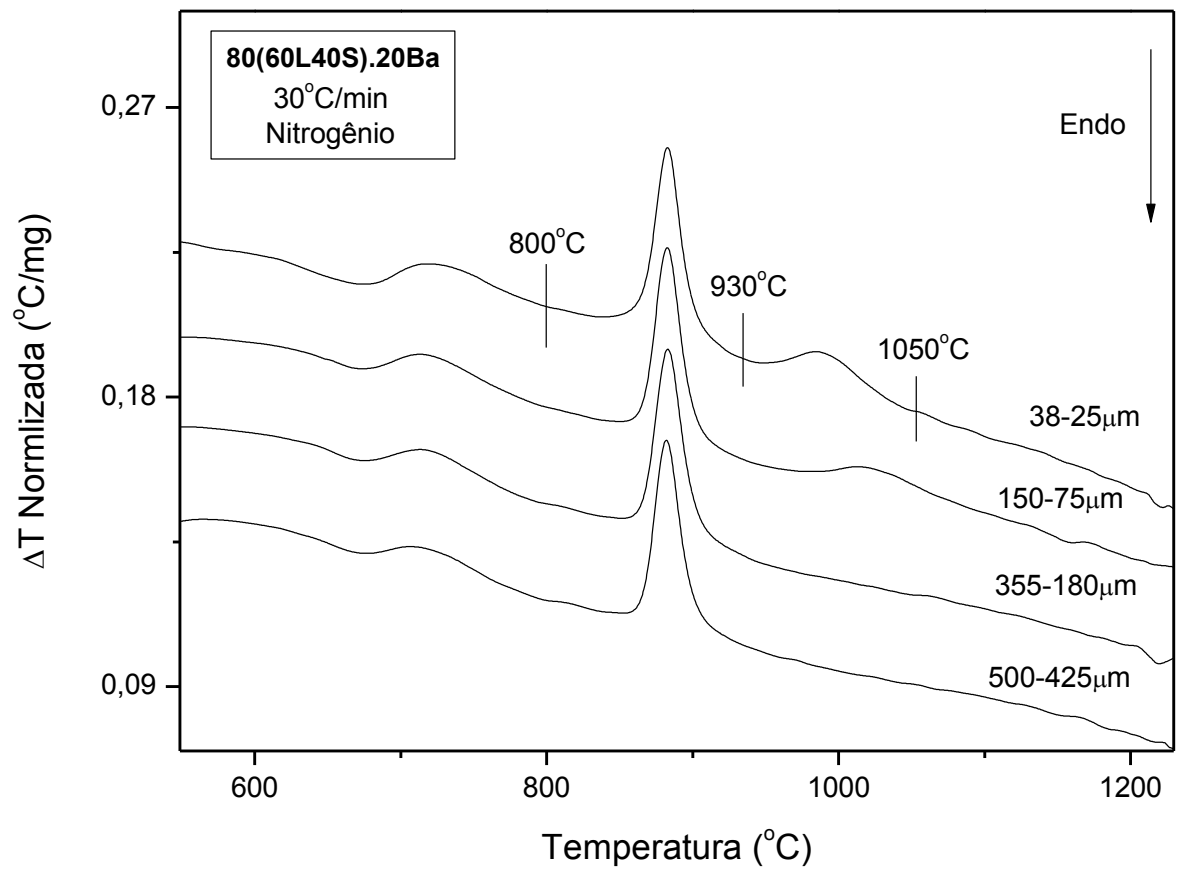

(a)

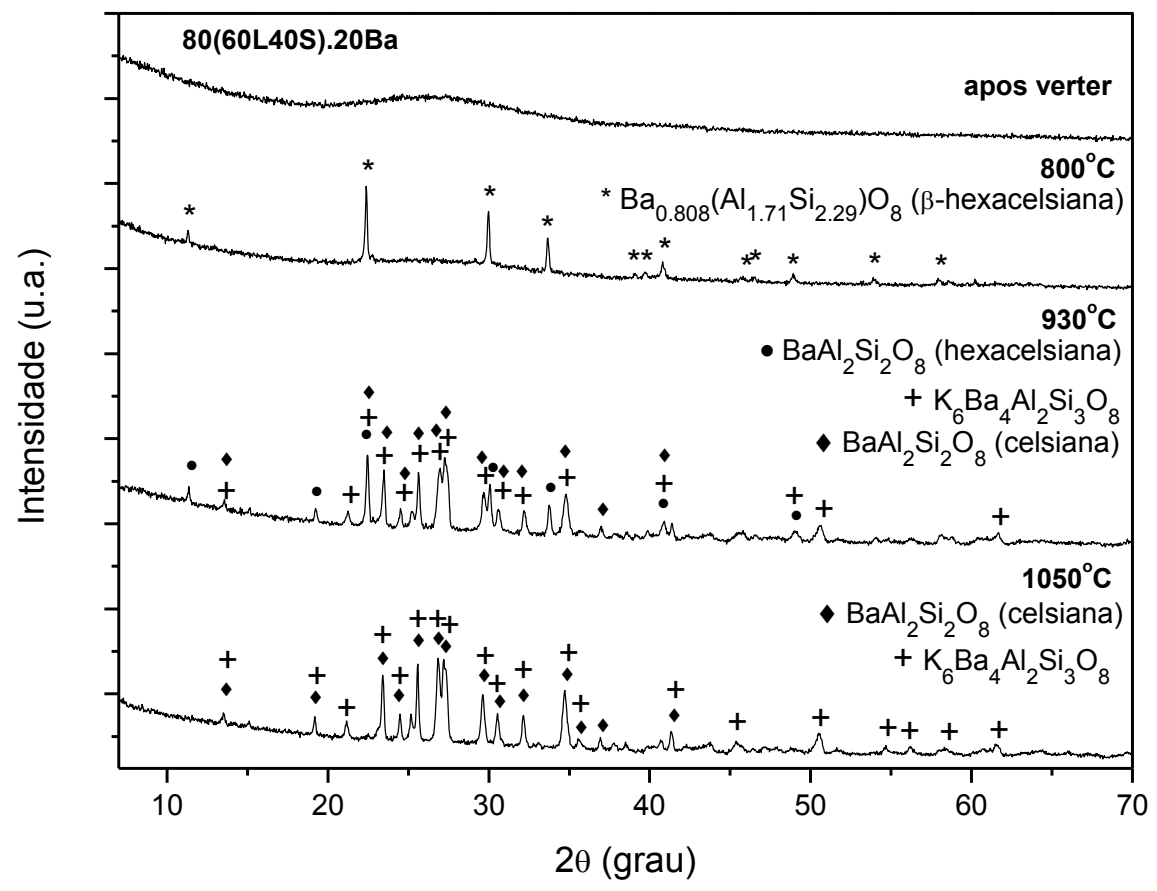

(b) 


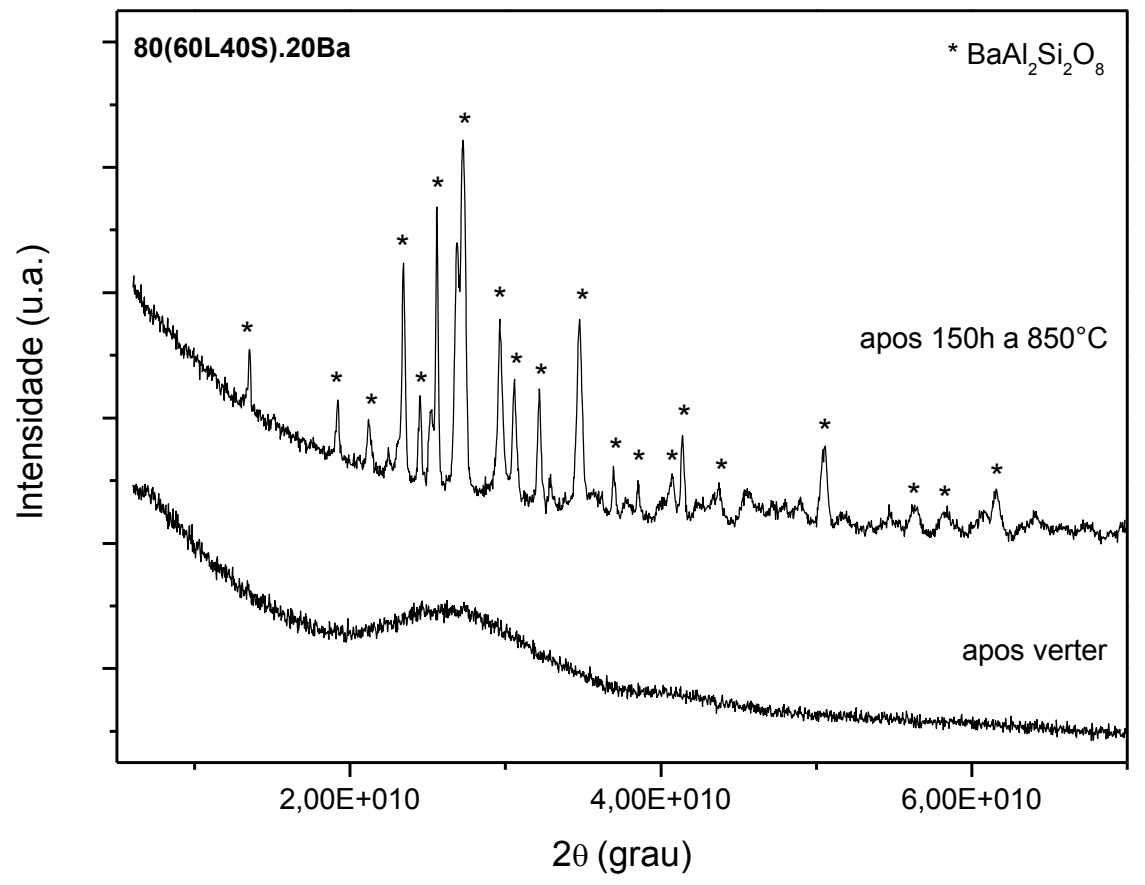

(C)

Figura 31: Análise térmica diferencial do material 80(60L40S)·20Ba com diferentes granulometrias (a), difratometria de raios $X$ da amostra $80(60 \mathrm{~L} 40 \mathrm{~S}) \cdot 20 \mathrm{Ba}$ após tratamento térmico realizado sob as mesmas condições de análise do DTA (b),

(c) difratometria de raios X da amostra 80(60L40S) 20Ba após tratamento isotérmico.

Foram realizadas análises térmicas diferenciais na amostra 85(60L40S) 15Sr também com diferentes granulometrias. Nos resultados apresentados na Fig. 32 (a) podemos observar que, neste caso, a granulometria interfere no processo de cristalização desse material, pois além de deslocar o pico de cristalização para temperaturas mais altas, separa em dois o pico original. Isso indica a formação de mais de uma fase cristalina e indica ainda que essa cristalização pode apresentar uma característica preferencialmente superficial.

Novas análises térmicas foram realizadas nessa amostra mantendo a granulometria entre 38 e $25 \mu \mathrm{m}$ e variando a taxa de aquecimento. Considerando os resultados obtidos e apresentados na Fig. 32 (b) observa-se um ligeiro deslocamento do pico de cristalização para temperaturas mais altas. Além disso, observamos também que, para este caso, não há a separação do pico principal em dois. Logo, considerando as condições aplicadas nessas análises, a granulometria 
parece ser o parâmetro principal a influenciar o mecanismo de cristalização desse material.

Tratamentos térmicos dinâmicos com taxa de aquecimento de $10^{\circ} \mathrm{C} / \mathrm{min}$ foram realizados no material $85(60 \mathrm{~L} 40 \mathrm{~S}) \cdot 15 \mathrm{Sr}$, com granulometria entre 38 e $25 \mu \mathrm{m}$, até as temperaturas $790^{\circ} \mathrm{C}, 950^{\circ} \mathrm{C}$ e $1220^{\circ} \mathrm{C}$, para avaliar as variações observadas nas curvas obtidas por meio da análise térmica desse material. Após os tratamentos, a amostra foi analisada por difração de raios X. Os resultados são apresentados na Fig. 32 (c).

Observamos na Fig. 32 (c) que a variação após a temperatura de $790^{\circ} \mathrm{C}$ observada na curva de DTA desse material não está relacionada a formação de uma fase cristalina. No entanto, após o tratamento térmico até as temperaturas de $950^{\circ} \mathrm{C}$ e $1220^{\circ} \mathrm{C}$, identificamos nos difratogramas as fases $\mathrm{NaAlSi}_{3} \mathrm{O}_{8}$ e $\mathrm{SrNaAl}_{2} \mathrm{Si}_{3} \mathrm{O}_{8}$, respectivamente.

A amostra $85(60 \mathrm{~L} 40 \mathrm{~S}) \cdot 15 \mathrm{Sr}$ foi também tratada isotermicamente a $950^{\circ} \mathrm{C}$ por 150 horas e analisada por difração de raios X. De acordo com o resultado obtido e apresentado na Fig. 32 (c), longos tratamentos isotérmicos promovem a formação apenas da fase cristalina $\mathrm{NaAlSi}_{3} \mathrm{O}_{8}$.

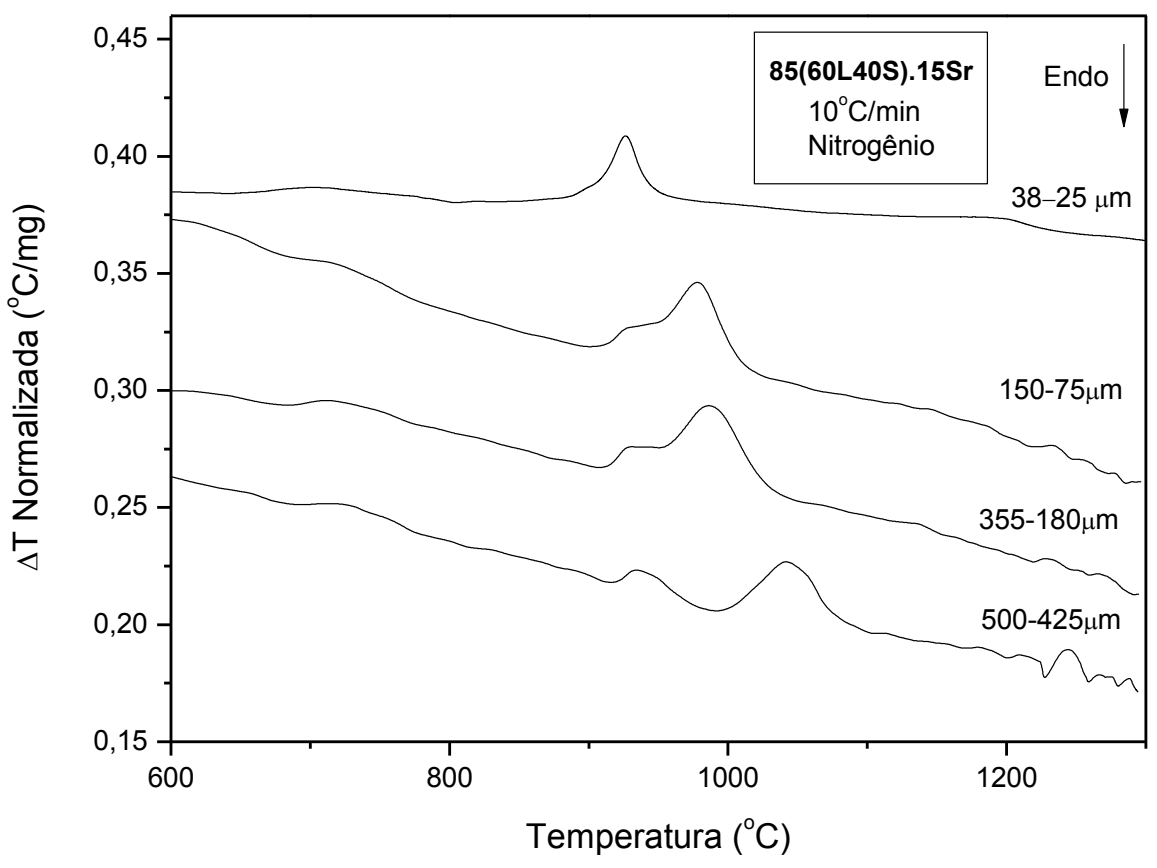

(a) 


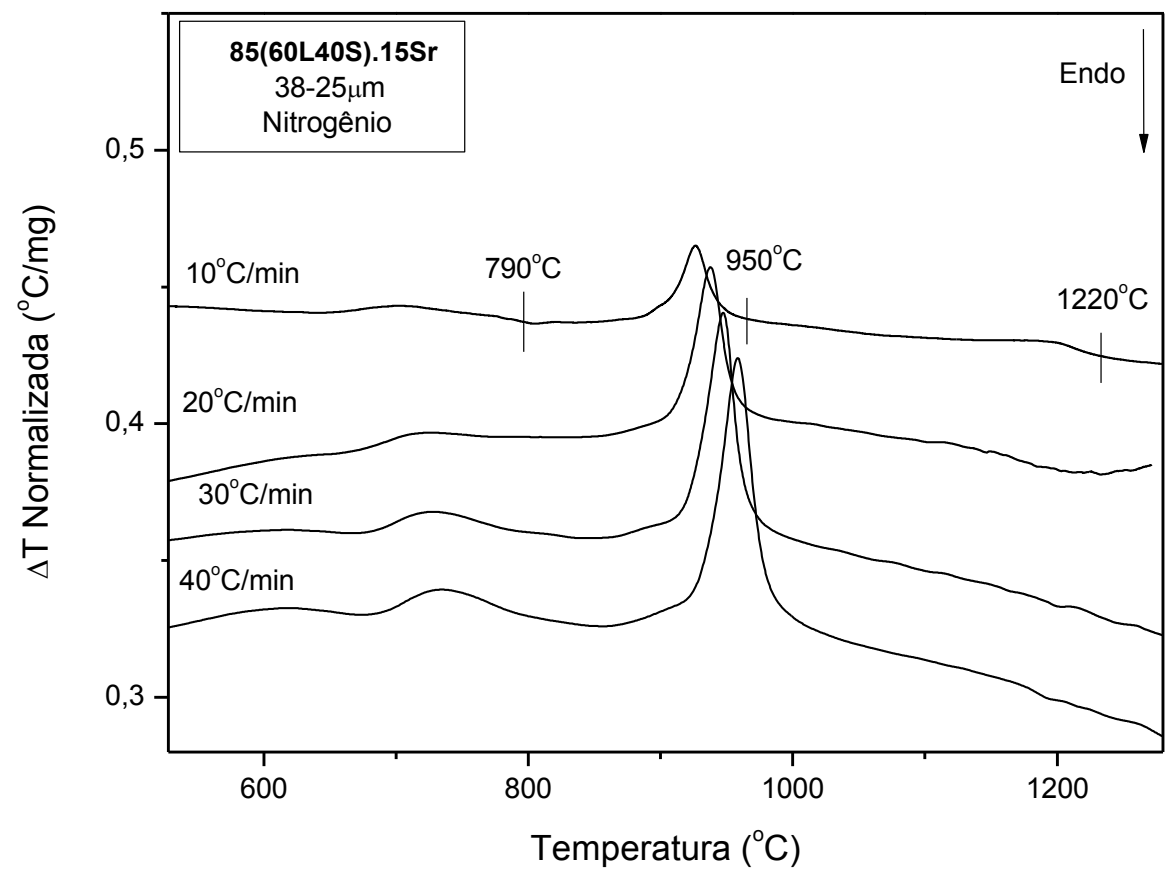

(b)

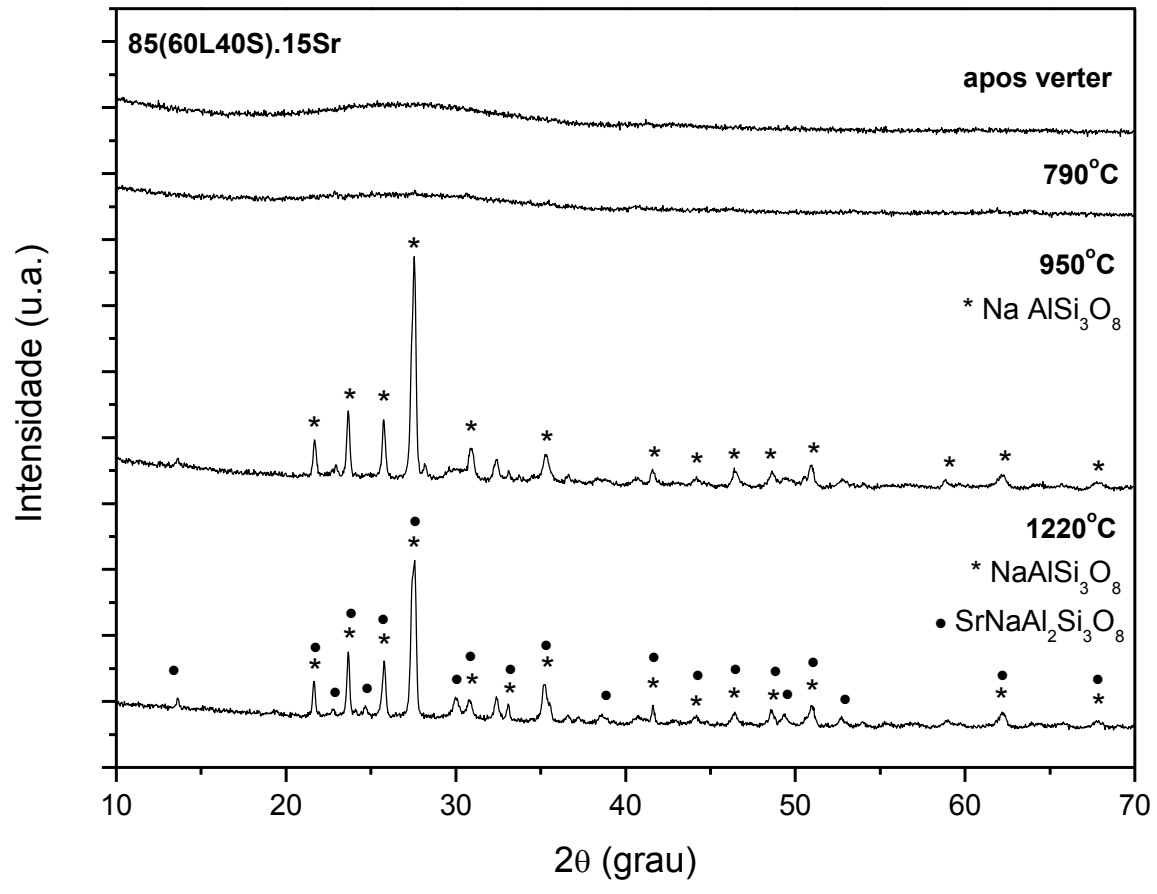

(c) 


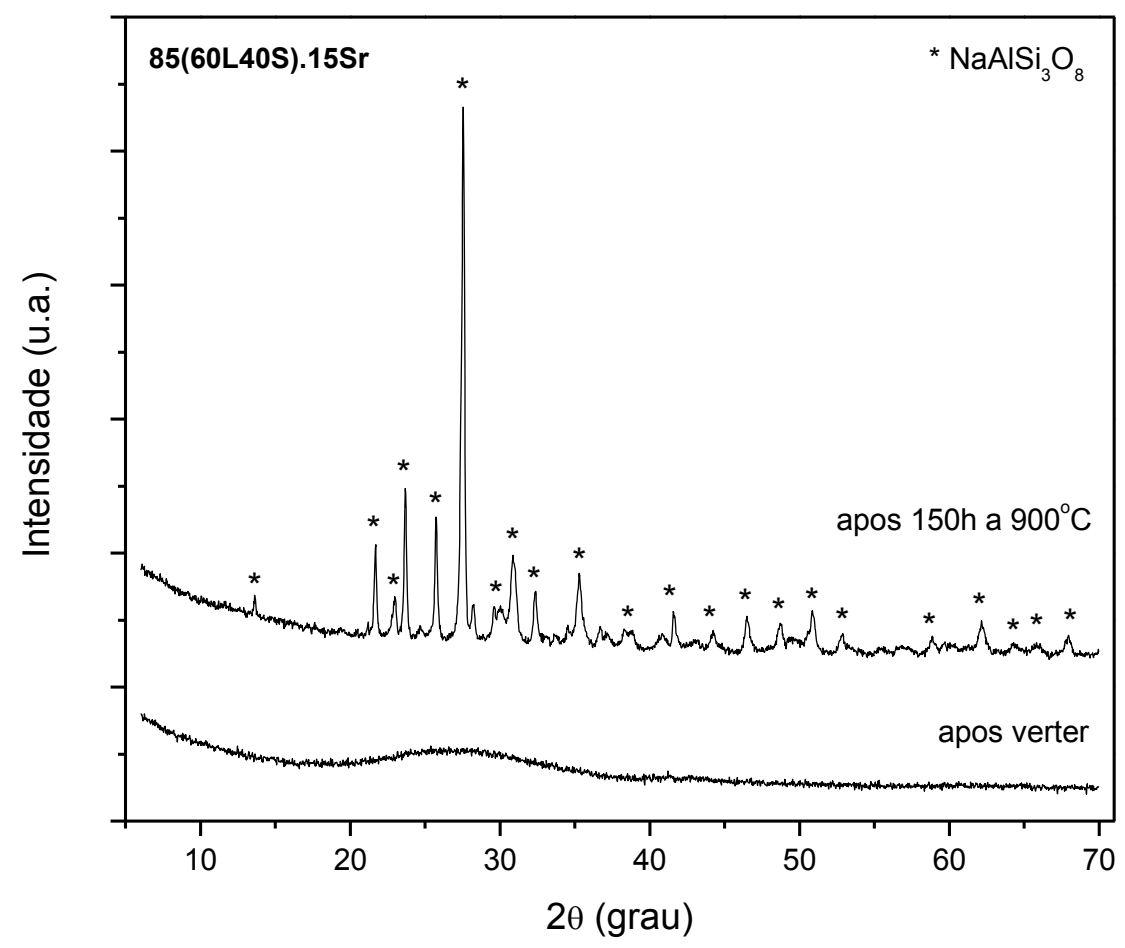

(d)

Figura 32: Análise térmica diferencial do material 85(60L40S)·15Sr com diferentes granulometrias (a), com a mesma granulometria e diferentes taxas de aquecimento (b), difratometria de raios $X$ da amostra 85(60L40S) $15 \mathrm{Sr}$ após tratamentos térmicos realizados sob as mesmas condições de análise do DTA (c), difratometria de raios $X$ da amostra 85(60L40S) $15 \mathrm{Sr}$ após tratamento isotérmico (d). 


\section{CAPÍTULO 5}

\section{CONCLUSÃO}

A composição química da lama vermelha contém elementos que favorecem a sua utilização como matéria-prima para a obtenção de vidros, no entanto, sílica deve ser adicionada para permitir a obtenção de fases amorfas. Porém, a adição de sílica aumenta a temperatura de fusão dos materiais de partida.

Dentre os materiais 60L40S e 60L25S15B, o material 60L40S é o mais indicado para a aplicação almejada, pois apresenta propriedades que justificam a continuação do seu estudo para aplicações nucleares, como por exemplo, a redução da razão de dissolução em água após a incorporação de até $10 \%$ em massa de óxidos comumente encontrados na composição química de rejeitos nucleares. Este efeito já foi observado em outro sistema vítreo estudado para o confinamento de diferentes composições de rejeitos.

A fração de lixiviação dos óxidos adicionados ao material 60L40S é menor quando comparada a fração dos elementos constituintes desse material. Isto indica que a retenção desses elementos na estrutura do material 60L40S é eficaz. 


\section{REFERÊNCIAS BIBLIOGRÁFICAS}

${ }^{1}$ Comissão Nacional De Energia Nuclear. Critérios de aceitação para deposição de rejeitos radioativos de baixo e médio níveis de radiação. Resolução 12/2002. (CNEN-NN-6.09).

2 Dantas, V. A verdade sobre os rejeitos radioativos. Revista Brasil Nuclear. Ano 13, n. 31, p. 15-21. 2007.

${ }^{3}$ Thomas, A. C.; Dacheux, N.; Le Coustumer, P.; Brandel, V.; Genet, M. Kinetic and thermodinamic studies of the dissolution of thorium-uranium (IV) phosphatedipohsphate solid solutions. J. Nucl. Mat. v. 295, p. 249-264, 2001.

4 Pichot, E.; Dacheux, N.; Emery, J.; Chaumont, J.; Brandel, V.; Genet, M. Preliminary study of irradiation effects on thorium phosphate-diphosphate. J. Nucl. Mat. v. 289, p. 219-226, 2001.

${ }^{5}$ Cooper, R.; Smith, K. L.; Colella, M.; Vance, E. R.; Phillips, M. Optical emission due to ionic displacements in alkaline earth titanates. J. Nucl. Mat. v. 289, p. 199-203, 2001.

${ }^{6}$ Thevuthasan, S.; Jiang, W.; Shutthanandan, V.; Weber, W. J. Accumulation and thermal recovery of disorder in $\mathrm{Au}^{2+}$ irradiated SrTiO3. J. Nucl. Mat. v. 289, p. 204209, 2001.

${ }^{7}$ Matzke, Hj.; Vernaz, E. Thermal and physicochemical properties important for the long term behavior of nuclear waste glasses.

8 Lutze, W.; EWING, R. C. Comparison of glass and crystalline nuclear waste forms. In: Materials Research Society Symposium. Proceedings., v. 127,p. 13-24, 1989.

${ }^{9}$ Day, D. E.; Wu, Z.; Ray, C. S.; Hrma, P. Chemically durable iron phosphate glass wasteforms. J. Non-Cryst. Sol. v. 241, p. 1-12, 1998. 
${ }^{10}$ Huang, W.; Day, D. E.; Ray, C. S.; Kim, C. W.; Milankovic, A. M. Vitrification of high chrome oxide nuclear waste in iron phosphate glasses. J. Nucl. Mat. v. 327, p. 46-57, 2004.

${ }^{11}$ Marasinghe, G. K.; Karabulut, M.; Ray, C. S.; Day, D. E.; Shuh, D. K.; Allen, P. G.; Saboungi, M. L.; Grimsdirch, M.; Haeffner, D. Properties and structure of vitrified iron phosphate nuclear wasteforms. J. Non- Cryst. Sol. v. 264 e 264, p. 146-154, 2000.

12 Huang, W.; Day, D. E.; Ray, C. S.; Kim, C. W.; Reis, S. T. D. Properties and solubility of chrome in iron alumina phosphate glasses containing high level nuclear waste. Glass Sci. Technol. v. 77, n. 5, p. 1-8, 2004.

13 Russo, D. O.; Rodríguez, D. S.; Rincón, J. M.; Romero, M.; Oliver, C. J. R. G. Thermal properties and crystallization of iron phosphate glasses containing up to 25 wt\% additions of Si-, Al-, Na- and U-oxides. J. Non- Cryst. Sol. v. 354, p. 1541-1548, 2008.

14 Shih, P. Y. Properties and FTIR spectra of lead phosphate glasses for nuclear waste immobilization. Mat. Chem. Phys. v. 80, p. 299-304, 2003.

15 Ghussn, L. Síntese e Caracterização de vidros niobofostatos e ferrofostatos utilizados como meio para a imobilização de de U308. 2005. Tese - (Doutorado) Instituto de Pesquisas Energéticas e Nucleares.

${ }^{16}$ Moncouyoux, J.P.; Nabot, J. P. La vitrification des déchetes ajoute des cordes à son arc. CLEFS CEA. n. 46, p. 56-60, 2002.

${ }^{17}$ Vernaz, E. Y. Des verres garantis pour des millions d'années. CLEFS CEA. n. 46, p. 81-84, 2002.

${ }^{18}$ Alvez, O. L.; Gimenez, I. F.; Mazali, I. O. Vidros. Cadernos Temáticos. Química Nova na Escola. 2001.

${ }^{19}$ Zachariasen, W. H. The atomic arrangement in glass. J. Am. Ceram. Soc. v. 54, p. 3841-3851, 1932. 
${ }^{20}$ Shelby, J. E. Introduction to glass science and technology. The Royal Society of Chemistry. USA, 1997.

21 Navarro, J. M. F. El vidrio. Consejo Superior de Investigaciones Científicas. Fundación Centro Nacional del Vidrio. $2^{\circ}$ ed. Espanha. 1991.

${ }^{22}$ Mendel, J. E. Final report of the defense high-level waste leaching mechanisms program. PNL-5157. Pacific Northwest Laboratory, Richland, WA, 1984.

23 Materials Characterization Center (MCC). Nuclear Waste Materials Handbook, DOE/TIC 11400, Pacific Northwest Laboratory, Richland, WA, 1981.

${ }^{24}$ McGrail, B. P.; Peeler, D. K. Evaluation of the single-pass flow-through test to support a low-activity waste specification. PNL 107-46. Pacific Northwest Laboratory, Richland, WA, 1995.

${ }^{25}$ Weed, H. C.; Jackson, D. D. Design of a variable-flow-rate, single pass leaching system. UCRL-52785. Lawrence Livermore National Laboratory, Livermore, CA, 1979.

${ }^{26}$ Apted, M. J.; Meyers, J.; Mazer, J. J. Hydrothermal reaction of simulated waste forms with barriers materials under conditions expected in a nuclear waste repository in basalt. SD-BWI-TI-141. Rockwell Ranford Operations, Richland, WA, 1983.

${ }^{27}$ Bates, J. K.; Steindler, M. J. D.G. in: Brookins. Scientific Basis For Nuclear Waste Management VI. North-Holland, New York, NY, 1983.

${ }^{28}$ Barkatt, A. in: R. G. Post. Waste Management. 85. University of Arizona, Tucson, AZ, 1985.

${ }^{29}$ McGrail, B. P. Nuclear Technology. 75 (1986) 168.

${ }^{30}$ Lei $n^{0}$ 12.305. Política Nacional de Resíduos Sólidos. 2010.

31 Hind, R. A.; Bhargava, S. K.; Grocott, S. C. The surface chemistry of Bayer process solids: a revew. Colloids and Surfaces A: Physicochemical and Engineering Aspects. n. 146, p. 359-374, 1999. 
Pan, Z.; Li, D.; Yu, J.; Yang, N. Properties and microstructure of the hardened alkali-activated red mud- slag cementitious material. Cement and Concret Research. v. 33, p. 1437-1441, 2003.

${ }^{33}$ Park, S. J.; Seo, D. I.; Nah, C. Effect of acidic surface treatment of red mud on mechanical interfacial properties of epoxy/red mud nanocomposites. Journal of Colloid and Interface Science. n. 251, p. 225-229, 2002.

${ }^{34}$ Altundogan, H. S.; Altundogan, S.; Tumen, F.; Bildick, M. Arsenic adsorption from aqueous solutions by activated red mud. Waste Management. n. 22, p. 357-363, 2002.

${ }^{35}$ Genç, H.; Tjell, J. C.; McConchie, D.; Schuiling, O. Adsorption of arsenate from water using neutralized red mud. Journal of Colloid and Interface Science. n. 264, p. 327-334, 2003.

${ }^{36}$ Sglavo, V. M.; Maurina, S.; Conci, A.; Salviati, A.; Carturan, G.; Cocco, G. Bautite red mud in the ceramic industry. Part 1: Thermal behavior. Journal of European Ceramic Society. n.20, p. 325-344, 2000.

${ }^{37}$ Agrawal, A.; Sahu, K. K.,; Pandey, D. B. Solid waste management in non-ferrous industries in India. Resources, Conservartion and Recycling. n. 42, p. 99-120, 2004.

${ }^{38}$ Kirkpatrick, D. B. Red mud product development. The Mineral, Metals \& Materials Society. 1996.

39 Ochsenkiihn-Petropulu, M.; Lyberopulu, T.; Ochsenkiihn, K. M.; Parissakis, G. Recovery ol lanthanides and yttrium from red mud leaching by selective. Analytica Chimica Acta, n. 319, p. 249-254, 1996.

${ }^{40}$ Lopez, E.; Soto, B.; Arias, M.; Nunez, A.; Rubinos, D.; Barral, M. T. Adsorbent properties of red mud and its use for waste water treatment. Water Research. v. 32, n. 4, p. 1324-1322, 1998.

41 Shimano, S.; Koga, T. Utilization of red mud as raw material for the cement industry. Light Metals. p. 53-68, 1979. 
42 Koumanova, B.; Drame, M.; Popangelova, M. Phosphate removal from aqueous solutions using red mud wasted in bauxite Bayer's process. Resources, Conservation and Recycling. n. 19, p. 11-20, 1997.

${ }^{43} \mathrm{Li}, \mathrm{L}$. Y. A study of iron mineral transformation to reduce red mud tailings. Waste Management. n. 21, p. 525-534, 2001.

44 Brunori, C., Cremisini, C., Massanisso, P., Pinto, V., Torricelli, L. Reuse of a treated red mud bauxite waste: studies on environmental compatibility. Journal of Hazardous Materials. B117, p. 55-63, 2005.

45 Kalkan, E. Utilization of red mud as a stabilization material for the preparation of clay liners. Engineering Geology. v. 87, p. 220-229, 2006.

${ }^{46}$ Díaz, B., Joiret, S., Keddam, M., Nóvoa, X.R., Pérez, M.C., Takenouti, H. Passivity of iron in red mud's water solutions. Electrochimica Acta. v. 49, p. 3039-3048, 2004.

${ }^{47}$ Alumina do Norte do Brasil. Disponível em:

$<$ http://www.alunorte.net/cgi/cgilua.exe/sys/start.htm?UserActiveTemplate=alunorte\& sid=12>. Acesso em: 29 julho 2010.

${ }^{48}$ Consórcio de Alumínio do Maranhão. Disponível em:

<http://www.alumar.com.br/Institucional/Internas.asp?Sessao=Alumar\&SubSessao=I nstitucional\&Lang=pt_Br>. Acesso em: 29 julho 2010.

${ }^{49}$ Companhia Brasileira de Alumínio. Disponível em:

<http://www.cia-brasileira-aluminio.com.br/pt/quem.php>. Acesso em: 29 julho 2010.

${ }^{50}$ Nguyen, Q. D., Boger, D. V. Application of rheology to solving tailings disposal problems. Int. J. Miner. Process. v. 54, p. 217-233, 1998.

${ }^{51}$ Consolidated European Waste Catalogue. Disponível em: <http://www.environment-agency.gov.uk/static/documents/GEHO1105BJVS-ee.pdf>. Acesso em: 10 agosto 2010.

${ }^{52}$ ABNT NBR 10004. Resíduos Sólidos - Classificação. Segunda edição, 2004. 
${ }^{53}$ Sofra, F., Boger, D. V. Environmental rheology for waste minimisation in the minerals industry. Chemical Engineering Journal. v. 86, p. 319-330, 2002.

${ }^{54}$ Nunn, R. F. Advnaces in red mud dewatering and disposal technologies. The Minerals, Metals \& Materials Society. 1998.

${ }^{55}$ Vick, S. G. Planning, design and analysis of tailings dams. United States of America. 1983.

${ }^{56}$ Alunorte. Relatório de impacto ao meio ambiente (RIMA). Belém, Pará, 1994.

${ }^{57}$ De Jesus, I. M., Santos, E. C. O., Brabo, E. S., Lima, M. O., Mendes, R. A., Faial, K. R. F., Carneiro, B. S., Mascarenhas, A. S., Silva, J. K. R., Carneiro, J. S., Rodrigues, A. V., Batista, E. F., Faial, K. F., Barbosa, F. F. S. Avaliação dos impactos ambientais no rio Murucupi em decorrência do transbordo de efluentes de uma bacia de resíduos sólidos no município de Barcarena-Pará. In: Congresso da Associação Brasileira de Química, Fortaleza, Ceará, Brasil, 2004.

${ }^{58}$ Rondon, J. E. Soda cáustica vaza e atinge rio em São Paulo. Disponível em: <http://www1.folha.uol.com.br/folha/cotidiano/ult95u97431.shtml>. Acesso em: 2 agosto 2010.

59 Hungria declara emergência após vazamento de lama vermelha e tóxica. Disponível em:

$<$ http://br.noticias.yahoo.com/s/afp/101005/mundo/hungria_acidente_ambiente>Ace sso em: 05 outubro 2010.

${ }^{60}$ Hungria decreta alerta por vazamento de lama tóxica. Disponível em: <http://noticias.terra.com.br/mundo/noticias/0,,Ol4717868-El8142,00Hungria+decreta+alerta+por+vazamento+de+lama+toxica.html\#tarticle>. Acesso em: 05 outubro 2010.

${ }^{61}$ Lama tóxica da Hungria chega ao rio Danúbio. Disponível em:

< http://www.estadao.com.br/noticias/vidae,lama-toxica-da-hungria-chega-ao-riodanubio,621869,0.htm\#bb-md-noticia-tabs-1>. Acesso em: 07 outubro 2010. 
${ }^{62}$ Vazamento de lixo tóxico na Hungria já mata peixes no rio Danúbio. Disponpivel em:

< http://www1.folha.uol.com.br/mundo/811303-vazamento-de-lixo-toxico-na-hungriaja-mata-peixes-no-rio-danubio.shtml>. Acesso em: 07 outubro 2010.

63 Zhua, C., Luana, Z., Wang, Y., Shan, X. Removal of cadmium from aqueous solutions by adsorption on granular red mud (GRM). Separation and Purification Technology. v. 57, p. 161-169, 2007.

${ }^{64}$ Zhang, S., Liu, C., Luana, Z., Peng, X., Rena, H., Wang, J. Arsenate removal from aqueous solutions using modified red mud. Journal of Hazardous Materials. v. 152, p. 486-492, 2008.

${ }^{65}$ Garau, G., Castaldi, P., Santona, L., Deiana, P., Melis, P. Influence of red mud, zeolite and lime on heavy metal immobilization, culturable heterotrophic microbial populations and enzyme activities in a contaminated soil. Geoderma. v. 142, p. 4757, 2007.

${ }^{66}$ Collazo, A., Fernández, D., Izquierdo, M., Nóvoa, X. R., Pérez, C. Evaluation of red mud as surface treatment for carbon steel prior painting. Progress in Organic Coatings. v. 52, p. 351-358, 2005.

${ }^{67}$ Ribeiro, D. V.; Labrincha, J. A., Morelli, M. R. Effect of red mud addiction on the corrosion parameters of reinforced concrete evaluated by electrochemical methods. Revista Ibracon de Estruturas e Materiais. v. 5, n. 4, 2012.

${ }^{68}$ Liu, W., Yang, J., Xiao, B. Review on treatment and utilization of bauxite residues in China. Int. J. Miner. Process. v. 93, p. 220-231, 2009.

69 Domas, D. D., Giannopoulou, I. P., Panias, D. Utilization of alumina red mud for synthesis of inorganic polymeric materials. Mineral Processing and Extractive Metallurgy Review. v. 26, p. 211-239, 2005.

${ }^{70}$ Macedo, A. N.; Costa, D. H. P.; Trindade, S. R. S.; Souza, J. A. S.; Carneiro, R. J. F. M. Comportamento de blocos cerâmicos estruturais produzidos a partir da mistura de lama vermelha e argila. Ambiente Construido. v. 11, n. 4, 2011. 
${ }^{71}$ Cunha, M. V. P. O.; Corrêa, J. A. M. Síntese e caracterização de hidróxidos duplos a partir da lama vermelha. Cerâmica. v. 57, n. 341, 2011.

${ }^{72}$ Ribeiro, D. V.; Silva, A. M. S.;, Labrincha, J. A.; Morelli, M. R. Estudo das reações álcalis-sílica associadas ao uso da lama vermelha em argamassas colantes e de revestimento. Cerâmica. v. 58, n. 345, 2012.

${ }^{73}$ Yang, J., Zhang, D., Hou, J., He, B., Xiao, B. Preparation of glass-ceramics from red mud in the aluminium industries. Ceramics International. v. 34, p. 125-130, 2008.

${ }^{74}$ Peng, F., Liang, K., Shao, H., Hu, A. Nano-crystal glass-ceramics obtained by crystallization of vitrified red mud. Chemosphere. v. 59, p. 899-903, 2005.

75 Erol, M., Küçükbayrak, S., Ersoy-Meriçboyu, A. Production of glass-ceramics obtained from industrial wastes by means of controlled nucleation and crystallization. Chemical Engineering Journal. v. 132, p. 335-343, 2007.

${ }^{76}$ American Society for Testing and Materials; C25, 1999.

${ }^{77}$ Nuclear Waste Materials Handbook, MCCP-1P static leach test method, Waste Form Test Methods, 1981. 